US Army Corps

of Engineers $S_{\circledast}$

Engineer Research and

Development Center

Environmental Security Technology Certification Program

\title{
Demonstration of Autonomous Aerial Acoustic Recording Systems to Inventory Department of Defense Bird Populations
}

David A. Buehler, Richard A. Fischer, John B. Wilkerson, Stacy Worley, March 2021 David R. Smith, Emily Hockman, and Stephanie Prevost 
The US Army Engineer Research and Development Center (ERDC) solves the nation's toughest engineering and environmental challenges. ERDC develops innovative solutions in civil and military engineering, geospatial sciences, water resources, and environmental sciences for the Army, the Department of Defense, civilian agencies, and our nation's public good. Find out more at www.erdc.usace.army.mil.

To search for other technical reports published by ERDC, visit the ERDC online library at https://erdclibrary.on.worldcat.org/discovery. 


\title{
Demonstration of Autonomous Aerial Acoustic Recording Systems to Inventory Department of Defense Bird Populations
}

\author{
Richard A. Fischer \\ Environmental Laboratory \\ US Army Engineer Research and Development Center \\ 3909 Halls Ferry Road \\ Vicksburg, MS 39180-6199
}

David A. Buehler, John B. Wilkerson, Stacy Worley, David R. Smith, Emily Hockman, and Stephanie Prevost

University of Tennessee

Department of Forestry, Wildlife, and Fisheries

246 Ellington Plant Sciences Building

Knoxville, TN 37996

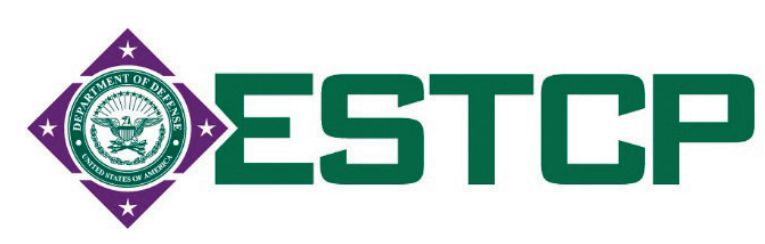

Final report

Approved for public release; distribution is unlimited.
Prepared for Strategic Environmental Research and Development Program/
Environmental Security Technology Certification Program
4800 Mark Center Drive, Suite 17D03
Alexandria, VA 22350-3605
Under Contract No. W912HZ-11-2-0024; Project No. RC-201112




\section{Abstract}

This demonstration project addressed the Department of Defense need for innovative technology for monitoring avian populations in inaccessible areas. This report presents results from field validation tests for an autonomous aerial acoustic recording system, a helium-filled weather balloon that transported an instrument payload over inaccessible areas (e.g., ordnance impact areas) to record avian vocalizations.

DISCLAIMER: The contents of this report are not to be used for advertising, publication, or promotional purposes. Citation of trade names does not constitute an official endorsement or approval of the use of such commercial products. All product names and trademarks cited are the property of their respective owners. The findings of this report are not to be construed as an official Department of the Army position unless so designated by other authorized documents. 


\section{Contents}

Abstract............................................................................................................................... ii

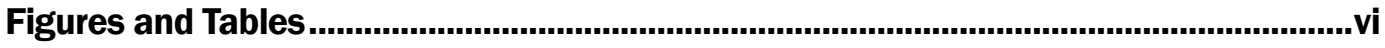

Preface ....................................................................................................................................... ix

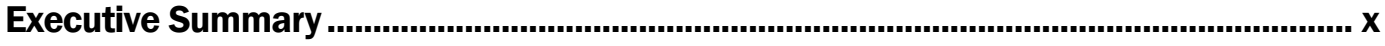

1 Introduction .............................................................................................. 1

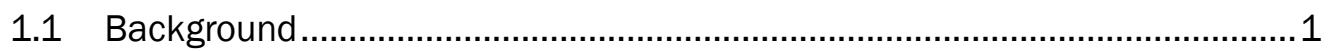

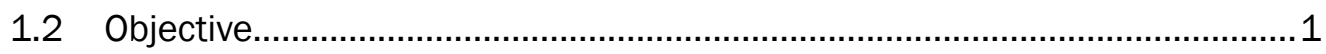

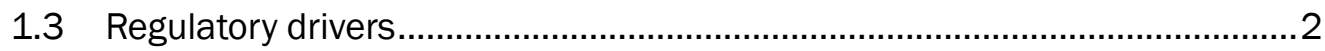

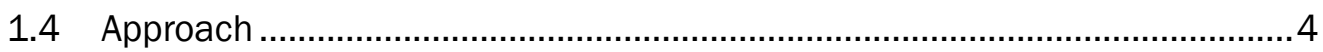

2 Technology/Methodology Description ........................................................... 6

2.1 Technology/methodology overview ................................................... 6

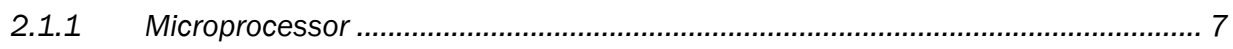

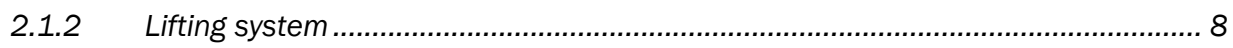

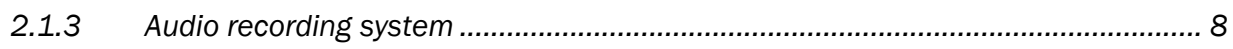

2.1.4 Global Positioning System (GPS) system ...................................................... 9

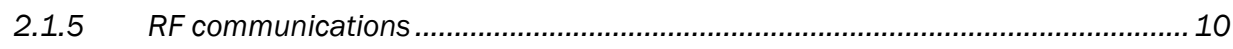

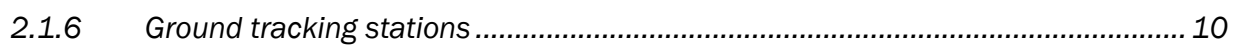

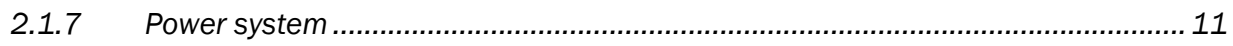

2.1.8 System control and recovery redundancies .................................................... 11

2.1.9 Construction details ..................................................................................... 12

2.1.10 Altitude control ................................................................................................... 12

2.2 Technology/methodology development ...............................................14

2.3 Advantages and limitations of the technology/methodology ....................14

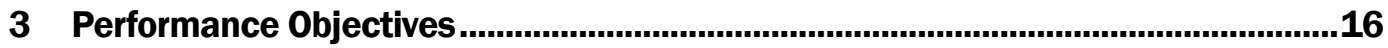

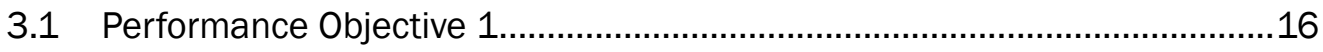

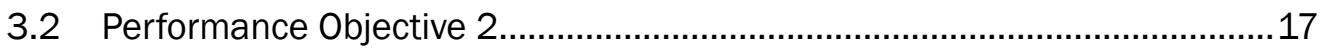

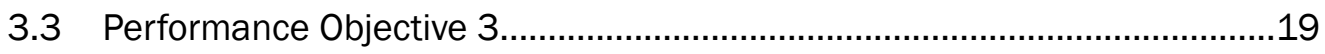

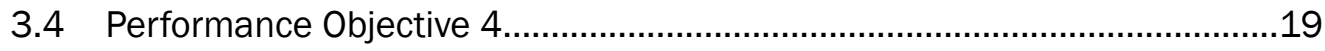

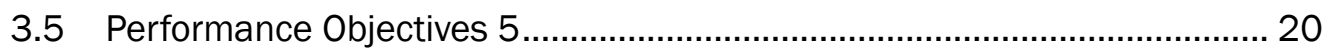

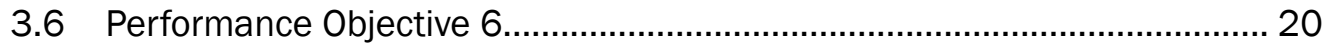

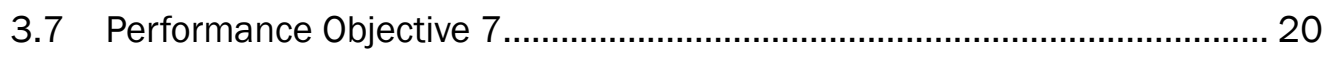

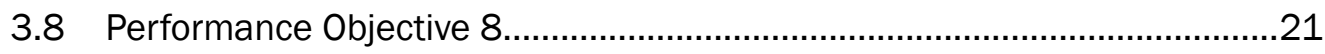

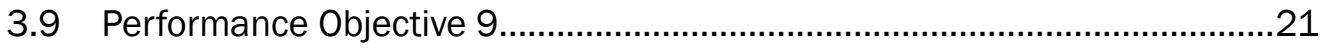

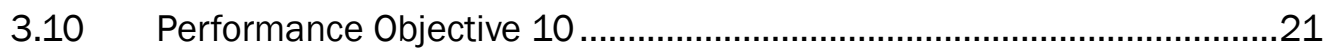

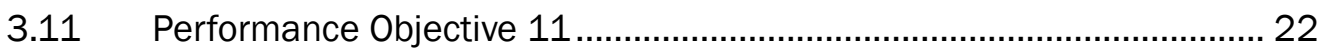

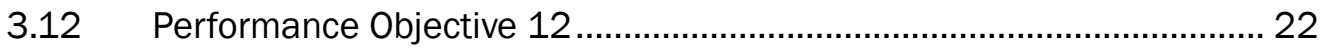

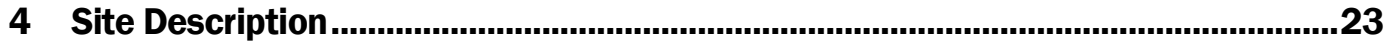




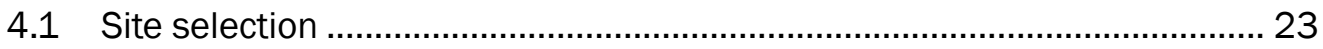

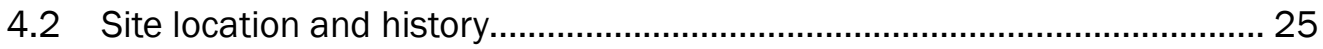

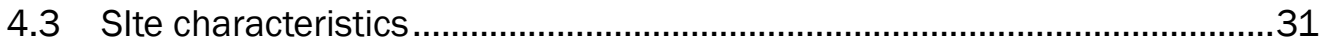

4.4 Site-related permits and regulations.......................................................31

5 Test Design ...................................................................................................33

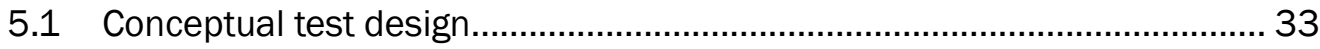

5.2 Baseline characterization and preparation .............................................. 33

5.3 Design and layout of technology and methodology components............... 35

5.3.1 Audio simulation system for validation tests...................................................... 35

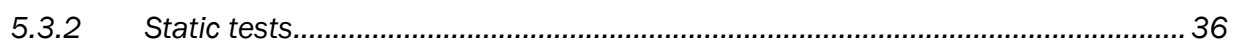

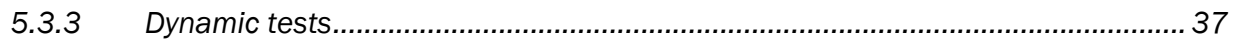

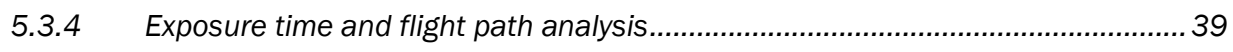

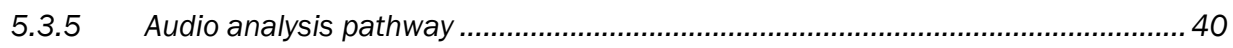

5.4 Field testing....................................................................................... 41

5.4.1 Performance Objective 1: Flight performance ..................................................43

5.4.2 Performance Objective 2: RF modem ............................................................... 43

5.4.3 Performance Objective 3: Latitude-longitude control system ................................ 44

5.4.4 Performance Objectives 4, 6, 7: Static and dynamic validation tests-

field conditions, simulated audio sources, with comparison with human-observer

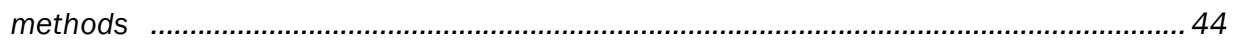

5.4.5 Performance Objective 5: Document availability for detection-field

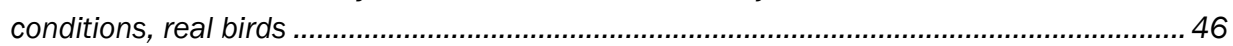

5.4.6 Performance Objectives 8-9: Classification of audio files ..................................... 46

5.4.7 Performance Objectives 10-11: Density estimates.............................................. 47

5.4.8 Performance Objective 12: Ease of use ............................................................. 48

5.5 Sampling protocol .............................................................................. 48

5.6 Equipment calibration and data quality issues ...................................... 48

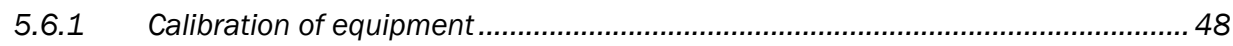

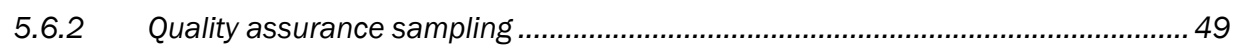

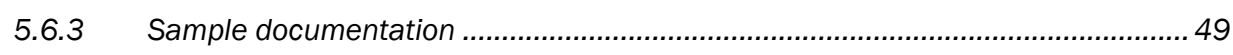

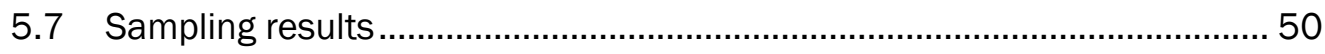

5.7.1 Demonstration trials and AAARS performance success .....................................50

5.7.2 Military access and flight weather conditions ................................................... 51

5.7.3 AAARS communication validation..................................................................... 52

5.7.4 Setting the latitude-longitude target box .............................................................. 52

5.7.5 Detection rates for simulated birds by AAARS and by human observers............. 53

5.7.6 Availability for detection by species..................................................................... 54

5.7.7 Precision of balloon vs. human-observer estimates .............................................. 54

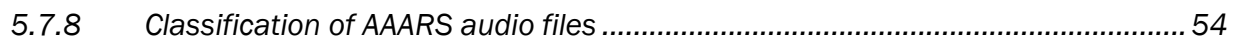

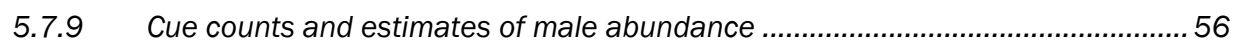

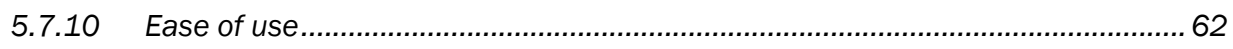

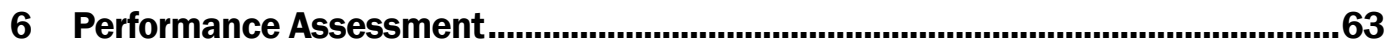

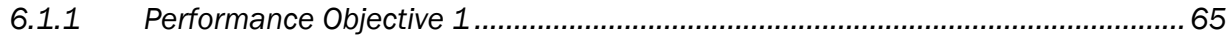

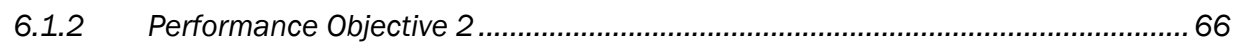




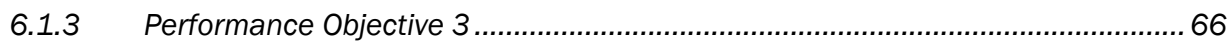

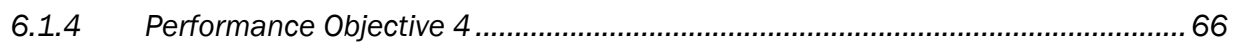

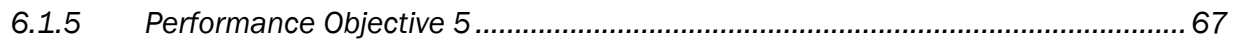

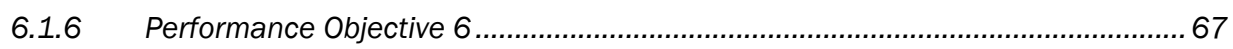

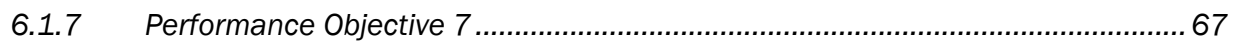

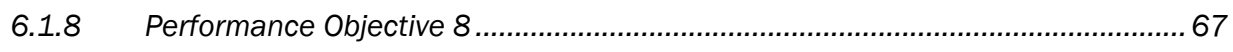

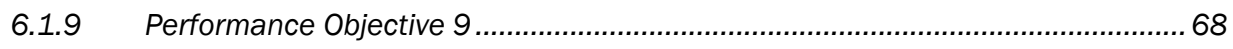

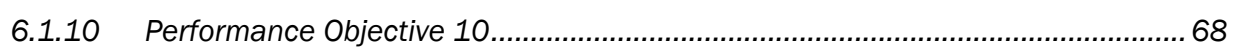

6.1.11 Performance Objective 11............................................................................. 69

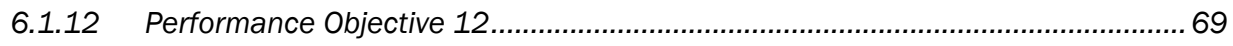

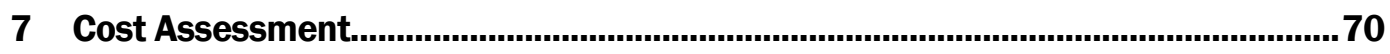

7.1 Cost model ................................................................................. 70

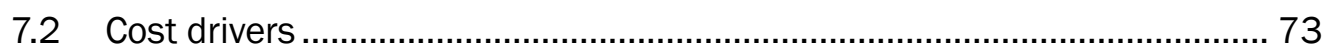

7.3 Cost analysis and comparison ...................................................... 73

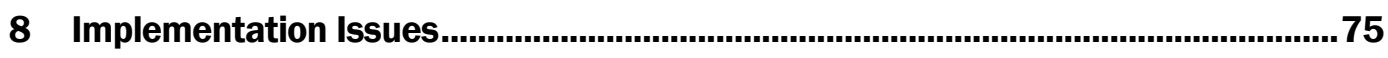

8.1 DoD access restrictions and weather limitations .................................. 75

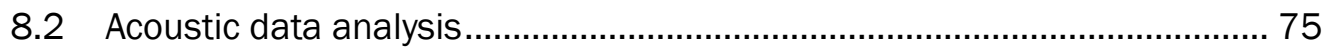

8.3 Limitations in communication range of AAARS ....................................... 76

8.4 Limitations in operation over mountainous terrain ...................................76

References........................................................................................................................... 77

Appendix A: Example Letter of Agreement .................................................................. 79

Appendix B: Health and Safety Plan ............................................................................80

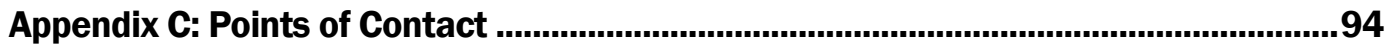

Appendix D: Avian Survey Protocols and Datasheets ...............................................95

Acronyms and Abbreviations............................................................................ 100

\section{Report Documentation Page}




\section{Figures and Tables}

\section{Figures}

Figure 2-1. AAARS payload with components.

Figure 2-2. Laptop computer screen capture showing base station Labview flight control software plotting the AAARS flight path and altitude over aerial imagery of Fort Bragg, NC.

Figure 2-3. AAARS block diagram of payload electronics.

Figure 4-1. Location of each installation in the demonstration plan...................................25

Figure 4-2. Example of sites selected for demonstration, JPG, IN .....................................2

Figure 4-3. Example individual field selected for demonstration, JPG, IN.

Figure 4-4. Installation map of Fort Riley showing selected training areas for demonstration and validation work.

Figure 4-5. Example of individual training area selected for demonstration, Fort

Riley, KS.

Figure 4-6. Installation map, Fort Bragg, NC, with demonstration areas highlighted.

Figure 4-7. Example training area selected for demonstration, Holland DZ, Fort Bragg, NC.

Figure 5-1. Conceptual design of the validation tests for the demonstration

Figure 5-2. Static validation test layout-baseline characterization.

Figure 5-3. Design of audio broadcast system for playing bird songs during validation tests.

Figure 5-4. Static validation test under field conditions.

Figure 5-5. Dynamic validation test - field conditions. Avian song transmitters were placed randomly in the $50 \times 50 \mathrm{~m}$ grid cells. Total grid measurements 500 $\times 200 \mathrm{~m}$. The observer and tethered AAARS walk/fly the center path and made recordings of observations.

Figure 5-6. Flight path analysis from flight GPS data including the $500 \mathrm{~m}$ flight path (A), individual buffers for each recorded AAARS location (B), total flight area covered by one species(C), total flight exposure in hectares/second (D), and altitude profile $(E)$.

Figure 5-7. Conceptualization of how acoustic data were analyzed for the demonstration

Figure 5-8. Flight performance success for the various stages of AAARS operation, 2011-2013.

Figure 5-9. AAARS to ground monitoring station communication capability by distance, Fort Riley, KS, 2013*.

Figure 5-10. Example of latitude-longitude GPS limits set to define a target area for AAARS operation. *

Figure 5-11. Availability for detection related to relative abundance of males for five focal songbird species for a 5 min count period. 
Figure 5-12. Male abundance and songs detected on 5 min point counts for six focal avian species.

Figure 5-13. Negative binomial regression models predicting average male abundance the total cumulative number of songs detected on 5 min acoustic recordings for five focal songbird species.

Figure 5-14. The amount of time it took field personnel to complete pre-flight and post-flight operations from 2011-2013.

Figure B-1. Directions to hospital with emergency services near Jefferson Proving Grounds, IN

Figure B-2. Directions to hospital with emergency services near Fort Bragg, NC.

Figure B-3. Directions to hospital with emergency care near Fort Riley, KS

\section{Tables}

Table 3-1. Performance Objectives.

Table 4-1. Site selection criteria for selecting installations for the demonstration.

Table 5-1. Example of acoustic parameters that can be used to discriminate target and non-target vocalization during acoustic analysis, derived from

RavenPro software (CLO).

Table 5-2. Location and duration of specific components of the demonstration.

Table 5-3. Number of successful validation trials conducted at each site, 20112013.

Table 5-4. Flight access and weather conditions during summer field seasons 2011-2013.

Table 5-5. Detection rates for Henslow's Sparrow based on assessment of detection of song simulators at various altitudes up to $300 \mathrm{~m}$ for AAARS and based on human observers.

Table 5-6. Precision (standard errors) of abundance estimates for AAARS vs. human-observer methods, for real birds and song simulators.

Table 5-7. Correct classification rates based on automated acoustic data analysis methods in program MonitoR for real birds and song simulators.

Table 5-8. Comparison of mean abundance estimates for AAARS vs. true values for song simulators among point count (PC), line transect (LT), and free flight (FF).

Table 5-9. Comparison of mean abundance estimates (birds/ha) for AAARS vs. human-observer PC and line-transect (LT) methods for real birds. "Human FF" refers to human observer line-transect surveys conducted along the AAARS free flight (FF) path.

Table 6-1. Analytical approach for evaluation of performance objectives.

Table 7-1. Cost model for monitoring technology......

Table 7-2. Cumulative costs to operate the AAARS technology for 3 yr.................................71

Table B-1. Health and Safety Plan approval form.

Table B-2. Example of emergency contact list to be filled out before each field season.

Table B-3. Basic emergency procedures, to be expanded for use at specific demonstration sites. 
Table B-4. Example of the risk assessment table to be included in the health and safety plan. 


\section{Preface}

This study was conducted for the Environmental Security Technology Certification Program under Contract No. W912HZ-11-2-0024; Project No. RC-201112. The technical monitors were Dr. John Hall and Dr. Kurt Preston.

The work was performed by the Ecological Resources Branch (ERB) of the Ecosystem Evaluation and Engineering Division (EEE), US Army Engineer Research and Development Center, Environmental Laboratory (ERDC-EL). At the time of publication of this report, Dr. Jennifer Seiter-Moser was ERB Chief; Dr. Mark Farr was EEE Chief; and Dr. Elizabeth Ferguson was the Technical Director for Military Environmental Engineering and Sciences. The Deputy Director of ERDC-EL was Dr. Brandon Lafferty, and the Director was Dr. Jack E. Davis.

The Commander of ERDC was COL Teresa A. Schlosser, and the Director was Dr. David W. Pittman. 


\section{Executive Summary}

The Department of Defense (DoD) needs new, innovative technologies for monitoring avian populations in inaccessible areas to comply with existing environmental regulations and as a means to enhance military testing and training. This demonstration project addresses this need by presenting results from field validation tests for an autonomous aerial acoustic recording system (AAARS). This system is based on a helium-filled weather balloon that transports an instrument payload over inaccessible areas (e.g., firing ranges, ordnance impact areas) to record avian vocalizations. Specific objectives of the project were to (1) demonstrate and validate the ability of the AAARS to collect data on avian vocalizations for threatened, endangered and at-risk species (TER-S) birds over accessible areas; (2) train project staff and installation staff on use of this technology; (3) evaluate the ability of trained project staff and installation staff to deploy the technology; (4) compare the accuracy and precision of monitoring data collected by AAARS; and (5) compare costs of data collection by AAARS to costs associated with conventional, human-based ground-sampling methods.

The AAARS instrument payload is comprised of a microprocessor for command/control functions, a servo-controlled valve for venting helium, a Global Positioning System (GPS) module for real-time location and altitude, and a radio frequency module for communication with a groundbased monitoring station. Avian vocalizations are recorded on a digital recorder (Zoom H2) with an active directional microphone during the flight. GPS telemetry data are used to track the balloon during flight and to locate and recover the system once it is on the ground. Once the system is recovered, audio data recorded during the flight are transferred from the digital recorder to a personal computer for analysis, along with the recorded spatial data.

The field validation portion of the demonstration was conducted at Fort Riley, KS; Fort Bragg, NC; and at Big Oaks National Wildlife Refuge, IN (formerly Jefferson Proving Grounds). Validation trials were conducted in static (tethered) and dynamic modes to simulate standard avian point counts and line transect methods. AAARS performance was compared against human-observer point counts and line transects on real bird populations and also on simulated bird populations. Training workshops were held for DoD staff in Kansas, Indiana, and North Carolina as a means 
of evaluation of the ability to transfer the technology to environmental staff from numerous installations and as a means of generating interest in, and identifying opportunities for, adopting the technology for application on military training ranges.

Overall, 331 free flights were attempted during validation testing in 20112013. The AAARS was successfully flown on $>85 \%$ of the attempted flights in 2013, the final year of testing, in terms of successfully launching, hitting the target area, tracking and recovery of the payload, and collection of audio data. AAARS performance met the objective of documenting the occurrence of all target species evaluated. In addition, abundance estimates were similar in accuracy and precision to estimates generated from human-observer based methods (point counts and line transects) depending on the target species being monitored. Compared to humanbased methods, the AAARS could monitor approximately 20 times more area per monitoring day (2000 ha vs. 94 ha) based on a field crew of three individuals and also provide a permanent geo-referenced audio record of what species were vocalizing on a given site on that given day. This apparent economy of scale is seen as a huge advantage of the technology, especially in situations where human access is problematic or where large areas need to be covered such as for documenting the relative abundance of threatened and endangered species, or DoD mission-sensitive species.

Implementation of the technology faces three challenges. First, because the AAARS was designed to cover large inaccessible areas, requiring launch points and recovery zones typically in training areas, deployment of the technology requires daily coordination with military range control and training schedules. Deployment on Fort Bragg and Fort Riley was limited to approximately 10-12 days per breeding bird season in which access was possible, usually on weekends and especially on holidays. Second, implementation is limited by appropriate weather for flying the AAARS, typically with winds aloft $<10 \mathrm{kt}$ and without rain, although these conditions are often also used as constraints on human-based monitoring. Finally, the analysis of acoustic data remains a challenge for any acousticbased monitoring technique. An analytic pathway was developed to facilitate this process, but acoustic data analysis still remains a significant cost of using the technology although this cost is not considered prohibitive for implementation of the technology. At the completion of the demonstration, it was concluded that the AAARS technology was successful in meeting project objectives and was cost effective for meeting a variety of DoD bird monitoring needs. 


\section{Introduction}

The Department of Defense (DoD) needs new, innovative technologies for monitoring avian populations in inaccessible areas to comply with existing environmental regulations, such as the Endangered Species Act, Migratory Bird Treaty Act, and National Environmental Policy Act. This demonstration project addresses this need.

\subsection{Background}

The DoD administers nearly 30 million acres of lands for the primary purposes of training troops and testing weapons platforms to ensure military readiness. These lands are very unique among federal land management agencies in that very large and inaccessible parcels have been set aside as impact areas for various types of munitions and explosive ordnance. Frequent disturbance to these impact areas, usually in the form of fires, makes them highly suitable as habitat for many threatened, endangered, and at-risk (TER-S) avian species across the country. DoD has both regulatory and stewardship responsibilities to manage and monitor for many of these species. However, this has been very difficult, if not impossible, on most installations because of the inability to access these restricted areas on the ground. DoD also has a unique stewardship challenge because military installations support significant populations and a disproportionately high number of TER-S bird species, relative to acreages of other federal land management agencies (Stein et al. 2008). Many installations contain highly threatened ecosystems that have been lost from the surrounding region because of development activities. In some cases, these habitats support the only remnant populations of TER-S in the region.

\subsection{Objective}

The overall objective of the project is to demonstrate and validate the use of autonomous aerial acoustic recording systems (AAARS) for monitoring TER-S species populations on military installations. 
The technical objectives of the project were the following:

1. Demonstrate and validate the ability of the AAARS to collect data on avian vocalizations for TER-S birds over accessible areas (as a proxy for demonstrating performance over non-accessible impact areas) across a broad range of military installations and habitats.

2. Train project staff and installation staff on use of this technology.

3. Evaluate the ability of trained project staff and installation staff to deploy the technology and analyze and use the data collected.

4. Compare the accuracy and precision of monitoring data collected by AAARS to standards of absolute performance and to standards based on conventional (human-observer) data collection methods across a range of DoD installations.

5. Compare costs of data collection by AAARS to costs associated with conventional, human-based methods.

\subsection{Regulatory drivers}

DoD is subject to several environmental laws and regulations establishing responsibilities for the conservation, management, and monitoring of migratory bird populations. The National Environmental Policy Act (NEPA), which requires federal agencies to evaluate and disclose the potential environmental impacts of their proposed actions, the Endangered Species Act, and the Migratory Bird Treaty Act (MBTA) are designed to protect a wide variety of bird species and their habitats. They also require focused monitoring activities for DoD to remain in compliance. The Sikes Act requires most military installations to prepare and implement Integrated Natural Resources Management Plans (INRMPs) to facilitate the conservation and rehabilitation of natural resources on military lands in a manner that is compatible with and supports the sustainability of the military mission. An INRMP also supports compliance with natural resources laws and guides the military in fulfilling its obligation to be a good steward of public land. The management and conservation of migratory birds is addressed in installation INRMPs.

Over the last couple of decades, the DoD has met various challenges in carrying out its training mission while simultaneously complying with environmental laws and regulations, particularly with the Migratory Bird Treaty Act. Section 315 of the Bob Stump National Defense Authorization Act (NDAA) for Fiscal Year 2003 provided temporary legislative relief to 
the DoD by exempting military readiness activities (MRAs) from incidental take under the MBTA. In February 2007, the Migratory Bird "Readiness" Rule, implementing Section 315 of the NDAA, was published in the Federal Register. The Readiness Rule established the conditions for incidental take authorization, with certain limitations, under the MBTA for MRAs. Furthermore, it addresses the potential impacts of MRAs on populations of migratory birds and establishes a process to implement conservation measures if and when an MRA is expected to have a significant adverse impact on a population of migratory bird species (as determined through the NEPA process). DoD must confer and cooperate with the US Fish and Wildlife Service (USFWS) if a proposed or an ongoing MRA may result in a significant adverse effect on a population of a migratory bird species. The USFWS can/may withdraw take authorization if conservation measures or required monitoring efforts have not been implemented. Thus, the Armed Forces must give appropriate consideration to the protection of migratory birds when planning and executing military readiness activities, but not at the expense of diminishing the effectiveness of such activities. Moreover, this requirement pertains to all military readiness activities not just those that may result in a significant adverse effect on a population of a migratory bird species (see Preamble to Final Rule on the Take of Migratory Birds by the Armed Forces, 72 Fed. Reg. 8931-8950 [February 28, 2007]).

The DoD also signed a Memorandum of Understanding (MOU) for migratory birds, under Executive Order 13186, with the USFWS in July 2006, which was revised and again signed by both agencies in 2014. The MOU states that for actions on military installations not considered as readiness activities, prior to initiating any activity likely to affect populations of migratory birds, DoD shall (1) identify the migratory bird species likely to occur in the area of the proposed action and determine if any species of concern could be affected by the activity and (2) assess and document, using NEPA when applicable, the effect of the proposed action on species of concern. By following these procedures, DoD will minimize the possibility for a proposed action to unintentionally take migratory birds to a level that would violate any of the migratory bird treaties and potentially impact mission activities. In addition, implementing conservation and monitoring programs for migratory birds and their habitats as a means to comply with regulatory requirements, as well as to remain sound stewards of the nation's natural resources, aids in 
maintaining realistic training environments that support the military training and testing mission.

\subsection{Approach}

Extensive field validation tests were conducted using an autonomous aerial acoustic recording system (AAARS) over open and forested habitats at or near three military installations (Fort Riley, KS; Fort Bragg, NC; and at Big Oaks National Wildlife Refuge, IN [formerly Jefferson Proving Grounds]) in the central and eastern United States. The AAARS vehicle included a helium-filled weather balloon that transports an instrument payload over inaccessible areas (e.g., firing ranges, ordnance impact areas) to record avian vocalizations. An existing platform was used that was developed by the Cornell Laboratory of Ornithology (CLO) (Fristup and Clark 2009), and provided significant technological updates to the payload, including a microprocessor for command/control functions, a servo-controlled valve for venting helium, a Global Positioning System (GPS) module for real-time location and altitude, and a radio frequency module for communication with a ground-based monitoring station. Avian vocalizations are recorded on a digital recorder (Zoom H2) with an active directional microphone during the flight. GPS telemetry data are used to track the balloon during flight and to locate and recover the system once it is on the ground. Once the system is recovered, audio data recorded during the flight are transferred from the digital recorder to a personal computer for analysis, along with the recorded spatial data.

Static (tethered) and dynamic validation trials were conducted at all three installations to simulate standard avian point counts and line transect methods, and the AAARS performance was compared against humanobserver point counts and line transects on real bird populations and also on simulated bird populations. To facilitate transfer of this technology to the field, training workshops were held for DoD staff in Kansas, Indiana, and North Carolina. Goals of this training were to evaluate the efficacy and efficiency of transferring this technology to environmental staff from numerous installations.

Numerous challenges associated with implementation of the AAARS were addressed. The first was determining how to cover large inaccessible areas with launch points and recovery zones typically in training areas. The second involved overcoming coordination with military range control and coordination with training schedules. Third, because implementation is 
limited by appropriate weather for flying the AAARS, thresholds for flights had to be assessed to ensure proper launch and recovery of the system. Finally, challenges associated with the analysis of acoustic data were addressed, to include available technology and costs. 


\section{Technology/Methodology Description}

The AAARS is the primary technology for this project. The system is a significant design and component upgrade of the system developed by the Cornell Laboratory of Ornithology (Fristup and Clark 2009). Virtually all of the system has been redesigned using contemporary components, with the exception of the helium release valve and the microphone, which have been retained. This system is designed to transport an instrumentation payload over inaccessible areas and record avian vocalizations. Additional technology used in this project includes audio devices that simulate a breeding avian community by playing back recorded vocalizations on demand.

\subsection{Technology/methodology overview}

The AAARS is composed of a weather balloon used to transport an electronic payload over otherwise inaccessible areas. The primary functions of the payload are to perform the following:

- record vocalizations of the target avian species

- provide tracking telemetry to both spatially correlate audio data and track the flight path of the system

- control the flight of the system

- reliably and safely recover the system.

For the Environmental Security Technology Certification Program (ESTCP) project design, avian vocalizations are recorded using a commercially available digital recorder (Zoom H2) and an active directional microphone (PA3-IL with a directional cone). A Global Positioning System (GPS) module (Trimble Copernicus II) generates position and altitude data used to provide spatial correlation of the audio data. These data are relayed to personal computer-based ground stations via radio frequency (RF) modems (XBee Pro XSC). The ground stations are used to log flight telemetry and send flight control commands to the payload via the RF modems. A custom servo-controlled valve is used to vent helium as needed to control the altitude of the system during flight. The servo-controlled valve is also used to terminate the flight by rapidly deflating the balloon on command. GPS telemetry data are used to control the balloon altitude, track the balloon during flight, and locate and recover the system once it is on the ground. Once the system is recovered, audio 
data recorded during the flight are transferred from the digital recorder to a personal computer for analysis, along with the recorded spatial data.

The balloon system has several advantages over alternative (e.g., drones) designs. First, the balloon-based system is simple and inexpensive to build and operate. Second, it flies (drifts) with prevailing winds without any selfgenerated noise, thus allowing for high-quality song recordings from target species. Third, it is relatively small and light (less than $2 \mathrm{~kg}$ ) such that it can be deployed without restrictions from Federal Aviation Administration (FAA) regulations and with minimal risk to military or civilian aircraft. Finally, flight crew communication with the system occurs on selected radio frequencies $(900 \mathrm{MHz})$ that do not interfere with installation military communications. Though drone technology has recently has made significant advances in size and cost, currently the use and operation of drones are banned on DoD installations without an arduous and lengthy approval process.

\subsubsection{Microprocessor}

The ESTCP design is based on an 8-core, 32-bit microprocessor (Parallax Propeller), with 32 digital input/output (I/O) pins and $64 \mathrm{~KB}$ of random access memory/read only memory (RAM/ROM). It is a $3.3 \mathrm{~V}$ device, consistent with the power requirements for the GPS module and RF modem. Each of the processor cores has access to the shared RAM, ROM, and I/O pins while executing independent programs. This allows each core to be assigned to a single task (e.g., one core each for payload-to-ground station communication, GPS module communications, servo valve control, ballast system control, and a watchdog to reboot the entire system in the unlikely event the microprocessor malfunctions). Multiple cores allow for uninterrupted communication with the ground station while other operations are being performed. The additional memory, processing power, and I/O pins allow more complete GPS data to be collected each second, more robust communications protocols to ensure accurate and complete data transmission, and additional functions such as a watchdog program, servo valve position monitoring, ballast dropping system, and automatic recovery based on GPS position. This capability expands the system performance substantially, utilizes the capabilities of the hardware more fully, and allows considerable flexibility for future improvements with little or no changes to the hardware. 


\subsubsection{Lifting system}

The lifting system for the ESTCP project design includes a $300 \mathrm{~g}$ weather balloon, custom servo-controlled valve, and custom enclosure. The custom enclosure consists of a streamlined design with a cylindrical coated paper tube to improve the probability of recovery in forested areas, save weight, and simplify construction (Figure 2-1). Use of a commercially available tube with minimal modification has made replacement of the enclosure easy and inexpensive in the event of enclosure damage. Foam is used to mechanically isolate the microphone cone from infrequent noise created during helium venting and to provide shock absorption during recovery. The ballast dropping system is critical to altitude control. The servocontrolled valve allows helium venting to arrest balloon ascent by decreasing buoyancy and to decrease altitude but does not provide the ability to increase buoyancy or altitude. The ballast system consists of nichrome wire attached to conductive pins and various non-toxic weights attached to the nichrome wire with monofilament line on the outside of the enclosure. The microprocessor applies power to nichrome wires after a command from the user, cutting the monofilament with heat and dropping the desired amount of weight necessary to establish and maintain sustained flight.

\subsubsection{Audio recording system}

The active microphone and cone system from the CLO system have been retained. Both the CLO research and the field testing have shown this system to be more than adequate. The cone that surrounds the microphone provides directionality and significant noise-free amplification $(\sim 2 \mathrm{O} \mathrm{dB})$. The Zoom $\mathrm{H} 2$ is capable of recording audio data in an uncompressed format directly to secure digital (SD) memory cards with capacities up to $32 \mathrm{~GB}$. The Zoom H2 has 10 levels of input amplification that provide more flexibility for recording vocalizations from various species with differing call intensities or more flexibility for different flight altitudes while maintaining the ability to detect vocalizations of the target species. In the current design, monitoring is accomplished with a single directional microphone rather than omnidirectional microphone because the need to monitor in directions other than the footprint directly below the AAARS is not necessary. Therefore, a directional microphone provided the greatest accuracy for sound detection with the design of the system. 
Figure 2-1. AAARS payload with components.

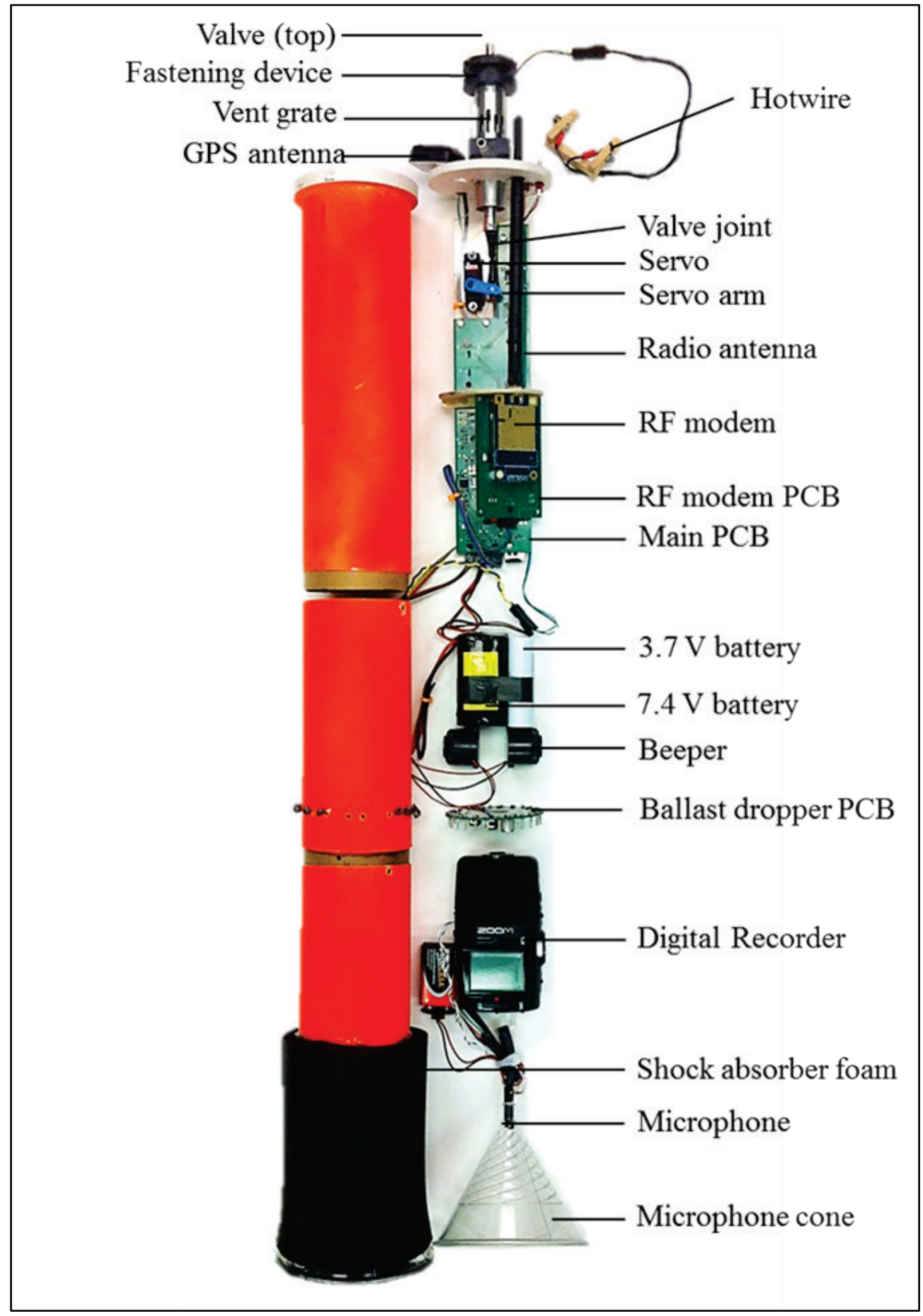

\subsubsection{Global Positioning System (GPS) system}

AAARS location and altitude tracking is accomplished with a Trimble Copernicus II original equipment manufacturer (OEM) module with an active patch antenna. The GPS module is small and lightweight, consumes 
relatively little power, is inexpensive and readily available, and is integrated directly into the printed circuit board (PCB). The Copernicus module also has wide area augmentation system correction capability, which improves positional accuracy and programmed in the air mode improves vertical accuracy. The implementation of a newer, faster microprocessor allows for more detailed GPS information to be relayed to the ground stations (including heading, horizontal and vertical velocity, and GPS fix quality information). Finally, the Trimble Standard Interface Protocol protocol was used between the processor and GPS module, which improves the quality of the altitude measurements. GPS systems are typically configured to weight horizontal position accuracy far more heavily than altitude accuracy primarily by selecting satellites that are positioned low on the horizon. Selecting a set of satellites that includes a mix of satellites both low on the horizon and overhead provides a better balance between horizontal position accuracy and altitude accuracy. This mix of satellites also provides a more stable position lock when launching in forested areas and addresses a satellite lock problem observed prior to this study during test flights at Fort Campbell, KY.

\subsubsection{RF communications}

The core of the AAARS RF communication system is a MaxStream XBeePRO XSC 9600 bps OEM RF modem module, which is integrated directly into the printed circuit board. The modem transmits in the $900 \mathrm{MHz}$ band at $100 \mathrm{~mW}$ in a true peer-to-peer mode, utilizing frequency hopping and 65,536 programmable network addresses to minimize interference from or with other devices. Furthermore, this band is restricted to nongovernmental use and generally does not interfere with any military RF transmissions. The payload is equipped with an omnidirectional $3 \mathrm{~dB}$ rubber-duck style whip antenna and the ground stations with a directional 4-element $\mathrm{PC} 904 \mathrm{~N}$ Yagi antenna mounted on a $10 \mathrm{~m}$ extendable pole. This system is rated at a line-of-sight range of up to $25 \mathrm{~km}$ when using a high-gain antenna.

\subsubsection{Ground tracking stations}

The AAARS ground tracking stations are comprised of a laptop computer, RF modem, directional Yagi antenna, and custom software written using LabVIEW. The LabVIEW software controls filling of the balloon and has a mapping component that plots the GPS flight path data over aerial imagery to improve situational awareness (Figure 2-2) and enhances the 
ability to fly and track the balloon via telemetry data. Horizontal velocity, heading, vertical velocity, and vertical acceleration are also monitored to aid in altitude control. At least two ground stations (one launch station and one recovery station) are used for flight control. Each station tracks the flight, logs telemetry data, and can control the balloon. An additional recovery station can be used to provide redundancy of control and data logging and effectively expand the area of positive flight control beyond the RF range of any single ground station.

\subsubsection{Power system}

The AAARS payload power system design is based on three rechargeable lithium ion (LI) $3.7 \mathrm{~V}$ batteries. Two LI batteries are connected in series to power the servo-controlled valve, active microphone, and ballast dropping systems whereas one LI battery is used to power the microprocessor. Zoom $\mathrm{H} 2$ recording units and the microphones use separate batteries from the LI system to ensure independent (from payload operation) collection of acoustic data. The Zoom H2 requires two AA batteries, and the microphone requires a $9 \mathrm{~V}$ battery.

\subsubsection{System control and recovery redundancies}

The payload processor was programmed to check GPS position against pre-programmed latitude and longitude limits (target area) that formed a geographic target box (Figure 2-2). If the balloon flew outside the limits of this target box, in the absence of commands from a ground station, the processor automatically initiated AAARS recovery by venting helium and deflating the balloon. A second fail-safe was added to bring the payload down in the event of malfunction. Nichrome wire was attached via a bracket around the neck of the balloon above the valve. Upon sending a signal and confirming it came from the base station, the nichrome heated and melted a $1 \mathrm{in}$. hole in the neck of the balloon, allowing for immediate deflation and recovery of the payload. 
Figure 2-2. Laptop computer screen capture showing base station Labview flight control software plotting the AAARS flight path and altitude over aerial imagery of Fort Bragg, NC.

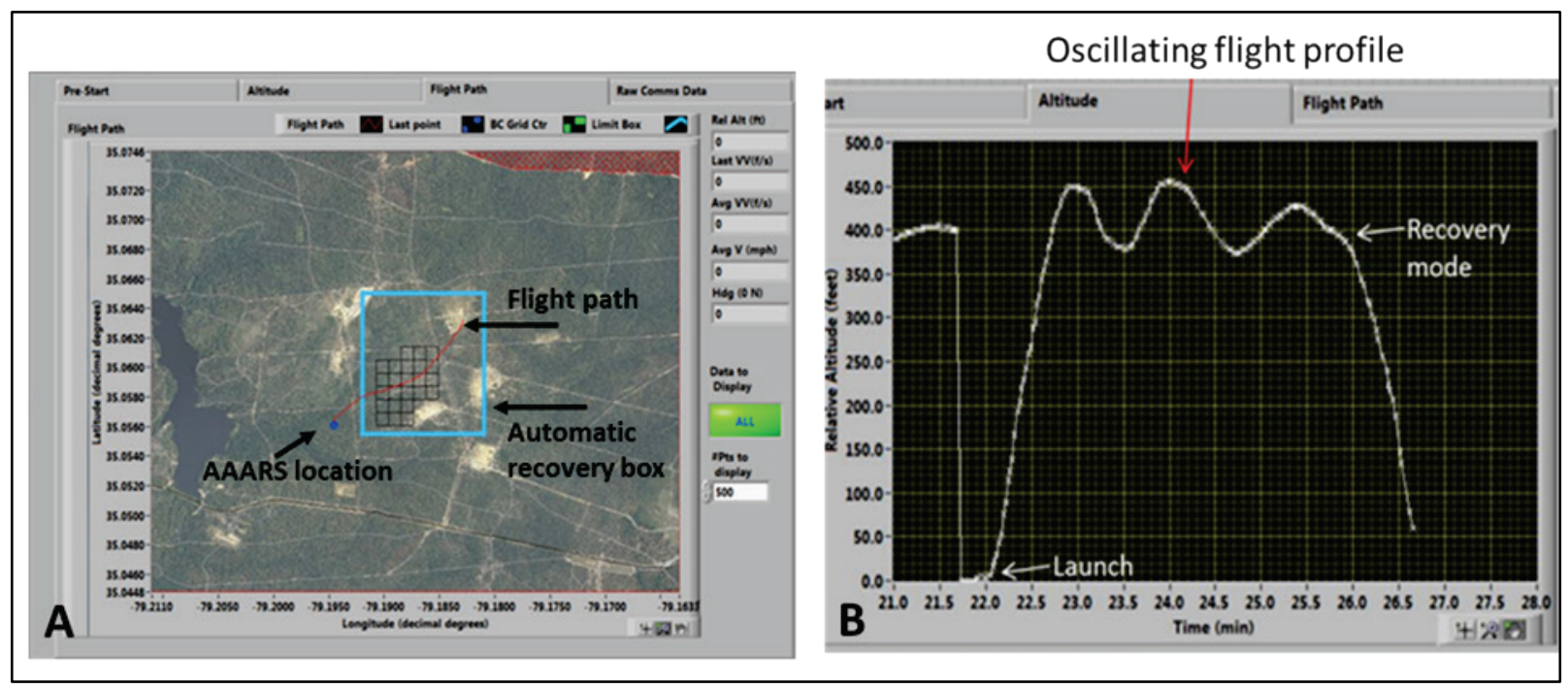

\subsubsection{Construction details}

The AAARS is designed with a custom manufactured PCB (Figure 2-3) with components mounted directly to the PCB and secured mechanically where practical. A modular approach has been used to simplify field repairs (power, processor, GPS, and RF modem modules). Damaged modules can be replaced in the field with replacement modules when possible to maximize the number of payloads that are operational at any one time when field conditions are conducive for flight operations.

\subsubsection{Altitude control}

The multi-core processor allows one core to accurately execute venting commands while another core continuously monitors the GPS module, and a third core transmits complete GPS data (including vertical velocity and altitude) every second without interruption. Constantly monitoring vertical velocity and changes in vertical velocity (vertical acceleration) allows the flight crew to vent and drop ballast more effectively, thereby fine-tuning altitude control. 
Figure 2-3. AAARS block diagram of payload electronics.

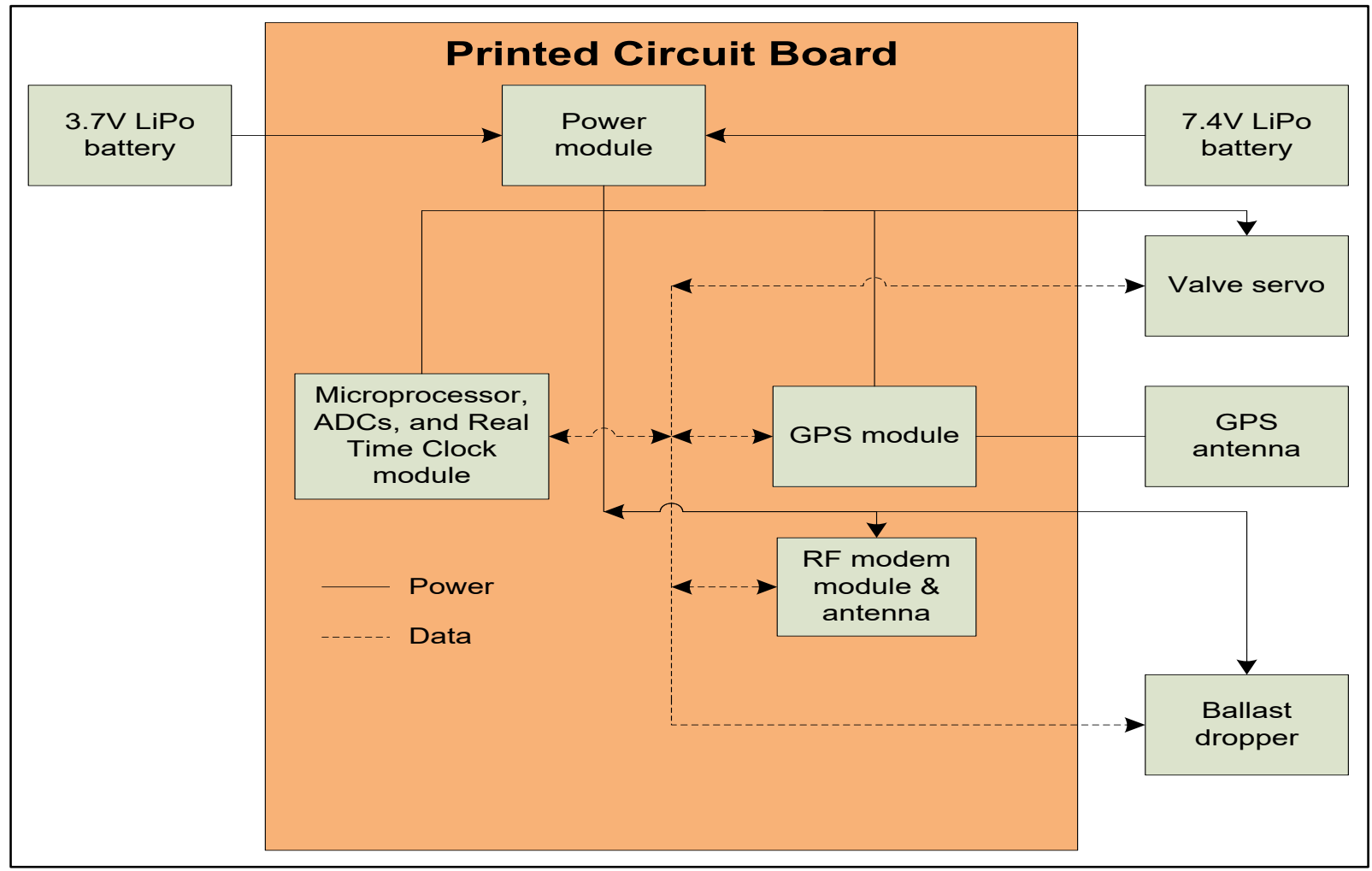

The primary limitation of altitude control through venting is that it only provides the ability to reduce buoyancy. Increasing buoyancy through the dropping of ballast is a powerful tool particularly when flight paths cross variable thermal layers in the atmosphere. In particular, transitioning from grasslands to forested areas results in a significant decrease in thermal lift. Long flights over varied terrain require numerous and varied sizes of droppable ballast weights as well as venting. The AAARS microprocessor allows 16 ballast weights to be carried and allows flight crew selection of a particular ballast weight to drop. The careful attention to weight reduction in the system design was intended to maximize the total weight available for ballast while maintaining the total payload weight below the $2 \mathrm{~kg}$ FAA limit.

In addition to a ballast system, other altitude control tools are necessary. Accurate altitude, rate of climb/descent, and vertical acceleration provide the flight crew with the information necessary to effectively and efficiently use venting and ballast. Specifically, small changes in ascent rate that are currently difficult to detect in a plot of the altitude data indicate the response of the system to venting events. Early detection of system response is the key to avoiding excessive venting, which can result in early 
termination of the flight. The combination of an improved ballast system, more precise initial buoyancy, improved venting control, and buoyancy tracking significantly improved the ability to control altitude.

\subsection{Technology/methodology development}

The AAARS system is a significant design and component upgrade of the system developed by the CLO as a funded DoD Strategic Environmental Research and Development Program project (Fristup and Clark 2009). Virtually all of the system was redesigned in 2011 using contemporary components with the exception of the helium release valve and the microphone, which have been retained from the Cornell design. Field demonstration and validation of the AAARS system was accomplished in 2011-2013 after the major redesign had been completed. Minor modification of the command and control software occurred after the system was redesigned to add GPS limits (the so-called target box), add the nichrome wire for emergency recovery, and separate the power supply for the Zoom $\mathrm{H} 2$ recorder to address an issue with power supply interference on the recordings.

\subsection{Advantages and limitations of the technology/methodology}

The AAARS provides several advantages over existing methods for monitoring avian populations. The existing human-observer methods include point counts, line transects, and spot mapping. One common limitation to these methods is the human bias inherent to the observer. Furthermore, these methods are generally unavailable for DoD impact areas and other inaccessible areas.

Use of ground-based autonomous recording units (ARU) (e.g., Wildlife Acoustics Song Meter) addresses human observer bias by allowing a single person to evaluate recorded avian vocalization data collected at different times and locations, making the population data more directly comparable. ARUs also provide a permanent record of the audio data rather than being limited to human observer field notes or datasheets. However, groundbased ARUs are limited to a single location, such that collection data over broad geographic areas either requires use of many units or the continual movement of ARUs to alternate locations during the field season.

As an acoustic recording system, the AAARS has the same advantages as other ARUs by addressing human observer bias. However, the AAARS 
allows observation in areas that are not accessible using any other established methodology. Given the stewardship and regulatory responsibilities of the military with respect to TER-S species, this capability has significant potential positive impact on natural resource management and the military training mission. Furthermore, the mobility of the sensor platform allows the system to sample avian vocalizations over large areas using a single sensor unit. This capability should allow more cost-effective data collection on a per-unit area basis.

The most obvious technical limitation of the AAARS is weather related. This system will be most effective in wind speeds of $<16 \mathrm{~km} / \mathrm{hr}$ and when wind direction is favorable for launch and recovery relative to a specific target area. The other obvious limitation is gaining access to launch and recovery areas for a specific target area for monitoring purposes. Given the large potential area that the AAARS can cover, use of the technology requires a greater level of coordination with range control and military training than human-observer-based monitoring to take advantage of the full capability of the system. Operation of the AAARS also must be conducted with consideration of the detection distance for a given target species, such that the system is flown at an appropriate altitude for detecting target species. These limitations can be mitigated by knowledge of the hardware performance, environmental impacts on performance, and vocalization parameters. This knowledge can be used to determine operational parameters (e.g., suitable altitude and wind speeds) and procedures to maximize detection potential. 


\section{Performance Objectives}

The overall conceptual design of the demonstration was centered on validating the performance of the AAARS in terms of flight performance and detection and correct classification rates of target avian vocalizations under the range of environmental and operational conditions present on a range of military installations. Individual performance objectives were developed at the start of this investigation as a means to evaluate specific components of system performance (Table 3-1). For each of these objectives, it was further quantified, in some cases somewhat arbitrarily, what was considered a successful test.

The first series of validation trials involved use of a grid of computercontrolled simulated audio sources transmitting actual focal species vocalizations. The performance objectives related to meeting an acceptable standard for AAARS performance in terms of detection accuracy and precision compared to truth - the known presence and density of the audio sources. A second series of validation trials compared AAARS performance against standard human-based avian monitoring methods. Success criteria related to the accuracy and precision of data collected by AAARS vs. human-based methods. Finally, how easy it was for novice personnel to use the technology and how that ability changed with experience during the course of one field season was monitored.

\subsection{Performance Objective 1}

The field validation trials focused on documentation of system performance under a range of field conditions on each installation. Objective 1 documented AAARS flight performance. Each free-flight trial was monitored for successful completion by stage of operation: pre-flight setup, the flight itself, and recovery. Success was defined based on the outcome of how the stage was completed and by whether the target area and altitude were achieved. Success during pre-flight stage meant that the balloon was inflated with helium and all system components were operational, such that the AAARS could be launched. Success during the flight stage means that AAARS covered the target area at a suitable altitude (100-250 m) and velocity $(<16 \mathrm{~km} / \mathrm{h})$ for the target species and collected meaningful acoustic data. Success at the recovery stage means that the AAARS was recovered intact and the data were successfully downloaded. Success rates by stage were calculated based on the number 
of trials achieving success divided by the total number of trials $\times 100 \%$. The standard for evaluation of this performance objective was related to improvement in performance during the course of the project. The baseline for this objective, then, was performance achieved during the first year of the project (2011).

\subsection{Performance Objective 2}

Objective 2 refers to validating the performance of the RF modem. This performance objective was developed because maintaining good communications between the base station and the AAARS is a critical requirement for successful control of the system, although remote latitude-longitude control (target box) capability was added. A good signal is anything on the receiver end that exceeds the receiver modem sensitivity. For the RF modems being used, that sensitivity is $-106 \mathrm{~dB} / \mathrm{m}$. Field testing indicated $>10 \mathrm{~km}$ line-of-sight performance was to be expected. Success was defined as achieving good signal strength at ranges consistent with flights over impact areas (up to $10 \mathrm{~km}$ ) in $95 \%$ of the trials.

Table 3-1. Performance Objectives.

\begin{tabular}{|c|c|c|c|}
\hline $\begin{array}{l}\text { Performance } \\
\text { Objective }\end{array}$ & Metrics & Data Requirements & Success Criteria \\
\hline $\begin{array}{l}\text { 1) Improve AAARS } \\
\text { flight performance } \\
\text { over the course of the } \\
\text { project }\end{array}$ & $\begin{array}{l}\text { Number of pre-flights, } \\
\text { flights, and recoveries } \\
\text { conducted; } \\
\text { performance of each } \\
\text { flight stage (mission } \\
\text { accomplished or not); } \\
\text { altitude }\end{array}$ & $\begin{array}{l}\text { Data log from each pre- } \\
\text { flight, flight; and post- } \\
\text { flight; final disposition of } \\
\text { AAARS at end of each } \\
\text { flight (recovered } \\
\text { undamaged, recovered } \\
\text { damaged, unrecovered); } \\
\text { weather data; GPS data } \\
\text { on location and altitude } \\
\text { by time during flight }\end{array}$ & $\begin{array}{l}\text { Complete } 95 \% \text { of pre-flights successfully; } \\
\text { complete } 90 \% \text { of short-distance }(<5 \mathrm{~km}) \\
\text { flights successfully (covered target area, } \\
\text { altitude and velocity and collected useful } \\
\text { data); complete } 75 \% \text { of long-distance }(5-10 \\
\mathrm{km} \text { ) flights successfully; recover AAARS from } \\
90 \% \text { of flights successfully }\end{array}$ \\
\hline $\begin{array}{l}\text { 2) Meet or exceed } \\
\text { good signal strength } \\
\text { at long range for RF } \\
\text { modem } \\
\text { communications }\end{array}$ & $\begin{array}{l}\text { Maximum distance } \\
(\mathrm{km}) \text { at which good } \\
\text { communications can } \\
\text { be maintained; signal } \\
\text { strength }\end{array}$ & $\begin{array}{l}\text { Distance }(\mathrm{km}) \text { and } \\
\text { performance data (signal } \\
\text { strength) for RF modem }\end{array}$ & $\begin{array}{l}\text { Maintain good signal strength in } 95 \% \text { of } \\
\text { flights at up to } 10 \mathrm{~km} \text { range between base } \\
\text { station and AAARS }\end{array}$ \\
\hline $\begin{array}{l}\text { 3) Meet or exceed an } \\
\text { acceptable standard } \\
\text { of performance for } \\
\text { latitude-longitude } \\
\text { control system }\end{array}$ & $\begin{array}{l}\text { Number of flights; } \\
\text { coverage of target } \\
\text { area; distance } \\
\text { traveled prior to } \\
\text { recovery; success of } \\
\text { recovery after invoking } \\
\text { lat-long control system }\end{array}$ & $\begin{array}{l}\text { GPS flight data, recovery } \\
\text { status } \\
\text { (recovered intact, } \\
\text { recovered damaged, } \\
\text { unrecovered) }\end{array}$ & $\begin{array}{l}\text { Complete } 95 \% \text { of flights with lat-long control } \\
\text { and with successful recovery }\end{array}$ \\
\hline
\end{tabular}




\begin{tabular}{|c|c|c|c|}
\hline $\begin{array}{l}\text { Performance } \\
\text { Objective }\end{array}$ & Metrics & Data Requirements & Success Criteria \\
\hline $\begin{array}{l}\text { 4) Meet or exceed an } \\
\text { acceptable standard } \\
\text { for detection of } \\
\text { simulated audio } \\
\text { sources }\end{array}$ & $\begin{array}{l}\text { Detection rate } \\
\text { compared to truth for } \\
\text { individuals and focal } \\
\text { species }\end{array}$ & $\begin{array}{l}\text { Audio files from } \\
\text { validation trials; data log } \\
\text { from simulated audio } \\
\text { sources; GPS data for } \\
\text { altitude and horizontal } \\
\text { position; weather data }\end{array}$ & $\begin{array}{l}\text { Detect } 90 \% \text { of simulated birds played from } \\
\text { audio sources that are within the footprint } \\
\text { of the microphone when the AAARS is within } \\
\text { the target altitude and velocity }\end{array}$ \\
\hline $\begin{array}{l}\text { 5) Meet or exceed an } \\
\text { acceptable detection } \\
\text { standard for } \\
\text { detection of real birds }\end{array}$ & $\begin{array}{l}\text { Detection rate based } \\
\text { on availability for } \\
\text { detection of } \\
\text { individuals and focal } \\
\text { species }\end{array}$ & $\begin{array}{l}\text { Audio files from } \\
\text { validation trials; data } \\
\text { from territory mapping of } \\
\text { real birds; GPS data for } \\
\text { altitude and horizontal } \\
\text { position; weather data }\end{array}$ & $\begin{array}{l}\text { The probability that real birds vocalize } \\
\text { within the footprint of the microphone when } \\
\text { the AAARS is within the target altitude and } \\
\text { velocity }\end{array}$ \\
\hline $\begin{array}{l}\text { 6) Improve AAARS } \\
\text { accuracy over } \\
\text { standard human- } \\
\text { observer methods }\end{array}$ & $\begin{array}{l}\text { Detection rates for } \\
\text { individuals and focal } \\
\text { species from AAARS } \\
\text { and human-observer } \\
\text { methods- simulated } \\
\text { audio sources }\end{array}$ & $\begin{array}{l}\text { Audio files from } \\
\text { validation trials for } \\
\text { simulated audio sources; } \\
\text { GPS data for altitude and } \\
\text { horizontal position; } \\
\text { weather data; detection } \\
\text { data from human- } \\
\text { observer methods }\end{array}$ & $\begin{array}{l}\text { Produce AAARS detection rates for } \\
\text { individuals and focal species } 10 \% \text { better } \\
\text { than human-observer point count and } \\
\text { transect surveys }\end{array}$ \\
\hline $\begin{array}{l}\text { 7) Improve AAARS } \\
\text { precision compared } \\
\text { to standard human- } \\
\text { observer methods- } \\
\text { Simulated audio } \\
\text { sources }\end{array}$ & $\begin{array}{l}\text { Precision (standard } \\
\text { error) of detection rate } \\
\text { estimates for } \\
\text { individuals and focal } \\
\text { species from AAARS } \\
\text { and human-observer } \\
\text { methods- simulated } \\
\text { audio sources }\end{array}$ & $\begin{array}{l}\text { Audio files from } \\
\text { validation trials with } \\
\text { simulated audio sources; } \\
\text { GPS data for altitude and } \\
\text { horizontal position; } \\
\text { weather data; detection } \\
\text { data from human- } \\
\text { observer methods }\end{array}$ & $\begin{array}{l}\text { Produce AAARS detection precision for } \\
\text { individuals and focal species } 10 \% \text { better } \\
\text { than human-observer point count and } \\
\text { transect surveys }\end{array}$ \\
\hline $\begin{array}{l}\text { 8) Meet or exceed an } \\
\text { acceptable standard } \\
\text { for classification } \\
\text { rates for individuals } \\
\text { and focal species- } \\
\text { simulated audio } \\
\text { sources }\end{array}$ & $\begin{array}{l}\text { Classification rates of } \\
\text { individuals and } \\
\text { species from } \\
\text { simulated audio files } \\
\text { compared to truth }\end{array}$ & $\begin{array}{l}\text { Audio files from } \\
\text { validation trials outlined } \\
\text { above; data log from } \\
\text { simulated audio sources }\end{array}$ & $\begin{array}{l}\text { Classify } 90 \% \text { of the simulated audio sources } \\
\text { correctly in terms of species and individuals }\end{array}$ \\
\hline $\begin{array}{l}\text { 9) Meet or exceed an } \\
\text { acceptable standard } \\
\text { for classification } \\
\text { rates for individuals } \\
\text { and focal species- } \\
\text { real birds }\end{array}$ & $\begin{array}{l}\text { Classification rates of } \\
\text { individuals and } \\
\text { species from real } \\
\text { birds from AAARS }\end{array}$ & $\begin{array}{l}\text { Audio files from static } \\
\text { and dynamic tests } \\
\text { outlined above; } \\
\text { transcription data from } \\
\text { audio files of real birds }\end{array}$ & $\begin{array}{l}\text { Produce AAARS correct classification rates } \\
\text { that exceed } 80 \% \text { for real birds for } \\
\text { individuals and focal species }\end{array}$ \\
\hline $\begin{array}{l}\text { 10) Meet or exceed } \\
\text { an acceptable } \\
\text { accuracy standard for } \\
\text { AAARS density } \\
\text { estimates for focal } \\
\text { species for simulated } \\
\text { audio sources }\end{array}$ & $\begin{array}{l}\text { Density estimates by } \\
\text { species from } \\
\text { simulated audio } \\
\text { sources compared to } \\
\text { truth }\end{array}$ & $\begin{array}{l}\text { Audio files from } \\
\text { validation tests outlined } \\
\text { above; data log from } \\
\text { audio sources }\end{array}$ & $\begin{array}{l}\text { Estimate mean density within } 1.96 \text { Standard } \\
\text { Error (SE) of true density with } 95 \% \\
\text { confidence for simulated audio sources. }\end{array}$ \\
\hline
\end{tabular}




\begin{tabular}{|l|l|l|l|}
\hline $\begin{array}{l}\text { Performance } \\
\text { Objective }\end{array}$ & Metrics & Data Requirements & Success Criteria \\
\hline $\begin{array}{l}\text { 11) Improve AAARS } \\
\text { density estimates for } \\
\text { focal species- real } \\
\text { birds compared to } \\
\text { human-based } \\
\text { methods }\end{array}$ & $\begin{array}{l}\text { Density estimates by } \\
\text { species from real } \\
\text { birds from AAARS and } \\
\text { human-observer data } \\
\text { analyses }\end{array}$ & $\begin{array}{l}\text { Audio files from real } \\
\text { birds in validation tests; } \\
\text { data from human-based } \\
\text { methods; transcription } \\
\text { data from audio files; } \\
\text { song frequency data } \\
\text { from songmeters }\end{array}$ & $\begin{array}{l}\text { Produce AAARS density estimates with } \\
\text { 10\% better than accuracy and precision of } \\
\text { estimates from human-observer methods }\end{array}$ \\
\hline $\begin{array}{l}\text { 12) Increase ease of } \\
\text { use }\end{array}$ & $\begin{array}{l}\text { Number of personnel, } \\
\text { experience, and } \\
\text { duration (min) for pre- } \\
\text { flight, flight, and } \\
\text { recovery stages }\end{array}$ & $\begin{array}{l}\text { Data logs on number of } \\
\text { personnel used in each } \\
\text { flight and their level of } \\
\text { training and experience. } \\
\text { Data logs on duration } \\
\text { (min) of pre-flight, flight } \\
\text { and recovery stages }\end{array}$ & $\begin{array}{l}\text { Decrease number of personnel and/or the } \\
\text { and recovery operations by 10\% for each } \\
\text { year of experience }\end{array}$ \\
\hline
\end{tabular}

\subsection{Performance Objective 3}

Objective 3 refers to validating the performance of the latitude-longitude control system. This system is a safety precaution in case communication is lost between the base stations and the AAARS for any reason. The system will automatically deflate (dump helium) once the latitudelongitude coordinates exceed the pre-defined flight limits. Success was defined based on the percentage of the flights in which this system was invoked that led to successful recovery of the AAARS. The success criteria was set at $95 \%$ in reflection of the confidence that this system will lead to successful recovery of the system the majority of the time.

\subsection{Performance Objective 4}

The first field validation trials involved static and dynamic trials with the AAARS tethered at a point over a grid of simulated audio sources in field or forested sites, or walked or flown over a transect of simulated audio sources. Objective 4 involved meeting an acceptable performance standard in terms of detection. The performance metric was the detection rate $(\rho)$ for target species (see Table 4-1) under a range of environmental and operational conditions. AAARS detections were compared against truth, the known location and timing of playing of the audio sources. In general, under normal operating conditions, the microphones were expected to detect the audio source as long as the AAARS is within the target area within the target altitude $(100-250 \mathrm{~m})$ and target velocity $(<16 \mathrm{~km} / \mathrm{h})$. The 
success criterion was set at meeting or exceeding 90\% detection (rather than $100 \%$ ) to account for unforeseen interference with audio signals.

\subsection{Performance Objectives 5}

The second field validation test involved documenting availability for detection for real birds present and singing on the site. The performance metric is an extension of Objective 4 focused on the probability that a given species actually sings and is available to be detected.

\subsection{Performance Objective 6}

Objective 6 described the performance of the AAARS compared to humanbased methods, point counts for static tests, and line transects for dynamic tests. Although the AAARS ultimately will be deployed in inaccessible areas where human-based methods are not possible, it is important to establish the relationship between AAARS and human-based methods so that data from both monitoring programs can be interpreted. The performance metric was the detection rate $(\rho)$ for target species under a range of environmental and operational conditions. Success criterion was defined as the AAARS detection rates $\geq$ human-observer detection rates based on the assumption that AAARS microphones were at least as sensitive as average human hearing.

\subsection{Performance Objective 7}

Objective 7 also described the performance of the AAARS compared to human-observer methods - point counts for static tests and line transects for dynamic tests. This objective focused on the precision of the detection estimates. To generate estimates of density or population size, it is important to estimate detection with precision. Variability around detection estimates leads to wide confidence intervals in density estimates, yielding poor statistical power and inability to detect population change over time. Human-observer methods are typically poor in this regard whereas it was expected that the AAARS would be more consistent. The performance metric was the precision (standard error) of the detection rate estimates. Success criterion was defined by the precision of the AAARS detection rate estimates $10 \%$ better than the precision of humanobserver detection rate estimates. 


\subsection{Performance Objective 8}

The third major phase of the demonstration was conducted in the Environmental Sensor Lab at the University of Tennessee. Audio files from the various field validation tests involving simulated audio sources were analyzed using XBAT and RavenPro software (CLO) to identify species and individuals for the operational conditions under which the test was conducted. This listing of species and individuals was compared with truthrecords of where and when individual simulated songs were transmitted during a given trial to generate the classification rates. The standard for success was set at $90 \%$ correct classification rate because we are confident in the ability to correctly classify these signals in XBAT and RavenPro.

\subsection{Performance Objective 9}

Objective 9 related to classification rates from trials involving real birds. Audio files from the various field validation tests involving real birds were analyzed using MonitoR software in the R statistical software environment and RavenPro software to identify species and individuals for the operational conditions under which the test was conducted. In this case, there is no absolute record of truth. Bird identification experts were used to transcribe the identification of species and individuals from the audio files. Classification rates were produced by comparing the AAARS data with the audio file transcriptions. Given the variability of real bird song, the classification rate standard was set $10 \%$ lower $(80 \%)$ than that set in Objective 8.

\subsection{Performance Objective 10}

Audio files that were classified to species and individuals (Objective 8 above) were used to generate density estimates and $95 \%$ confidence intervals for each validation test involving simulated audio sources. AAARS density estimates were compared with truth from the record of the number of different species and individuals transmitting songs during a given trial. The success criterion for this objective was defined as estimates being within $1.96 \mathrm{SE}$ of the true densities. The criterion was set in this fashion so that estimates would essentially be no different than the true mean statistically. Although this would be considered the ideal, density estimates from human observers seldom if ever achieve this level of accuracy and precision. 


\subsection{Performance Objective 11}

Audio files from real birds that were classified to species and individuals (Objective 9 above) were used to generate density estimates and 95\% confidence intervals for each validation test. Objective 11 compared density estimates between AAARS and human-based methods. If the AAARS was as accurate and as precise as the standard human-based methods, then it is believed that the system would provide data of sufficient quality to be useful, especially since conventional ground-based sampling methods very rarely can be used in inaccessible areas. The success criterion, then, was defined as accuracy and precision of AAARS density estimates $10 \%$ more accurate and precise than density estimates from human-observer methods.

\subsection{Performance Objective 12}

This performance objective related to the ease of use of the AAARS. The demonstration assessed how many personnel were required and how long it took for pre-flight set-up, flight, and recovery of the AAARS and also determined how proficiency of use increased with experience. The performance metrics included the number of personnel, duration of preflight, flight, and recovery, and experience of the crew. For each flight, records were kept: the number of individuals used for the flight, their training and experience, and the amount of time required for pre-flight setup, flight, and recovery. These metrics were tracked within a given field season and across the years of the demonstration to demonstrate improvement in ease of use over time. It was expected that there would be significant improvement in performance over time as the experience of the team increased (within and among years). The success criterion was set at $10 \%$ improvement in ease of use per year of operation. This improvement could be realized in terms of reduced time for deployment, reduced personnel needed for deployment, or a combination of both. 


\section{Site Description}

Three installations across the eastern United States were selected that exhibited a broad range of environmental conditions to demonstrate the use of the technology. No installations were selected in the western United States because of cost, logistics to transport equipment, and the desire to focus on installations with varied terrain and habitats but that also had some overlap in species occurrences necessary for the study design.

\subsection{Site selection}

The first selection criterion was habitat type; selected sites had a range of the major representative habitats (e.g., grasslands, savannas, forests) that occur on installations in the eastern United States. The second site-selection criterion was the presence of focal species that were of monitoring interest. Selected installations supported a variety of focal species that enhanced the value of the demonstration. The presence of more common focal species was of interest for demonstration because they would challenge the ability to discriminate between individuals for density estimation. The presence of focal species that represent different types of behaviors also would be of interest for demonstration purposes because behavior will affect detection and classification abilities. Also, selected installations shared some of their focal species so that the effect of site-tosite variability in avian behavior (e.g., song frequency) and operational conditions that may affect cost performance could be evaluated. The third selection criteria was climate; selected sites represented a range of climactic conditions related to wind conditions, temperature, and relative humidity that may affect sound transmission or operational conditions.

Based on the site selection criteria outlined above, and based on willingness to support the project, the AAARS demonstration was conducted at Fort Riley, KS; Big Oaks National Wildlife Refuge (BONWR, formerly Jefferson Proving Grounds; JPG), IN; and Fort Bragg, NC (Figure 4-1). These installations were selected because of their differing habitat types, presence and variation in abundance of focal species, and climate (Table 4-1). This technology was demonstrated across a broad range of landscapes to adequately demonstrate its value for military applications. The midwestern installation (Fort Riley) is an open prairie/scrub/agricultural landscape. Deployment of the AAARS in this setting is representative of the open landscapes found in many midwestern (e.g., Fort Sill, OK) and western (e.g., Fort Bliss, NM and Tx) installations. 
In contrast, the southern installation (Fort Bragg, NC) is located within a Longleaf (Pinus palustris) and Loblolly (Pinus taeda) pine-dominated landscape, although impact areas and other large areas (i.e., landing zones [LZ], drop zones [DZ]) are kept open by regular burning to meet training needs. Demonstration of the technology in this setting was necessary to confirm the success of the program because operation and recovery of the balloon system in a more forested landscape poses challenges that are not present in open landscapes. The Fort Bragg landscape is representative of many other southeastern coastal plain installations, such as Eglin Air Force Base, FL; Camp Lejeune, NC; and Forts Benning and Stewart, GA. The most northern location (BONWR/JPG) is a hardwood forest and field complex with small oak savannahs scattered amongst the deciduous forest. Using this installation allowed very effective training in a habitat that is intermediate between the forest and field of the first two sites. JPG is representative of other midwestern installations, such as Fort Campbell, KY; Fort Knox, KY; Fort Leonard Wood, MO; and Fort McCoy, WI.

Each of the three sites fulfilled the selection criteria of having either TER-S bird species that need to be monitored to support the DoD coordinated Bird Monitoring Plan, the presence of more common species used to create robust detection algorithms both on each installation individually and for comparison among installations, and the presence of birds with unique behaviors that will affect density estimation using the AAARS technology (Table 4-1). Focal avian species for the demonstration included Greater Prairie-Chicken (Tympanuchus cupido) (Fort Riley); Northern Bobwhite (Colinus virginianus) (Fort Riley, Fort Bragg, JPG); Grasshopper Sparrow (Ammodramus savannarum) (Fort Riley); Henslow's Sparrow (Ammodramus henslowii) (Fort Riley, JPG); Field Sparrow (Spizella pusilla) (Fort Bragg, JPG); Bachman's Sparrow (Peucaea aestivalis) (Fort Bragg); Prairie Warbler (Dendrioca discolor) (Fort Bragg, JPG); and Red-cockaded Woodpecker (Picoides borealis) (Fort Bragg).

Three to four training areas, management areas, DZs or LZs were selected for the demonstration on each installation. Sites were chosen based on accessibility, history of focal species presence, and presence of representative vegetation types needed to meet demonstration goals for each installation. Locations of training areas to be used were specific to each base, and the sites were used for tethered and free-flying portions of the demonstration. 
Figure 4-1. Location of each installation in the demonstration plan.

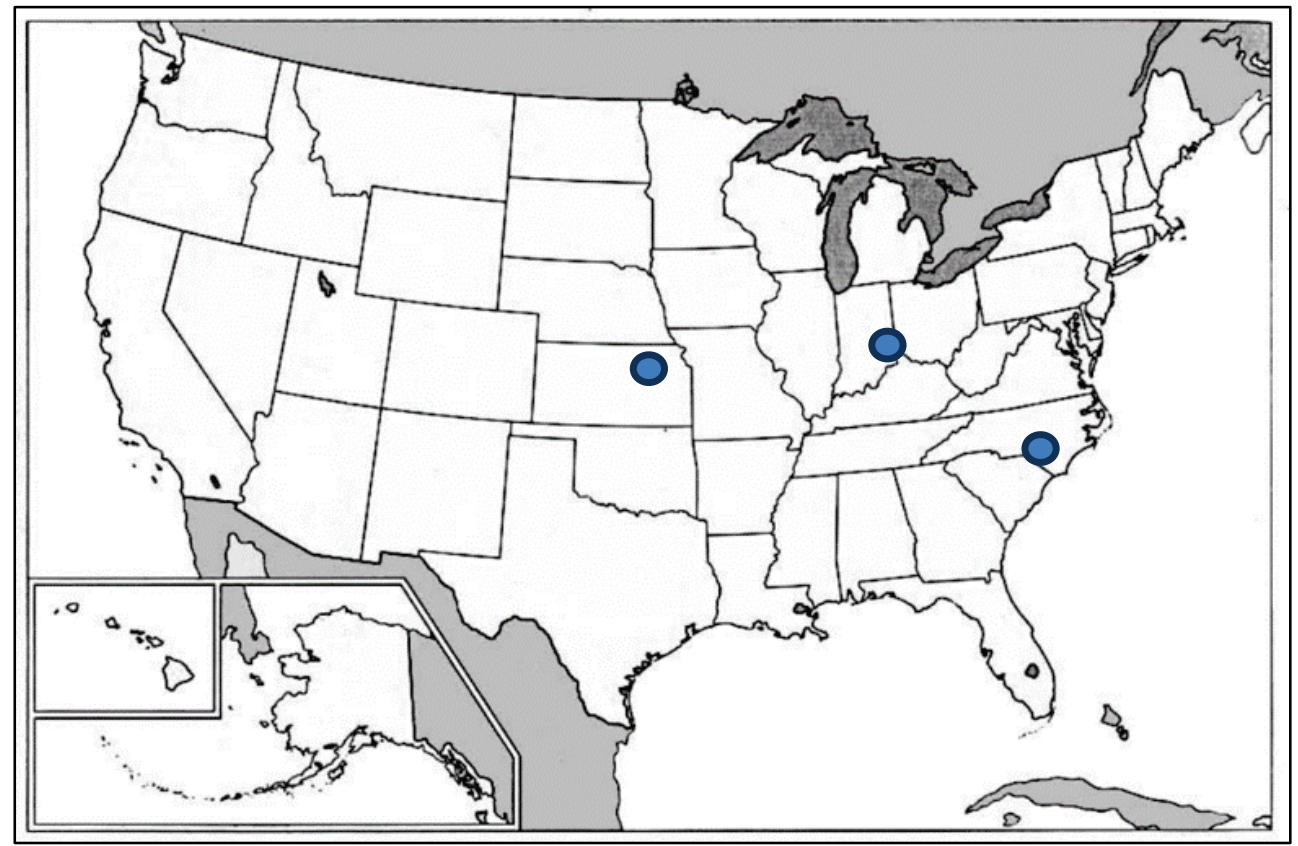

\subsection{Site location and history}

JPG, IN, is a 21,00o ha mosaic of grassland, forest, successional, and riparian habitat (Figure 4-2). The area was used as a munitions testing ground by the US Army from 1940 until 1995 and remains an Air National Guard training range. The property is managed by the USFWS as BONWR. Unexploded ordnance still contaminates most of the property and is a major safety concern leading to complete access restriction on 9,0oo ha ( $42 \%$ of total area). The landscape surrounding the refuge is predominately agricultural row crops, providing a stark contrast to the natural land cover provided by the refuge. The property contains an extensive grid-like network of roads providing access throughout. Management areas 14, 46, 52, 57 contain large fields that provide sufficient habitat for the target species of interest at JPG (Figure 4-3). 
Table 4-1. Site selection criteria for selecting installations for the demonstration.

\begin{tabular}{|c|c|c|c|c|}
\hline Installation & Habitat & Focal Species* & Behavior and Song & $\begin{array}{l}\text { Climate } \\
\text { Region }\end{array}$ \\
\hline $\begin{array}{l}\text { Fort Riley, } \\
\text { KS }\end{array}$ & $\begin{array}{l}\text { Open } \\
\text { grasslands, } \\
\text { flat to rolling } \\
\text { terrain }\end{array}$ & $\begin{array}{l}\text { Henslow's Sparrow } 2 \\
\text { Field Sparrow } 2,4 \\
\text { Grasshopper } \\
\text { Sparrow } 2,4 \text { Northern } \\
\text { Bobwhite } 2,3 \text { Greater } \\
\text { Prairie Chicken2,3 }\end{array}$ & $\begin{array}{l}\text { Low amplitude, territorial } \\
\text { Moderate amplitude, territorial } \\
\text { High amplitude, large home } \\
\text { range } \\
\text { Large amplitude, low } \\
\text { frequency, localized on leks }\end{array}$ & $\begin{array}{l}\text { Continental } \\
\text { hot } \\
\text { semi-arid } \\
\text { windy }\end{array}$ \\
\hline $\begin{array}{l}\text { Jefferson } \\
\text { Proving } \\
\text { Ground } \\
\text { (BONWR), } \\
\text { IN }\end{array}$ & $\begin{array}{l}\text { Deciduous } \\
\text { forest with } \\
\text { open } \\
\text { grasslands } \\
\text { and oak } \\
\text { savannas, flat } \\
\text { to rolling } \\
\text { terrain }\end{array}$ & $\begin{array}{l}\text { Henslow's Sparrow } 2 \\
\text { Field Sparrow } 2,4 \\
\text { Northern Bobwhite } \\
\text { Prairie Warbler } 2,4\end{array}$ & $\begin{array}{l}\text { Low amplitude, territorial } \\
\text { Moderate amplitude, territorial } \\
\text { High amplitude, large home } \\
\text { range } \\
\text { Moderate amplitude, territorial }\end{array}$ & $\begin{array}{l}\text { Continental } \\
\text { warm } \\
\text { intermediate } \\
\text { humidity } \\
\text { intermediate } \\
\text { winds }\end{array}$ \\
\hline $\begin{array}{l}\text { Fort Bragg, } \\
\text { NC }\end{array}$ & $\begin{array}{l}\text { Pine forests, } \\
\text { with open } \\
\text { fields and } \\
\text { pine } \\
\text { savannas, flat } \\
\text { terrain }\end{array}$ & $\begin{array}{l}\text { Red-cockaded } \\
\text { Woodpecker } 1,3 \text { Field } \\
\text { Sparrow } 2,4 \text { Prairie } \\
\text { Warbler } 2,4 \text { Northern } \\
\text { Bobwhite } 2,3 \\
\text { Bachman's Sparrow } 2,4\end{array}$ & $\begin{array}{l}\text { Moderate amplitude, } \\
\text { aggregated } \\
\text { Moderate amplitude, territorial } \\
\text { Moderate amplitude, territorial } \\
\text { High amplitude, large home } \\
\text { range } \\
\text { Infrequent singer, territorial }\end{array}$ & $\begin{array}{l}\text { Humid } \\
\text { Subtropical } \\
\text { hot } \\
\text { humid } \\
\text { light winds }\end{array}$ \\
\hline
\end{tabular}

* Key for selection of focal species

${ }^{1}$ Listed threatened or endangered species

2 Species of conservation concern

3 Species of unique behaviors

${ }_{4}^{4}$ Common species that will yield ample data 
Figure 4-2. Example of sites selected for demonstration, JPG, IN.

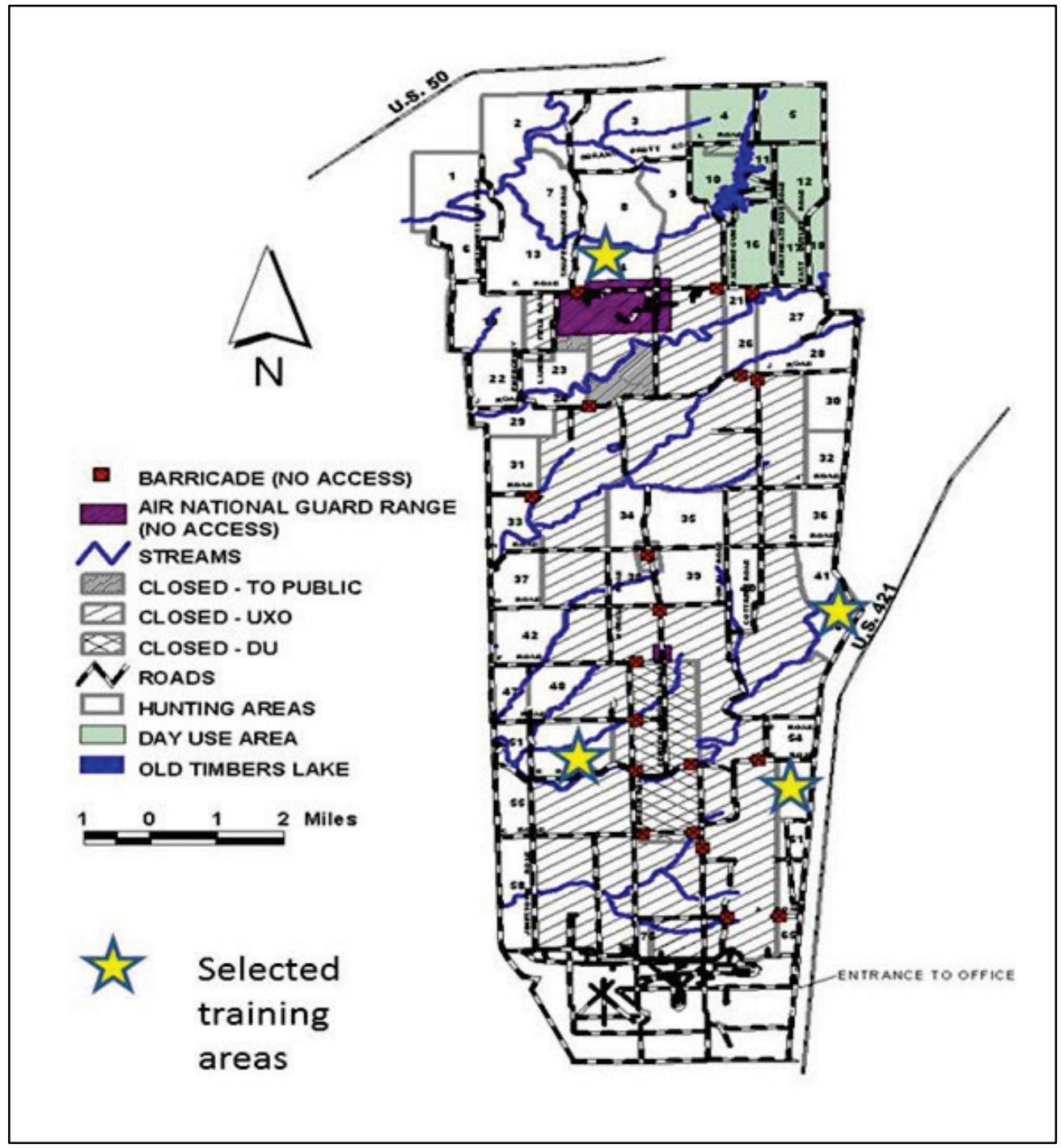


Figure 4-3. Example individual field selected for demonstration, JPG, IN.

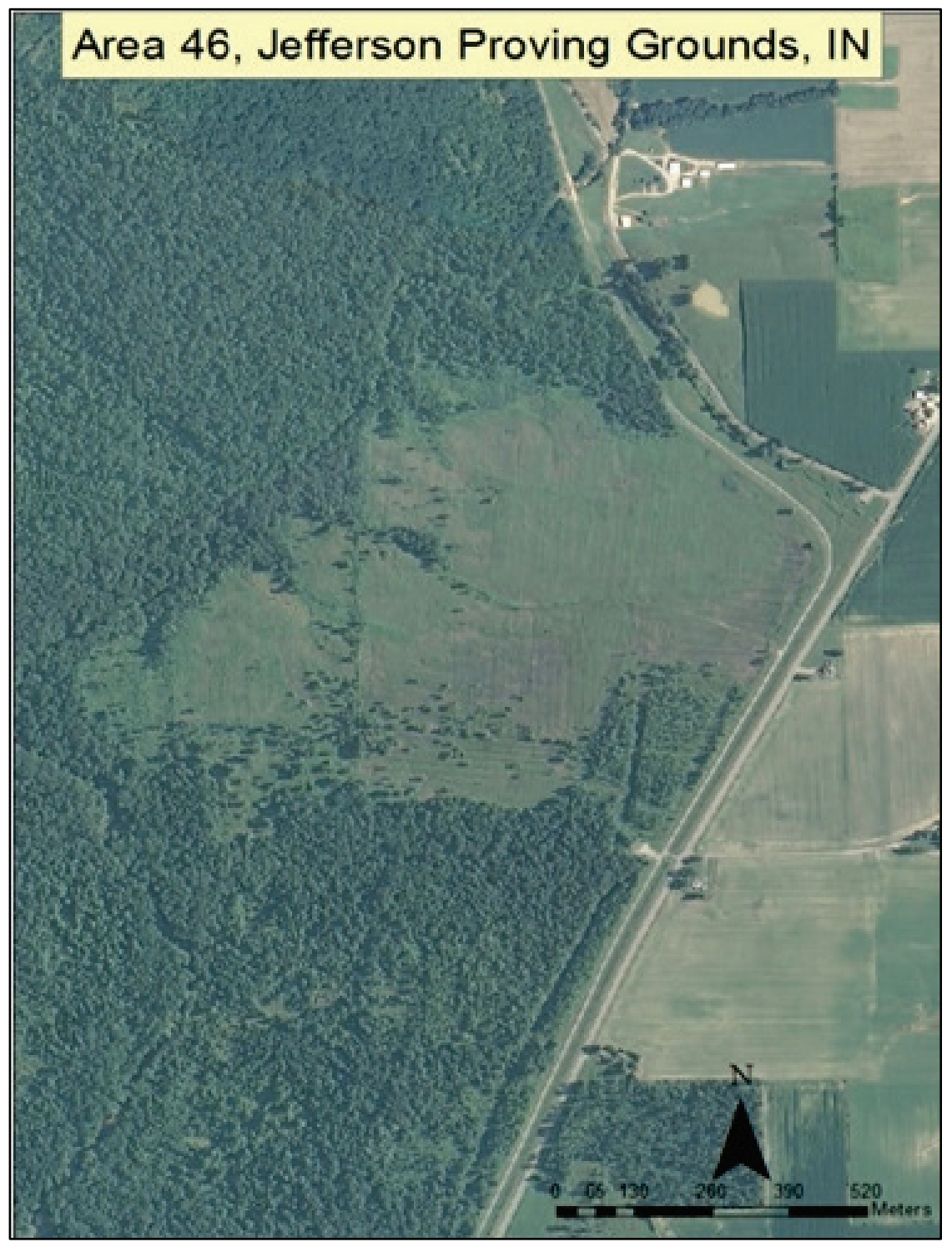

Fort Riley is located in the Flint Hills of Kansas (Geary and Riley counties), which has the largest remaining tract of native tallgrass prairie in the United States. The base was established in 1853 and is comprised of 40,000 ha of prairie habitat, small (mainly riparian) forested strips, and some agricultural fields. Training areas are large enough to accommodate long flights, and as a result, site selection was not as at other installations. Training areas 48, 56, 90, and 95 were identified by staff at Fort Riley as having the best vegetation and physical characteristics to meet project goals and were used for the majority of the demonstration (Figures 4-4 and 4-5).

Fort Bragg is a 65,000-ha installation primarily used in airborne and special forces training in Cumberland and Hoke counties, North Carolina. This 
installation provided the most challenging demonstration environment because of the need to deploy the AAARS over pine forestland. Two of the target species (Red-cockaded Woodpeckers and Bachman's Sparrows) are pine savanna obligates, and therefore training areas were included that had the proper habitat for these birds as well as multiple DZs for the demonstration. The presence of scattered trees in the intended flight paths made it impossible to fly the AAARS on a tether as in the other installations such that dynamic tests were accomplished with free flights (Figure 4-6). The demonstration at Bragg was based primarily on free flights and tethered static trials (point counts) within these target forested stands (Figure 4-7).

Figure 4-4. Installation map of Fort Riley showing selected training areas for demonstration and validation work.

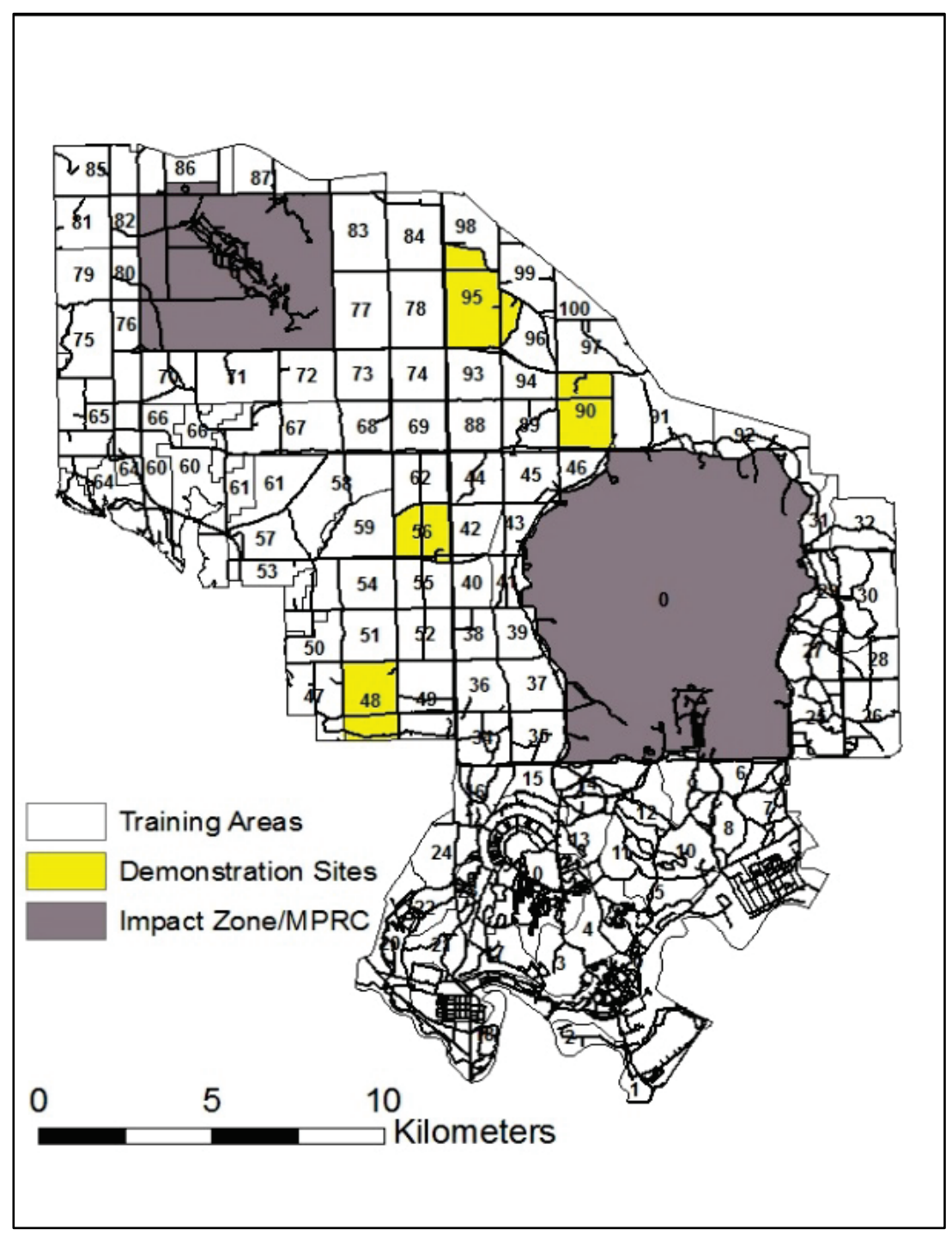


Figure 4-5. Example of individual training area selected for demonstration, Fort Riley, KS.

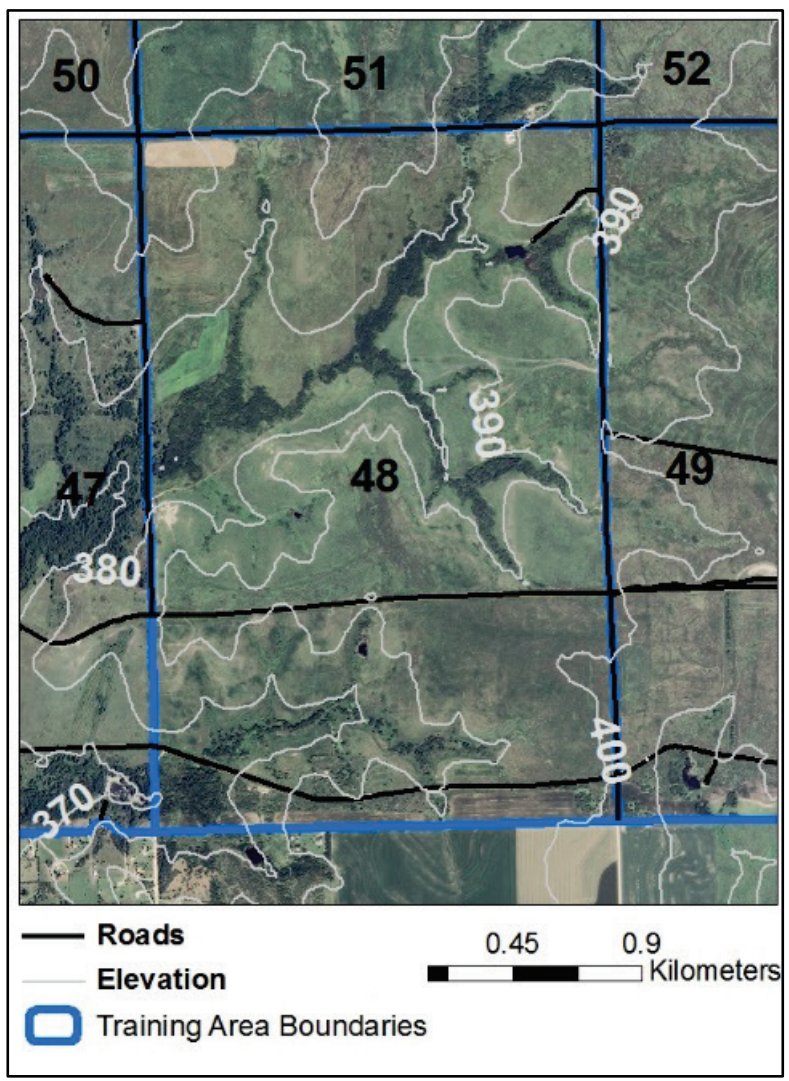

Figure 4-6. Installation map, Fort Bragg, NC, with demonstration areas highlighted.

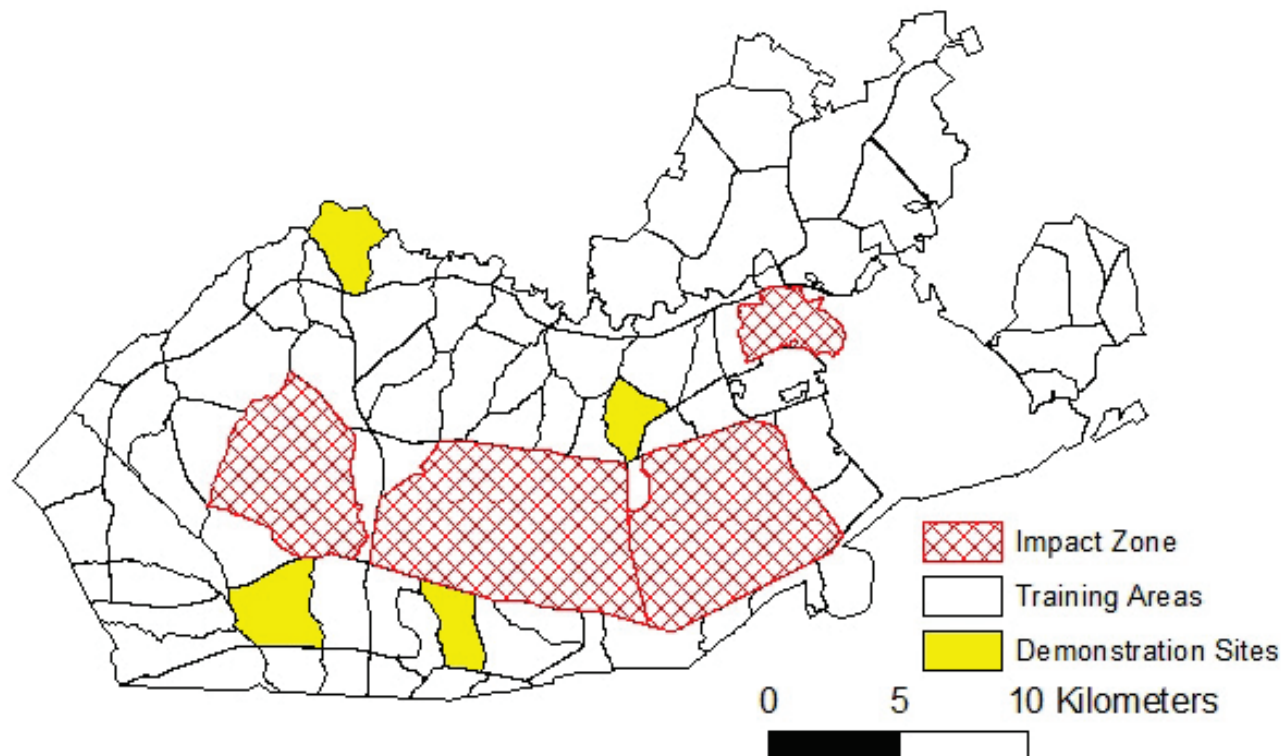


Figure 4-7. Example training area selected for demonstration, Holland DZ, Fort Bragg, NC.

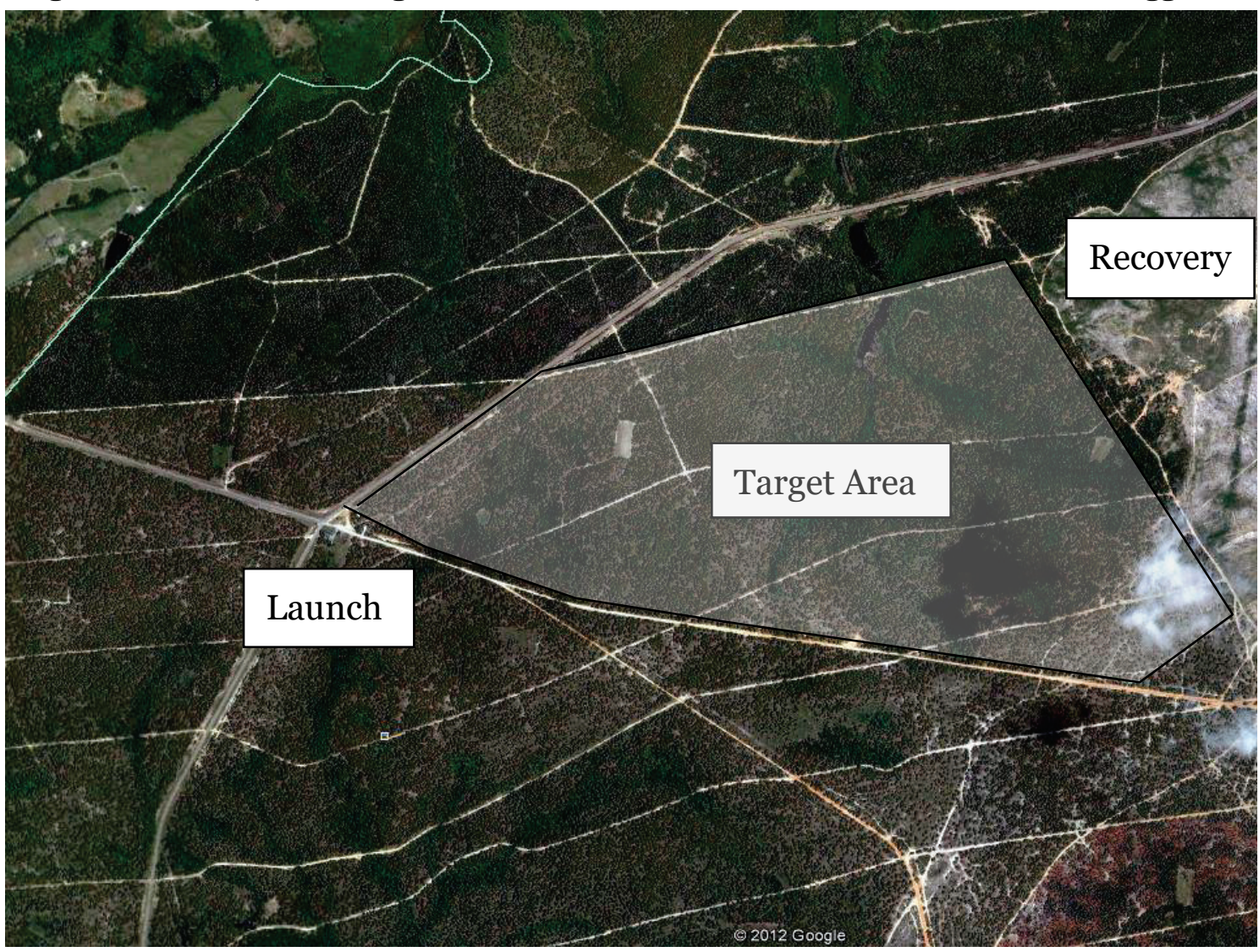

\subsection{SIte characteristics}

Sections 4.1 and 4.2 describe the differences in vegetation and land cover that have been taken into consideration when planning which sites on each installation to use. The elevation and climate at each installation were not limiting factors in the implementation of the demonstration plan as none of these sites had terrain-based limitations (Figures 4-2 through 4-7). The differences in atmospheric thermal conditions among sites did affect altitude control, which in part is reflected in the AAARS flight performance results.

\subsection{Site-related permits and regulations}

The AAARS, as designed, is exempt from FAA regulation because the weight is less than $1.8 \mathrm{~kg}$ (14 CFR Part 101, section 101.1a4i: Weather balloon with payload $<1.8 \mathrm{~kg}$ ). AAARS use on each installation is at the discretion of range and air traffic control offices. A meeting was held with all relevant personnel before beginning the field testing at each installation to discuss the goals and objectives, demonstrate the use of the technology, 
and ensure that correct procedures were followed. Appendix A is an example of a memorandum of agreement used with range and air control on the project. Daily coordination was instituted with each installation's range control to avoid all training activities and utilized weekends and holidays as much as possible to decrease interference with the recording equipment and maintain safety around military training. 


\section{Test Design}

The overall conceptual design of the demonstration was centered on validating the performance of the AAARS in terms of how the system performed in collecting target avian vocalizations under the range of environmental and operational conditions present on the installations.

\subsection{Conceptual test design}

Baseline performance characteristics were documented, where the system was tested in a controlled environment on tether with computercontrolled, simulated audio sources at the University of Tennessee. The demonstration then documented performance with simulated audio sources under a range of field conditions on each installation. Finally, the demonstration documented performance with real avian vocalizations under a range of field conditions on each installation. In each case, the validation tests were compared with standardized human-observer based methods (Figure 5-1).

\subsection{Baseline characterization and preparation}

The baseline characterization of AAARS system performance was documented under a range of environments. An array of speakers was used to play target species' songs broadcasting at biologically accurate amplitudes. The AAARS was flown over these grids both on and off tether and at different heights to determine the relationship between balloon height and the horizontal limit of where the microphone picked up each species' song. This relationship between the horizontal to vertical distance at flight heights differs by species due to song characteristics; higher frequency sounds and trills do not carry as far as sustained tones or lower frequency sounds. The footprint ratio resulting from microphone testing was the basis of all area-based calculations.

The baseline characterization generated parameter estimates for detection rates and classification rates. These parameter estimates served as the foundation for establishing the performance standards for performance objectives related to detection and classification (Objectives 4 and 8). By determining what was possible in terms of detection and classification under ideal conditions with simulated sources, informed decisions were made for setting performance standards for what was possible under field conditions with simulated sources and real birds. 
Figure 5-1. Conceptual design of the validation tests for the demonstration.

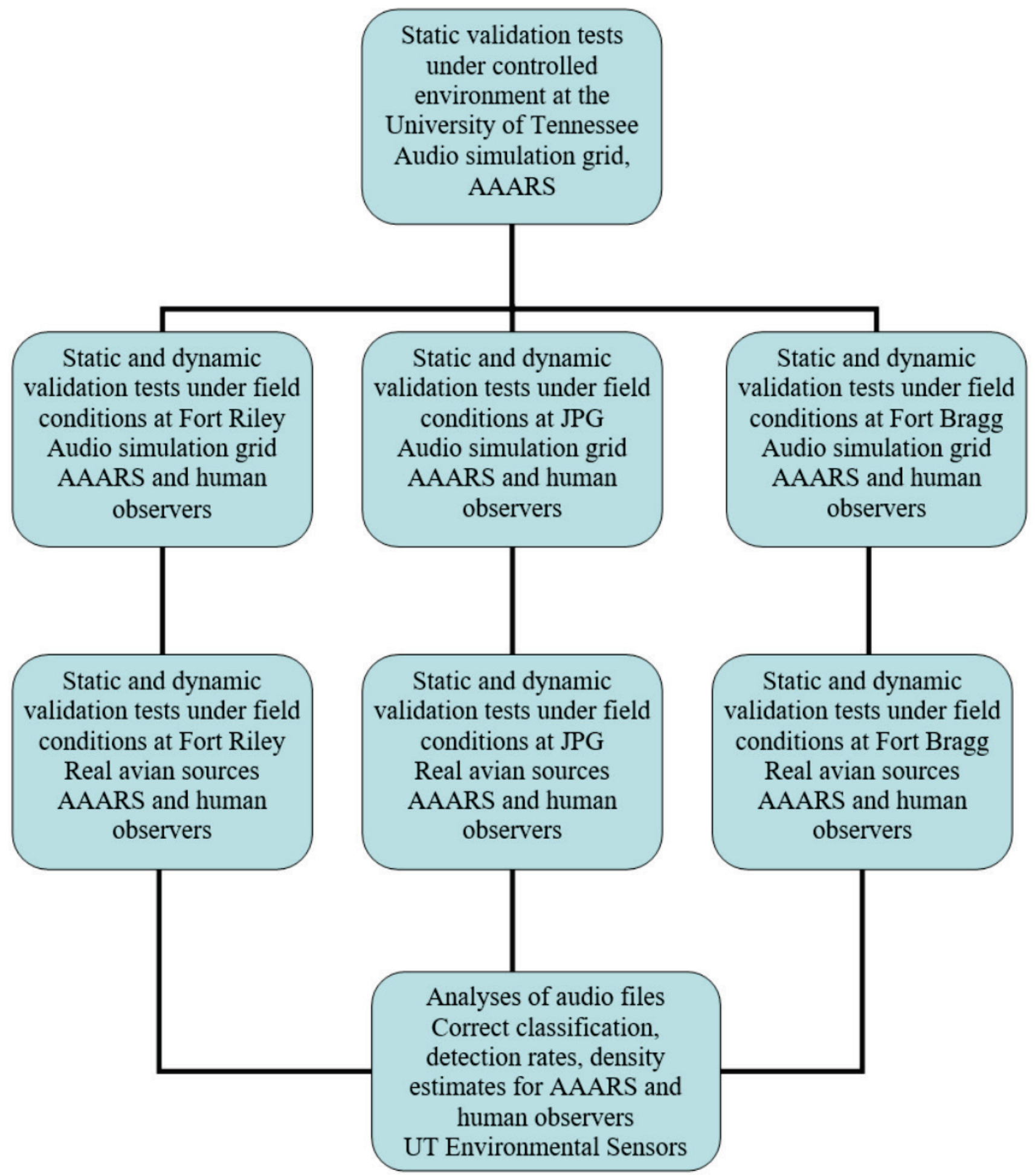




\subsection{Design and layout of technology and methodology components}

The ability of the system to document known sources of auditory cues under a variety of field conditions was validated. Two major field validation tests were involved: static tests (Figure 5-2) in which the AAARS was tethered over a given site in which the song simulation grid was deployed and dynamic tests in which the AAARS was walked on tether along a line transect or flown over a given target area (free flight) in which the song simulation grid had been deployed.

Figure 5-2. Static validation test layout-baseline characterization.

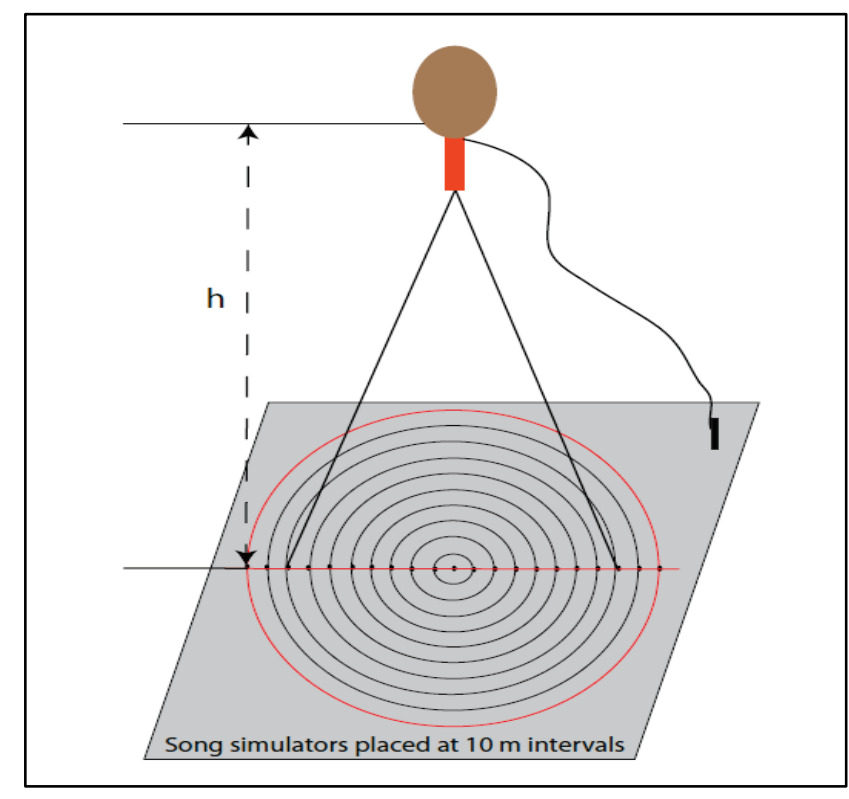

\subsubsection{Audio simulation system for validation tests}

A system was developed to broadcast avian songs at variable frequency and amplitude for the validation tests, similar in design to the system developed by Simons et al. (2007). The bird song simulator consists of an MP3 player, audio power amplifier, speaker, RF modem, batteries, and battery charging system (Figure 5-3). The MP3 player (MP3 Trigger v2, Sparkfun Electronics) was used to play digital recordings of avian vocalizations. The line level output of the MP3 player was amplified by a $25 \mathrm{~W}$ mono power amplifier (TPA3112D1, Texas Instruments, Inc.) to drive a 3 in. diameter, $60 \mathrm{~W}$, water-resistant marine midrange speaker (MA-3013G, Poly-Planar, LLC). The system was powered by three $3.7 \mathrm{~V} \mathrm{LI}$ batteries that could be charged in place using an integrated charge controller (MAX745, Maxim Integrated Products). The MP3 player was 
remotely controlled by a PC via an addressable RF modem (XBee XSC XBPo9-XC, Digi International, Inc.). The personal computer used LabVIEW software to play selected vocalizations at the desired time on each simulator in a grid of multiple simulators. The electronic systems were integrated on a custom printed circuit board and were installed in a plastic enclosure. The enclosure was mounted on a commercially available camera tripod and placed in the field at specific GPS coordinates.

The computer controlled each MP3 player independently in terms of when it broadcasted, the song being broadcast, and the amplitude of the broadcast.

Figure 5-3. Design of audio broadcast system for playing bird songs during validation tests.

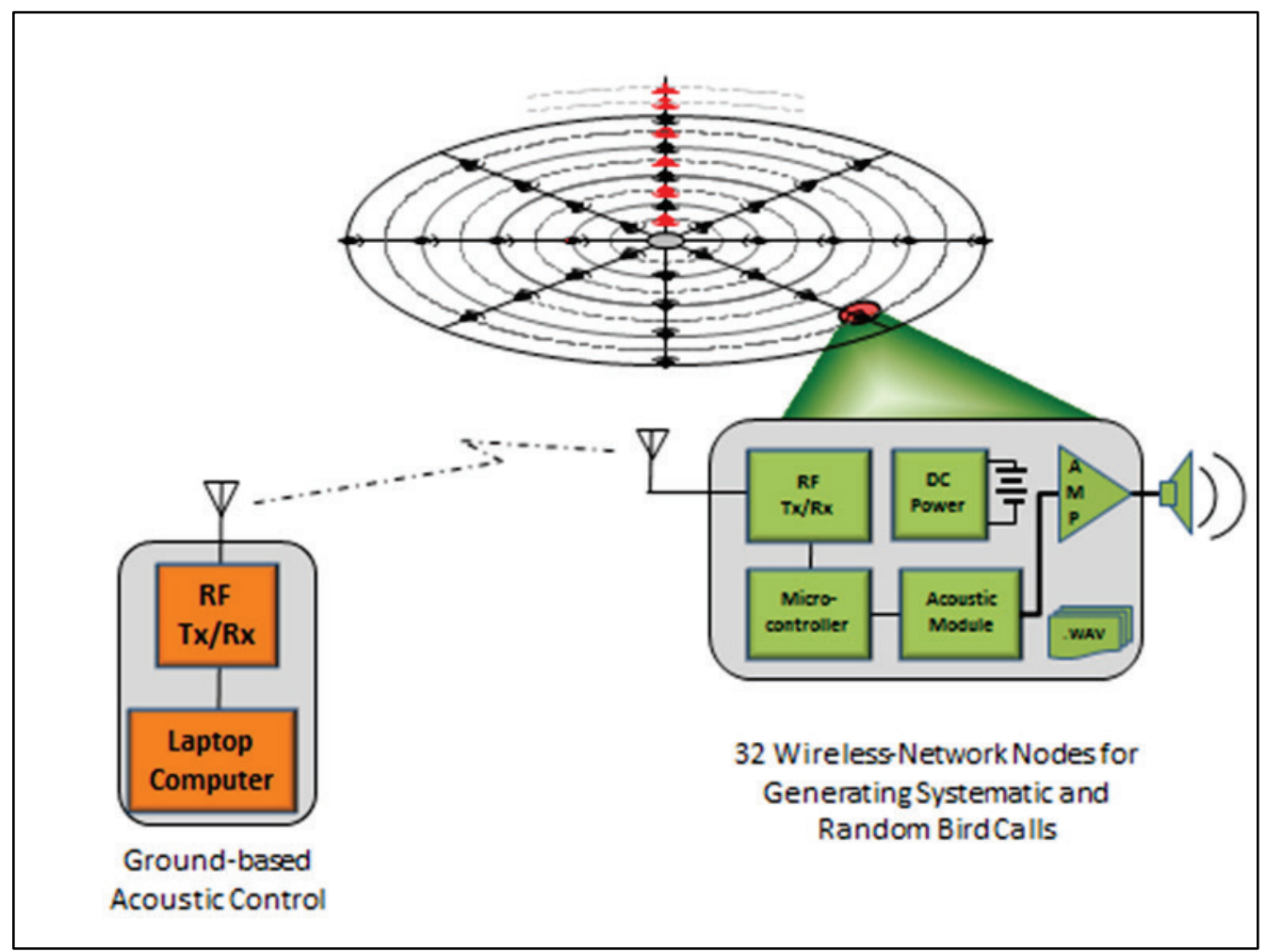

\subsubsection{Static tests}

Location: The static tests were conducted in each selected training area. The static tests with the song simulation grid were centered on a consistent point location in the field where there was limited real bird activity (Figure 5-4). The simulation grid was surveyed once to locate the song simulators, with survey flags placed at each song simulator location. All static simulation tests were run at the same set of points. Song 
simulators were removed after each day's test activities. The static tests involving real birds were located at the same set of monitoring points in each field as that used for the song simulator grid. Point counts for real birds followed standard protocols (see Appendix D).

\section{Equipment}

- AAARS on tether

- Base station with laptop computer, RF modem, and antenna running Labview software logging flight record

- Grid of song simulators on tripods

- Laptop computer with RF modem and antenna controlling song simulators

Figure 5-4. Static validation test under field conditions.

- 10 min point count

- Balloon vs. human observer

- Bird song simulators or real birds
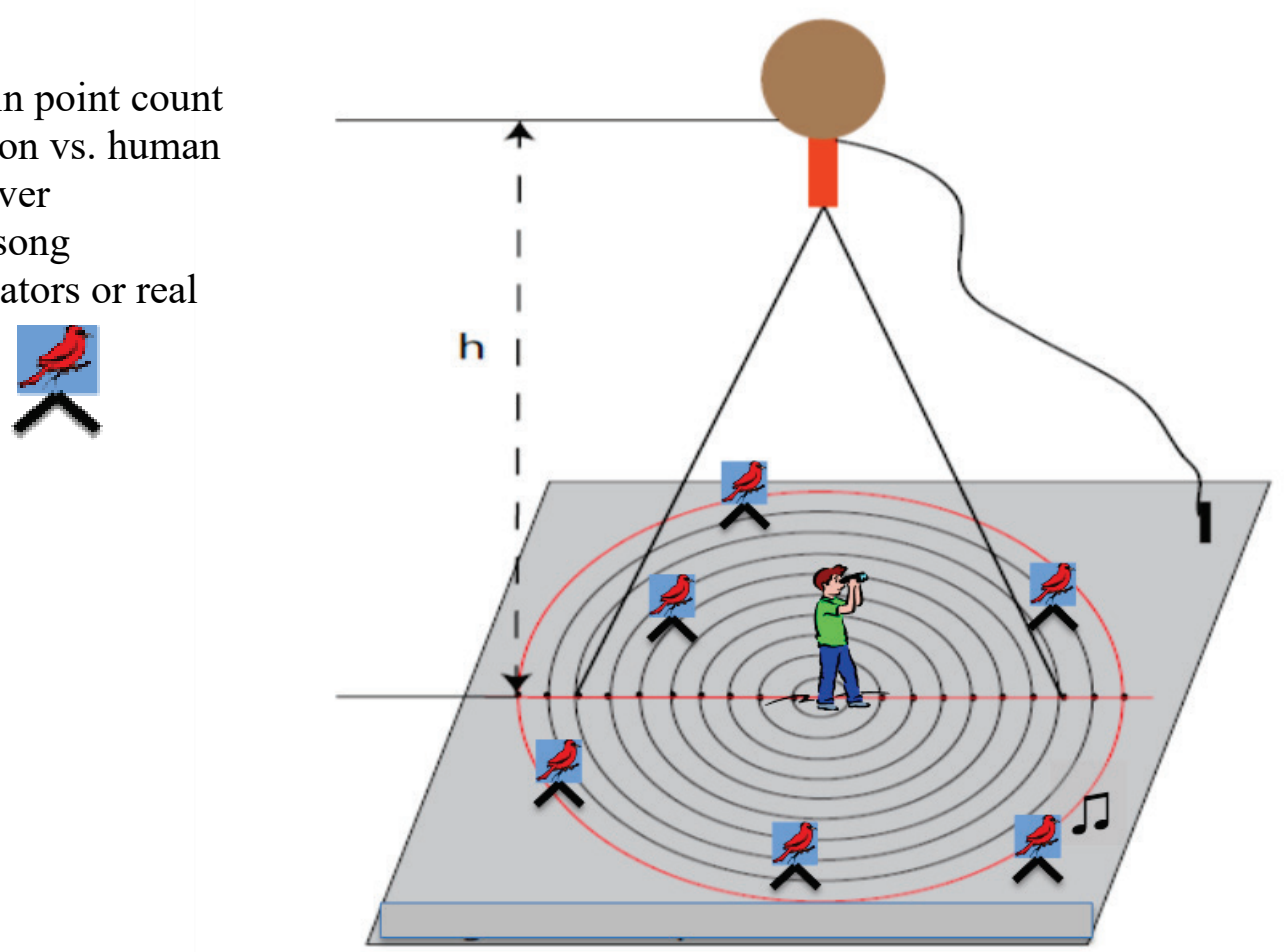

\subsubsection{Dynamic tests}

Location: The dynamic tests were conducted in the same fields used for the static tests. For the song simulation tests, a $200 \mathrm{~m} \times 500 \mathrm{~m}$ grid was established in each field (Figure 5-5). The grid was located so that the long axis of the grid followed the prevailing wind direction. The simulation grid 
was surveyed once to locate the song simulators, with survey flags placed at each song simulator location. All dynamic simulation tests were run over the same grid in each field. Song simulators were removed after each day's test activities. The dynamic tests involving real birds involved a standard distance-based line transect (see Appendix D) were located along the same $500 \mathrm{~m}$ transect in each field. Spot-mapping of real birds was conducted (Appendix D) to estimate the true density of birds on linetransect sites during tethered and free flights.

\section{Equipment}

- AAARS on tether and free flight

- Base stations (three) with laptop computers, RF modems, and antennas running Labview software logging flight record

- Grid of song simulators on tripods

- Laptop computer with RF modem and antenna controlling song simulators

Figure 5-5. Dynamic validation test - field conditions. Avian song transmitters were placed randomly in the $50 \times 50 \mathrm{~m}$ grid cells. Total grid measurements $500 \times 200 \mathrm{~m}$. The observer and tethered AAARS walk/fly the center path and made recordings of observations.

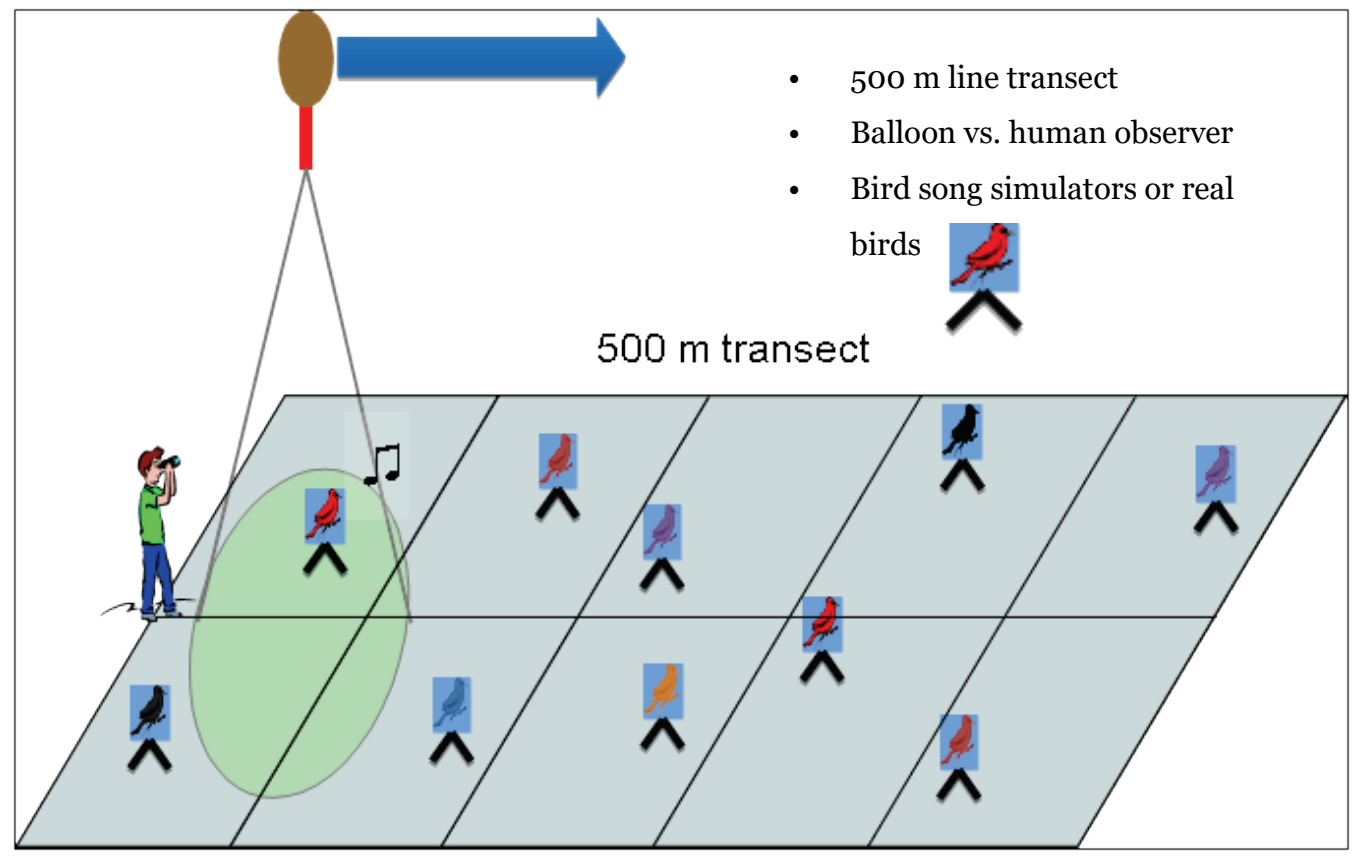




\subsubsection{Exposure time and flight path analysis}

For analysis purposes, there was a need to model the flight path for each validation trial and the exposure time for the AAARS microphone on a square-meter pixel by pixel basis. To accomplish this, the flight path and exposure time were modeled using ArcMap 10.3 model builder (ESRI, Redlands, CA) based on AAARS second-by-second GPS data (Figure 56A). Based on this flight path, a focal species-specific flight path was modeled in ArcGIS on a second-by-second basis, which used the detection radius of a given focal species and the flight altitude to generate a secondby-second area of coverage (Figure 5-6B). The individual second-bysecond exposure radii, were joined in ArcGIS to generate the cumulative flight path (Figure 5-6C). Microphone exposure time for each squaremeter pixel in the flight path was calculated in ArcGIS based on AAARS flight speed over a given pixel to produce a flight exposure surface (Figure 5-6D). Although a consistent altitude is generally the goal during a flight, change in altitude altering the exposure footprint is accounted for in the exposure model (Figure 5-6D and E). Summing the pixel exposure times on this flight area then produced an estimate of the cumulative exposure time-hectares used in bird density estimation. 
Figure 5-6. Flight path analysis from flight GPS data including the $500 \mathrm{~m}$ flight path (A), individual buffers for each recorded AAARS location (B), total flight area covered by one species(C), total flight exposure in hectares/second (D), and altitude profile (E).
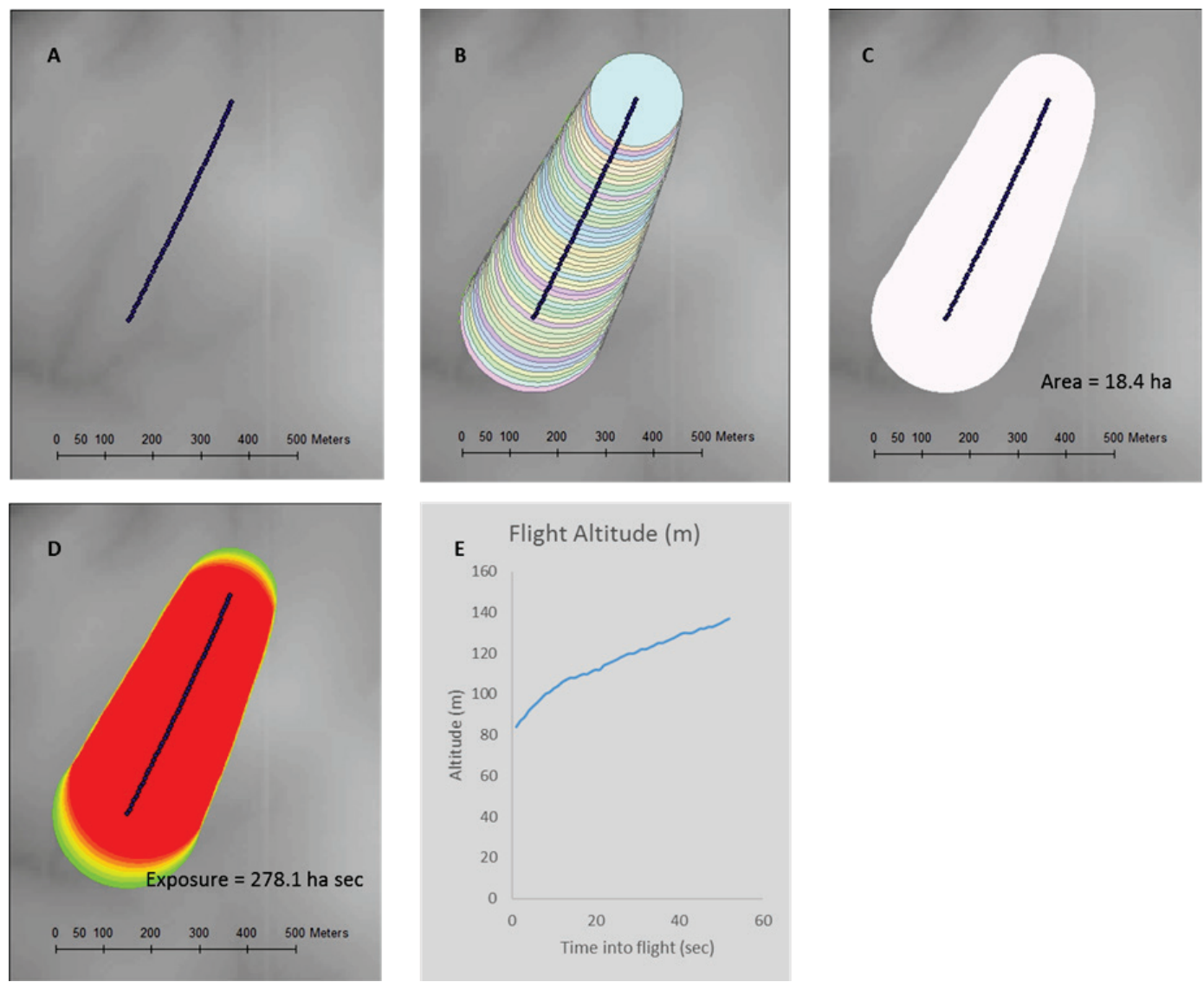

\subsubsection{Audio analysis pathway}

The audio files that were collected from the demonstration were analyzed with RavenPro software (Bioacoustics Research Program, CLO) and package monitoR in program $R$ ( $R$ 2015). Program $R$ is a crowd-sourced and highly extensible statistical platform with downloadable packages and support available for distribution online. Package monitoR was created in 2014 by S. D. Hafner and J. Katz through CLO and incorporates certain functions of the seewave and tuneR packages. MonitoR is a platform for acoustic template detection and monitoring, where users can use templates for detection of animal vocalizations as well as view, verify, and extract results from large datasets. Unlike commercial programs (e.g., Raven Pro), Program R does not require a licensing fee. The package can be used in all steps of the audio analysis pathway (Figure 5-7).

The acoustic analysis pathway was developed to extract a high percentage (i.e., 95\%) of the target vocalizations and then discriminate between target 
and non-target vocalizations using multivariate statistical procedures on a variety of acoustic signal parameters (Table 5-1). Correct species classification of birdsongs in continuous recordings relies first on the quality of the templates chosen for analysis. Vocalizations selected for use as templates should be clean songs of the target species with no overlapping noise from other birds, insects, or anthropomorphic sources. Templates should include examples of all song types, excluding chip notes, to produce the best results. Raven Pro software was used to locate and isolate vocalizations used as templates for each focal species.

The interactive detection process in monitoR uses selected templates of the focal species and runs quickly through lengthy sound files to identify acoustic signals that match the energy signature and pattern of the templates. The degree of correlation between template and detections can be managed by using a threshold cut-off defined by the user. Different templates can be tried for a given species until templates that maximize the correct classification rates are identified. Templates can be saved and used in multiple files, and all detections in a given file can be saved and analyzed at that time or exported for further analysis. Automatically derived selections were compared against manually inspected truth files to determine the correct classification rates (i.e., true positives vs. false positives) for the final template set and threshold settings for a given focal species.

Results from the template detection analysis are based on correlation between sounds in a natural environment and as such may contain falsepositive hits or false-negative misses depending on the correlation threshold and source of non-target noise. Multivariate statistical program $\mathrm{R}$ packages can then be used in a discriminant function analysis and machine learning techniques to discriminate between accurate and inaccurate detections. Due to the inherent messiness and overlapping noises of passive recording, it is not feasible to get $100 \%$ accuracy of all target songs in a recording even when using these post-processing methods. An index between detection results and manual detections can be applied to monitoR detection results of novel files to improve accuracy in song counts.

\subsection{Field testing}

The field demonstration involved validation tests under field conditions with simulation and real audio sources in static and dynamic modes with 


\begin{abstract}
AAARS and human observers, as outlined in Section 5.3 (Table 5-2). All major equipment was removed from the field site after the duration of each test, but survey flags were left until all tests were completed in each field or by July 31 of each year.
\end{abstract} Figure 5-7. Conceptualization of how acoustic data were analyzed for the
demonstration.

\begin{tabular}{|c|c|c|c|c|c|}
\hline $\begin{array}{l}\text { Filtering } \\
\text { Use band- } \\
\text { width filter to } \\
\text { remove noise } \\
\text { from audio } \\
\text { files that is not } \\
\text { within the } \\
\text { frequency band } \\
\text { associated with } \\
\text { target } \\
\text { vocalization }\end{array}$ & $\begin{array}{l}\text { Template } \\
\text { Selection } \\
\text { Identify a } \\
\text { set of } \\
\text { potential } \\
\text { templates }\end{array}$ & $\begin{array}{l}\text { Template } \\
\text { Refinement } \\
\text { Evaluate template } \\
\text { performance, } \\
\text { determine an } \\
\text { appropriate } \\
\text { threshold, and } \\
\text { finalize template } \\
\text { set for target } \\
\text { species signal } \\
\text { extraction }\end{array}$ & $\begin{array}{l}\text { Signal } \\
\text { Extraction } \\
\text { Apply } \\
\text { templates in } \\
\text { monitoR to } \\
\text { audio files } \\
\text { and extract } \\
\text { "hits" from } \\
\text { training } \\
\text { datasets }\end{array}$ & $\begin{array}{l}\text { Statistical } \\
\text { Analysis I } \\
\text { Conduct } \\
\text { multivariate } \\
\text { statistical } \\
\text { analysis on } \\
\text { training } \\
\text { datasets to } \\
\text { discriminate } \\
\text { between true } \\
\text { and false } \\
\text { signals }\end{array}$ & $\begin{array}{l}\text { Statistical } \\
\text { Analysis II } \\
\text { Apply the } \\
\text { statistical } \\
\text { relationships to } \\
\text { extractions } \\
\text { from novel } \\
\text { audio files to } \\
\text { determine the } \\
\text { number of true } \\
\text { signals }\end{array}$ \\
\hline
\end{tabular}

Table 5-1. Example of acoustic parameters that can be used to discriminate target and non-target vocalization during acoustic analysis, derived from RavenPro software

(CLO).

\begin{tabular}{|c|c|}
\hline Measurement & Description \\
\hline Bandwidth $90 \%$ & Difference between the $5 \%$ and $95 \%$ frequencies $(\mathrm{Hz})$ \\
\hline Center Frequency & Frequency $(\mathrm{Hz})$ that divides selection into two frequency intervals of equal energy \\
\hline Center Time & Point in time when selection is divided into two time intervals of equal energy (s) \\
\hline Duration $90 \%$ & Difference between the $5 \%$ and $95 \%$ times (s) \\
\hline Frequency $5 \%$ & $\begin{array}{l}\text { Frequency }(\mathrm{Hz}) \text { that divides selection into intervals containing } 5 \% \text { and } 95 \% \text { of energy } \\
\text { in selection }\end{array}$ \\
\hline Frequency 95\% & $\begin{array}{l}\text { Frequency }(\mathrm{Hz}) \text { that divides selection into intervals containing } 95 \% \text { and } 5 \% \text { of energy } \\
\text { in selection }\end{array}$ \\
\hline IQR Bandwidth & Difference between first and third quartile frequencies $(\mathrm{Hz})$ \\
\hline IQR Duration & Difference between the first and third quartile times (s) \\
\hline Peak Frequency & Frequency where the maximum power occurs $(\mathrm{Hz})$ \\
\hline Time 5\% & $\begin{array}{l}\text { Point in time that divides selection into time intervals containing } 5 \% \text { and } 95 \% \text { of } \\
\text { energy of selection (s) }\end{array}$ \\
\hline Time 95\% & $\begin{array}{l}\text { Point in time that divides selection into time intervals containing } 95 \% \text { and } 5 \% \text { of } \\
\text { energy of selection (s) }\end{array}$ \\
\hline $\begin{array}{l}\text { First Quartile } \\
\text { Frequency }\end{array}$ & $\begin{array}{l}\text { Frequency }(\mathrm{Hz}) \text { that divides selection into intervals containing } 25 \% \text { and } 75 \% \text { of } \\
\text { energy in selection }\end{array}$ \\
\hline
\end{tabular}


Table 5-2. Location and duration of specific components of the demonstration.

\begin{tabular}{|c|c|c|}
\hline Performance Objective & Location & Duration \\
\hline 1- Flight Performance & Riley, JPG & June-July 2011 \\
\hline 1- Flight Performance & JPG, Bragg & May-July 2012 \\
\hline 1- Flight Performance & Riley, Bragg & May-July 2013 \\
\hline 2- RF Communications & Riley & May-July 2011 \\
\hline 3- Lat-Long Control System & Riley & May-July 2011 \\
\hline 4- Static and Dynamic Test- simulation & Riley, JPG & June-July 2011 \\
\hline 4- Static and Dynamic Test- simulation & JPG, Bragg & May-July 2012 \\
\hline 4- Static and Dynamic Test- simulation & Riley, Bragg & May-July 2013 \\
\hline 5- Static and Dynamic Test- real birds & Riley, JPG & June-July 2011 \\
\hline 5- Static and Dynamic Test- real birds & JPG, Bragg & May-July 2012 \\
\hline 5- Static and Dynamic Test- real birds & Riley, Bragg & May-July 2013 \\
\hline 6-7 Trials involving human observers & Riley, JPG & June-July 2011 \\
\hline 6-7 Trials involving human observers & JPG, Bragg & May-July 2012 \\
\hline 6-7 Trials involving human observers & Riley, Bragg & May-July 2013 \\
\hline 8-11 Audio File Analyses & University of Tennessee & August-Sept 2011, 12, 13 \\
\hline 12- Ease of Use & Riley, JPG, Bragg & May-July 2011, 12, 13 \\
\hline
\end{tabular}

\subsubsection{Performance Objective 1: Flight performance}

Flight performance data were collected during all of the free flight trials conducted during the demonstration. Data logs within the Labview software recorded the amount of time required to complete pre-flight preparations; flight conditions, including the time of each flight, the GPS coordinates associated with each flight, and the altitudes covered during each flight; and the time spent on recovery of the system and the condition of the system upon recovery. Data on the flight area and altitude coverage were compared with target area and desired altitude range to determine whether the flight achieved target conditions.

\subsubsection{Performance Objective 2: RF modem}

RF modem performance was tested at Fort Riley under field conditions. Fort Riley was selected for this test because of the excellent line-of-sight conditions on the open prairies in the training areas. The AAARS was placed on tether at $100 \mathrm{~m}$ altitude to maintain minimal line-of-sight conditions with the base stations. The test was conducting by moving a 
base station away from the tethered AAARS, documenting the percent of commands that were received by the AAARS when sent from the base station and also the percent of GPS strings that were complete when sent from the AAARS and received by the base station. GPS data were sent from the AAARS to the base station $1 \times /$ sec. "Good GPS data" was defined as receipt of a complete GPS data string allowing for generation of a GPS location $50 \%$ of the time (or 1 GPS location/2 sec). The test was started at $16 \mathrm{~km}$ (the expected line-of-sight limit of communication) and then moved to greater distances until no communications were received between the AAARS and the base station.

\subsubsection{Performance Objective 3: Latitude-longitude control system}

The latitude-longitude control system was also validated at Fort Riley because the open prairies and line-of-sight conditions in the training areas facilitated flight control. Under normal operating conditions during free flights, the helium dump command was executed manually based on desirable, unobstructed recovery zones that enhanced successful recovery. On a sample $(\mathrm{n}=20)$ of the free flights being conducted for other validation tests outlined below, the system for automatic deflation was programmed based on the latitude and longitude control box of the target area. For each of these tests, the altitude when the dump command was issued was documented, the distance traveled beyond the target area, prevailing wind direction and speed, the success of the recovery in terms of whether the package was retrieved, and the condition of the package on retrieval.

\subsubsection{Performance Objectives 4, 6, 7: Static and dynamic validation tests-field conditions, simulated audio sources, with comparison with human-observer methods}

Static validation tests occurred under actual field conditions found on each installation. For each test, a systematic grid of audio sources was deployed prior to the morning of the test (Figure 5-3). On the morning of the test, the AAARS was deployed at a range of altitudes $(100 \mathrm{~m}, 150 \mathrm{~m}, 200 \mathrm{~m}$, $250 \mathrm{~m}, 300 \mathrm{~m}$ ) over the center of the grid, tethered in a fixed position. A trained observer located at the grid center conducted a standard $10 \mathrm{~min}$ variable-distance point-count (Buckland et al. 2001).

The audio sources were played in a randomized pattern with different song frequency patterns for each trial so the observer did not develop a 
pre-conceived sense as to the location of any specific source. The audio sources included two to four individuals (mean $=3$ ) of each of four focal species. Additional non-focal species that used the site were included in the broadcasts to impart realism to the validation trial and add complexity to the test. The simulated songs for each species used in the validation tests included a short, characteristic tone after the song was played. The tone allowed identification of which vocalizations on the audio files were in fact simulated and allowed the human observers to identify individual song simulators for detection purposes. The test was repeated with different observers $(n \geq 4)$ to allow for evaluation of observer variability on data collected.

The dynamic test occurred along a systematic grid $500 \mathrm{~m}$ long $\times 200 \mathrm{~m}$ wide, laid out prior to the morning of the test (Figure 5-4). Audio sources were located randomly at $50 \times 50 \mathrm{~m}$ grid cell centroids $(\mathrm{n}=30$ total sources, including 6 individuals of each of 4 focal species and 6 additional non-focal species). On the morning of the test, the AAARS was launched to a fixed altitude $(100 \mathrm{~m}, 200 \mathrm{~m}$, and $300 \mathrm{~m})$ and walked over the long axis of the grid at a speed of $5 \mathrm{~km} / \mathrm{hr}$. Simultaneously, an observer also walked the long axis centerline of the grid at a speed typical of ground-based counts $(\sim 1 \mathrm{~km} / \mathrm{hr})$ and detected and recorded the distance to each audio source detected, using a standard variabledistance line transect count methodology (Buckland et al. 2001, Appendix D). Simulated songs were broadcast continuously at the same frequency so that even though the AAARS was passing through the grid more rapidly than the human observer, each method had a realistic opportunity to detect each simulated source.

The audio sources along line transects were played in a randomized pattern with different songs broadcast from different locations for each trial so the observer did not develop a pre-conceived sense as to the location of any specific source. The test was repeated by walking the AAARS back across the grid at the range of altitudes outlined above and by switching observers $(n \geq 4)$. Once the walking tests were completed, a free flight trial of the AAARS was conducted across the grid, with the goal of maintaining a fixed altitude. The pathway of the AAARS was recorded, and an observer conducted a final line transect survey along the pathway of the AAARS. 


\subsubsection{Performance Objective 5: Document availability for detection-field conditions, real birds}

Based on results from Objective \#4, it is known that if a bird sings, the AAARS will detect it with high probability. An important component of the detection process, however, is documenting the probability that a given individual of a species is actually singing and hence available to be detected by acoustic monitoring methods. To address this objective, ground-based acoustic recording units were used to document song rates for focal species by time of day and day of season. These data allowed the modeling of song rates and availability for detection so that it could be ultimately factored into the density estimation process. For Red-cockaded Woodpecker (RCWO) and Greater Prairie-Chicken (GPCH), availability for detection was determined by placing acoustic recording devices within known breeding locations (RCWO) and on or near leks (GPCH). Simultaneous humanobserved counts within those territories were conducted to document the number of individuals present and the rates of vocalizations.

\subsubsection{Performance Objectives 8-9: Classification of audio files}

Audio files from each field validation test were recorded on micro-SD cards in digital format in the Zoom2 Recorder and were retrieved from the AAARS after each flight. Audio files were uploaded from the micro-SD cards to desktop computer for storage daily. Each file was processed using the same basic approach for each focal species with RavenPro software. A trained transcriber viewed each audio file on a computer monitor and listened to the file with headphones as the file was played. Focal species detections were confirmed by the transcriber visually and aurally and then marked on the file in RavenPro. Classification rates for each audio file were attained by comparing the confirmed detections with the broadcast $\log$ from the song simulators, noting when the AAARS correctly recorded a given song being broadcast and when the AAARS missed the signal. For Objective 9, the acoustic analysis pathway was used (Figure 5-7) to process acoustic data for target species. MonitoR in $\mathrm{R}$ was used to extract potential signals of target species. Threshold values in MonitoR were set to reach performance objective targets (i.e., 90\% correct classification of true target individual songs) and then record the number of false positives and false negatives at that level of performance. 


\subsubsection{Performance Objectives 10-11: Density estimates}

The final step in data processing was the calculation of density estimates from audio files and from human-observer data. AAARS density estimates for real birds were calculated based on a cue count method, in which a relationship was determined between song rate and relative abundance for focal songbirds and determined the total number of songs for a given focal species on a given trial's audio file. This cue count approach has been used successfully to estimate relative abundance for a variety of avian species (Buckland 2006; Lambert and McDonald 2014). A cue count approach avoids problems associated with double-counting individuals because total calls/unit time is being related to relative abundance. By dividing by the exposure area, estimates of relative abundance are converted to actual density. The song frequency of focal species was documented by placing automated recording units (Songmeter 2) in the center of territories and documenting the song rate across the breeding season. Human observer song counts were conducted on a sample of days to document the number of individuals that were audible from the monitoring point and the number of songs by each individual. Using the human observer data, negative binomial regression was used to model the relationship between the number of singing males of a focal species and the number of songs they produced during a 5 min period (Prevost 2016). Although point counts were conducted for $10 \mathrm{~min}$, only the first $5 \mathrm{~min}$ of audio files were analyzed to determine call frequency to reduce the time required for audio analyses. These relationships, then, were used to predict how many individual males were present that generated the observed number of songs per 5 min period on a given trial audio file. The altitude and velocity of the AAARS defined the flight exposure pathway across the landscape and was factored into the analysis to determine density (Figure $5-6$ ) by adjusting the exposure time-area to an assumed $5 \mathrm{~min}$ period to generate an effective area of the flight. This approach, then, converted the call count to a density estimate in males/ha.

For the human observer data, Program Distance software (Thomas et al. 2010) was used to convert point-count distance estimation data to density estimates for real birds of each focal species. The distance-detection function was developed globally using all of the human-observer data for each species, but then individual density estimates were generated for each static or dynamic test for real birds. 
For song simulator data, a similar approach for density estimation for AAARS flights was used, except the flight path was used to determine in ArcGIS which song simulators were actually available to the AAARS during the flight. The density estimate was adjusted accordingly based on song simulator availability. The song simulator density estimates for human observers were calculated in Program Distance similar to real birds. (See Prevost [2016] for a more detailed description of density calculations.)

\subsubsection{Performance Objective 12: Ease of use}

Data on the number of personnel for each of three field seasons, their experience, and the amount of time required to conduct the various stages of operation (pre-flight, flight, and recovery) were collected for each validation test involving a free flight.

\subsection{Sampling protocol}

The baseline characterization work outlined above in Section 5-2 yielded audio files that were analyzed to determine detection rates and correct classification rates of individual species from song simulator sources. For each of these parameters, sufficient trials were conducted to produce parameter estimates with $95 \%$ confidence intervals with $\pm 5 \%$ variation. Based on the baseline parameter estimates, success criteria for detection and classification rates were established. Detection rates are a function of the sensitivity of the microphone, the capability of the digital recorder, the amplitude of the sources compared to the background sound environment, the altitude of the AAARS, and ultimately, the speed of the AAARS relative to the song frequency.

\subsection{Equipment calibration and data quality issues}

\subsubsection{Calibration of equipment}

a. Microphone calibration. The microphone was calibrated for sensitivity to all frequencies of avian vocalizations that were expected to be detected. Song recordings were collected of all focal species from the CLO and compared their frequency ranges to the specifications on the microphone and the audio recording system. Based on this comparison, the microphone was capable of detecting all of the focal species vocalizations. 
b. Calibration of height of AAARS flight to detection distances of aural frequencies. The song simulators were used to calibrate the AAARS microphone-altitude-frequency relationship by conducting tethered tests at a range of altitudes over a grid of song simulators. In general, the footprint radius was approximately 1:1 with the altitude because of the microphone cone, such that when the AAARS was at $100 \mathrm{~m}$ altitude, the footprint was $100 \mathrm{~m}$ radius.

c. Calibration of sound transmitters/bird song simulators. The test grid of simulated bird song transmitters was calibrated based on the amplitude of real bird vocalizations being used in the validation trials at a fixed distance. Sound meter pressure readings were recorded at a fixed distance $(25 \mathrm{~m})$ from target individuals $(\mathrm{n}=10)$ for focal species. A mean sound pressure estimate $(\mathrm{dB})$ was calculated for each species. The song transmitters were set at sufficient amplitude to reproduce the mean sound pressure measured horizontally from the source at the $25 \mathrm{~m}$ distance. The number of songs played per unit time (i.e., song rate) was determined from analysis of song recordings of focal species ( $\mathrm{n}=10$ song files/species) from the CLO Macaulay Library.

d. Ground truth AAARS. See Section 3, Objectives 2 and 3. The goal of the validation trials described validated the performance of the AAARS. In the simulation studies, it is known what the actual detectability was at any point in time and space for any focal species. The validation trials, then, essentially ground-truthed the performance of the AAARS.

\subsubsection{Quality assurance sampling}

The demonstration was designed to evaluate and validate AAARS performance. Therefore, assessment of the quality of the data collected by the AAARS (GPS data, acoustic data) was reflected in the performance objectives. Quality assurance of data collected by humans (humanobserver bird data and transcription of audio files) was achieved by proofreading data entry and by a second observer proofing the audio file transcriptions for consistency in transcription.

\subsubsection{Sample documentation}

Each test flight produced an SD card with the acoustic data record, the GPS data, and the flight command operational datalog. Human-based avian surveys produced datasheets that included environmental 
conditions and bird observations (Appendix C). All data were entered into an Access database for storage and analysis.

\subsection{Sampling results}

\subsubsection{Demonstration trials and AAARS performance success}

Two demonstration field seasons were completed at each of the installations, including summer 2011-2012 at JPG, summer 2011 and 2013 at Fort Riley, and summer 2012 and 2013 at Fort Bragg (Table 5-3).

During these field seasons, 179 free flights, 289 point count trials, and 172 line transect trials were completed, totaling 640 flights in which there were both good GPS data and good audio data. Overall flight performance varied from year to year but generally improved as more experience with AAARS operation was gained (Figure 5-8). By the end of the demonstration, overall success was $>85 \%$. Note that all but two payloads were recovered during free flight operations (recovery $=99 \%$ ). 
Table 5-3. Number of successful validation trials conducted at each site, 2011-2013.

\begin{tabular}{|c|c|c|c|c|c|c|c|}
\hline & \multicolumn{3}{|c|}{ Real Birds } & \multicolumn{3}{c|}{ Song Simulator } & \\
\hline Site & $\begin{array}{c}\text { Point } \\
\text { Counts }\end{array}$ & $\begin{array}{c}\text { Line } \\
\text { Transects }\end{array}$ & $\begin{array}{c}\text { Free } \\
\text { Flights }\end{array}$ & $\begin{array}{c}\text { Point } \\
\text { Counts }\end{array}$ & $\begin{array}{c}\text { Line } \\
\text { Transects }\end{array}$ & Free Flights & $\begin{array}{c}\text { Total } \\
\text { Flights }\end{array}$ \\
\hline JPG & 59 & 65 & 37 & 61 & 43 & 4 & 269 \\
\hline $\begin{array}{c}\text { Fort } \\
\text { Bragg }\end{array}$ & 0 & 0 & 65 & 64 & 0 & 45 & 174 \\
\hline $\begin{array}{l}\text { Fort } \\
\text { Riley }\end{array}$ & 38 & 28 & 28 & 67 & 36 & 0 & 197 \\
\hline \multicolumn{7}{|l}{} \\
\hline
\end{tabular}

Figure 5-8. Flight performance success for the various stages of AAARS operation, 2011-2013.

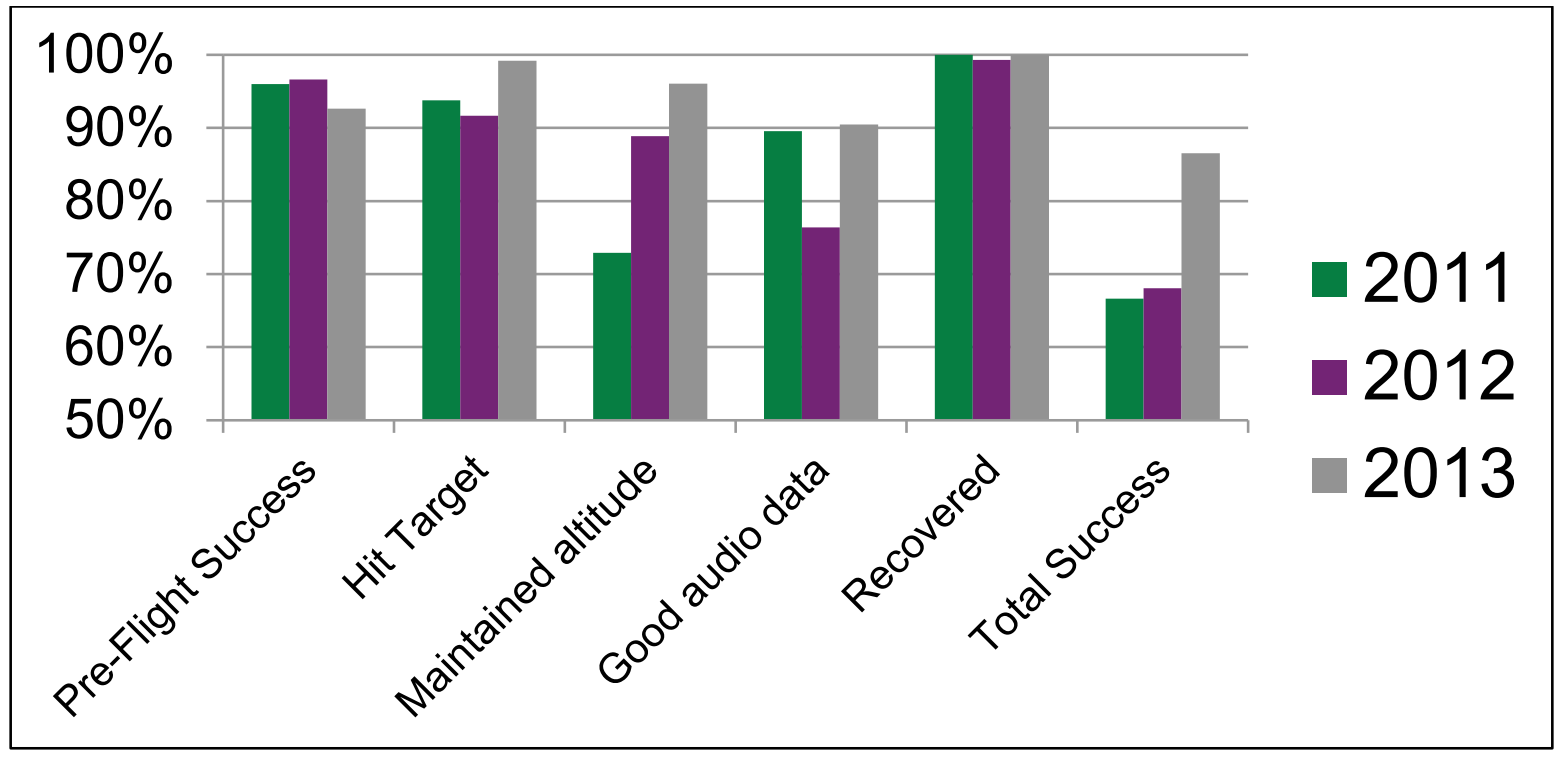

\subsubsection{Military access and flight weather conditions}

Based on daily monitoring of military access constraints and weather conditions, there was documentation of how many days per field season (May-July) had appropriate access and weather for completing AAARS flights over select target field sites on each installation (Table 5-4). JPG had the greatest access because military operations on the installation are more limited than the other two installations and weather conditions (wind speed and direction) were generally favorable. Fort Riley conditions were variable from year to year based on the military training schedule. Fort Bragg access was generally limited to weekends and holidays because of the training schedules. 
Table 5-4. Flight access and weather conditions during summer field seasons 2011-2013.

\begin{tabular}{|c|c|c|c|c|c|}
\hline Location & Year & $\begin{array}{c}\text { Days Favorable } \\
\text { Wind Speed/ } \\
\text { Precipitation }\end{array}$ & $\begin{array}{c}\text { Days Favorable } \\
\text { Wind Direction }\end{array}$ & $\begin{array}{c}\text { Days with } \\
\text { Access }\end{array}$ & $\begin{array}{c}\text { Total Favorable } \\
\text { Days }\end{array}$ \\
\hline JPG & 2011 & 89 & 92 & 36 & 34 \\
\hline JPG & 2012 & 89 & 92 & 33 & 33 \\
\hline JPG & 2013 & 67 & 92 & 34 & 20 \\
\hline Bragg & 2011 & 90 & 84 & 12 & 12 \\
\hline Bragg & 2012 & 89 & 86 & 12 & 12 \\
\hline Bragg & 2013 & 76 & 78 & 12 & 12 \\
\hline Riley & 2011 & 64 & 41 & 73 & 34 \\
\hline Riley & 2012 & 54 & 36 & 57 & 26 \\
\hline Riley & 2013 & 63 & 92 & 7 & 5 \\
\hline
\end{tabular}

\subsubsection{AAARS communication validation}

Based on testing at Fort Riley in open prairie conditions, radio communication between the AAARS and the ground monitoring stations was very good at $16 \mathrm{~km}$. At $16 \mathrm{~km}, 100 \%$ of the commands that were sent from the base station to the AAARS were received, and $49 \%$ of the GPS data that were sent from the AAARS to the base station contained complete data strings allowing for GPS locations of the payload to be generated once every 2 seconds. As distance increased to $20.5 \mathrm{~km}$, communication capability declined rapidly, suggesting that the operational limit for the equipment as designed was $16 \mathrm{~km}$ (Figure 5-9). Additional ground-tracking stations can be used to extend the operational limit of the AAARS beyond $16 \mathrm{~km}$.

\subsubsection{Setting the latitude-longitude target box}

A total of 109 free-flight trials were conducted at Fort Riley in which there was an evaluation of the performance of setting the latitude-longitude target area. In 104 trials (96\%), the AAARS went into recovery mode when 
it reached one of the GPS boundaries of the target area (Figure 5-10). In five trials, the system did not perform as designed because of human error in setting the latitude-longitude limits.

Figure 5-9. AAARS to ground monitoring station communication capability by distance, Fort Riley, KS, 2013*.

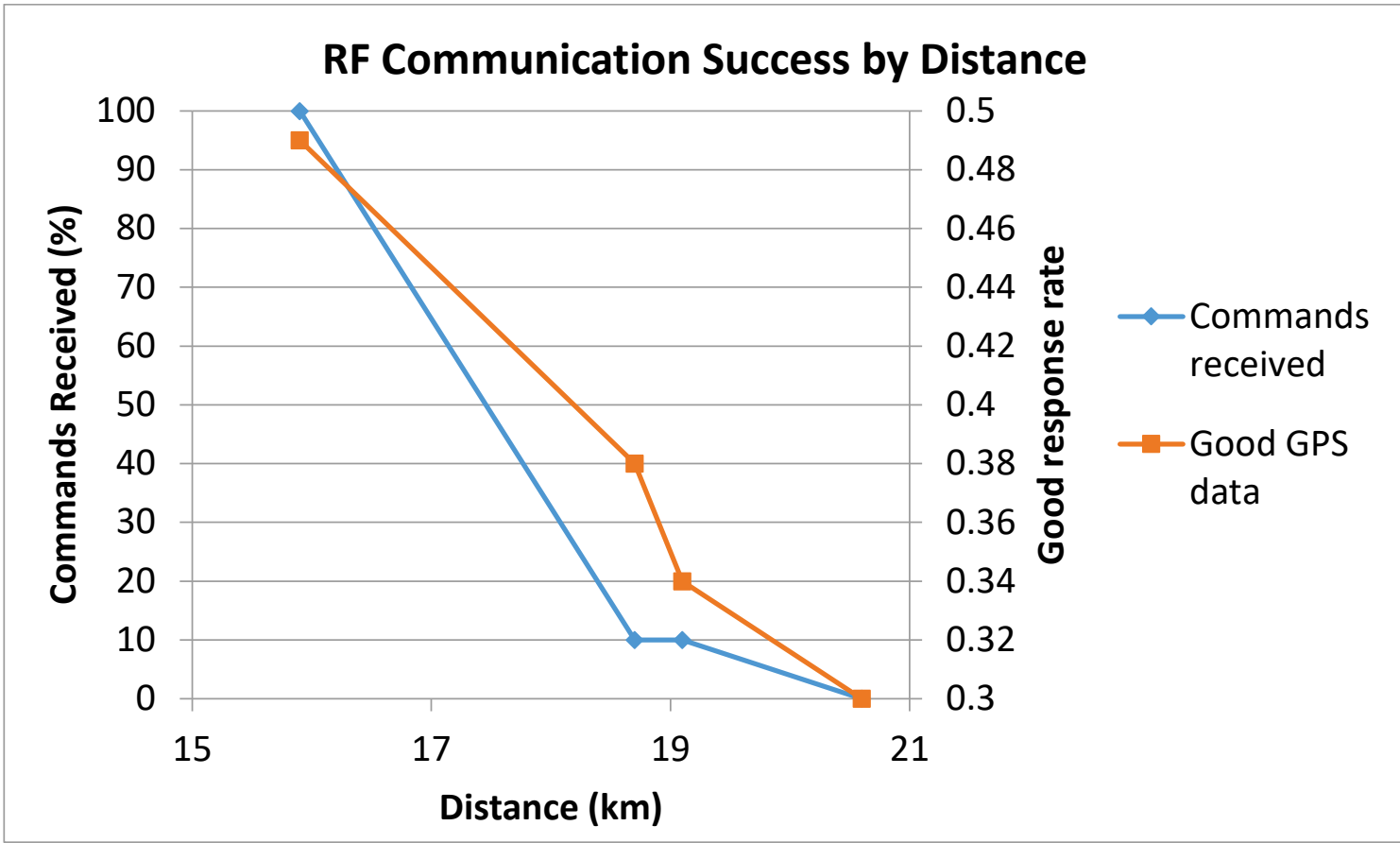

*Commands received was a measure of the percent of commands sent from the base station to the AAARS that were confirmed received by the AAARS. Good GPS response rate was a measure of the percent of GPS data strings sent from the AAARS and received by the base station that were complete and allowed for the generation of a GPS location.

\subsubsection{Detection rates for simulated birds by AARS and by human observers}

AAARS and human detection rates were measured for simulated birds by evaluating point count trials in which the AAARS was tethered over a grid of song simulators at altitudes up to $300 \mathrm{~m}$ (Table 5-5). Detection was calculated as the percent of the song simulators that were picked up by the AAARS and were audible/visible on the accompanying audio file in RavenPro. This assessment was also conducted with human observers during point count trials. This assessment was conducted with Henslow's Sparrow vocalizations because this species song is at the lowest amplitude, such that if the AAARS could detect a Henslow's Sparrow vocalization, it could detect all of the other species as well because the other species vocalize at greater amplitude. 


\subsubsection{Availability for detection by species}

The relationships between song rates and abundance by time of day and day of season for the focal songbird species was documented. For most species, availability for detection, which is a result of the song rate, was positively related to relative abundance, where availability for detection increased as the number of males increased (Figure 5-11); Grasshopper Sparrow was a notable exception.

For RCWO, 70 AAARS free flights were conducted over areas where there was known RCWO breeding/foraging occurring at Fort Bragg while simultaneously conducting human line-transect counts along the same flight path. On 16/70 flights (22.8\%), human observers documented RCWO activity; thus, the birds were available for detection by the AAARS. On 6/16 (37.5\%) of the flights with known RCWO activity, the AAARS recorded RCWO vocalizations.

For GPCH, 18 AAARS free flights were conducted over GPCH leks to document detection rates in which there was simultaneous deployment of ground-based human observers. GPCH vocalizations were detected on 12/18 flights (66.7\%) in which ground-based samplers documented GPCH vocal activity.

\subsubsection{Precision of balloon vs. human-observer estimates}

Standard errors associated with the mean abundances for AAARS estimates and human-observer estimates for both real birds and simulated birds was calculated. In general, the AAARS estimates were similar in precision compared to the human-observer estimates for the song simulators, but precision was poorer for the real birds (Table 5-6). The difference in precision in part was attributed to the fact that the distance sampling approach used for the human-observer abundance estimates was based on the distance-detection function based on all distance data. If the distance-detection function were based on a more limited sample size, the standard errors of density estimates would have been much greater.

\subsubsection{Classification of AAARS audio files}

Based on acoustic analysis of AAARS flight files for real birds and simulated birds, the correct classification rates were estimated (Table 5-7). The percent true positive for a given species, location, and trial type 
indicated how well the analyses identified the true songs in the acoustic data. The ratio of true positive/false positive is a measure of how successful the analysis was at discriminating between true songs and other similar acoustic signals.

Figure 5-10. Example of latitude-longitude GPS limits set to define a target area for AAARS operation.*

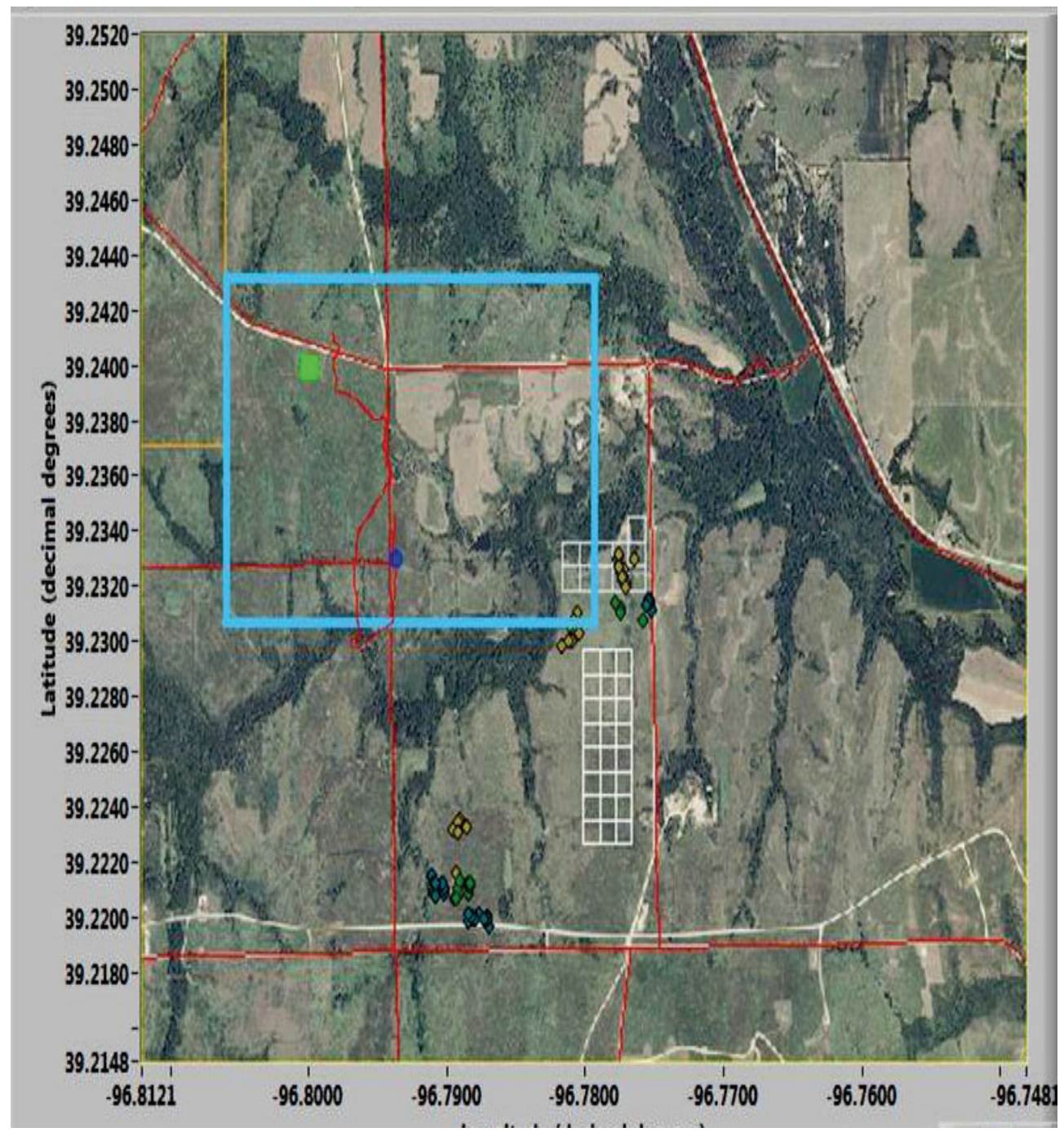

*When the AAARS reaches one of the boundaries of the target area, it automatically goes into recovery mode, venting until it reaches the ground. 
Table 5-5. Detection rates for Henslow's Sparrow based on assessment of detection of song simulators at various altitudes up to $300 \mathrm{~m}$ for AAARS and based on human observers.

\begin{tabular}{|c|c|c|c|c|c|}
\hline Site & $\begin{array}{c}\text { Simulators } \\
\text { Available }\end{array}$ & $\begin{array}{c}\text { Simulators } \\
\text { Detected- } \\
\text { AAARS }\end{array}$ & $\begin{array}{c}\text { AAARS } \\
\text { Detection } \\
\%\end{array}$ & $\begin{array}{c}\text { Simulators } \\
\text { Detected- } \\
\text { Human } \\
\text { Observer }\end{array}$ & $\begin{array}{c}\text { Human } \\
\text { Observer } \\
\text { Detection } \\
\%\end{array}$ \\
\hline $\begin{array}{c}\text { Jefferson } \\
\text { Proving } \\
\text { Ground }\end{array}$ & 129 & 117 & 91 & 83 & 64 \\
\hline Fort Bragg & 139 & 135 & 97 & 110 & 79 \\
\hline Total & 268 & 252 & 94 & 193 & 72 \\
\hline
\end{tabular}

Figure 5-11. Availability for detection related to relative abundance of males for five focal songbird species for a 5 min count period.

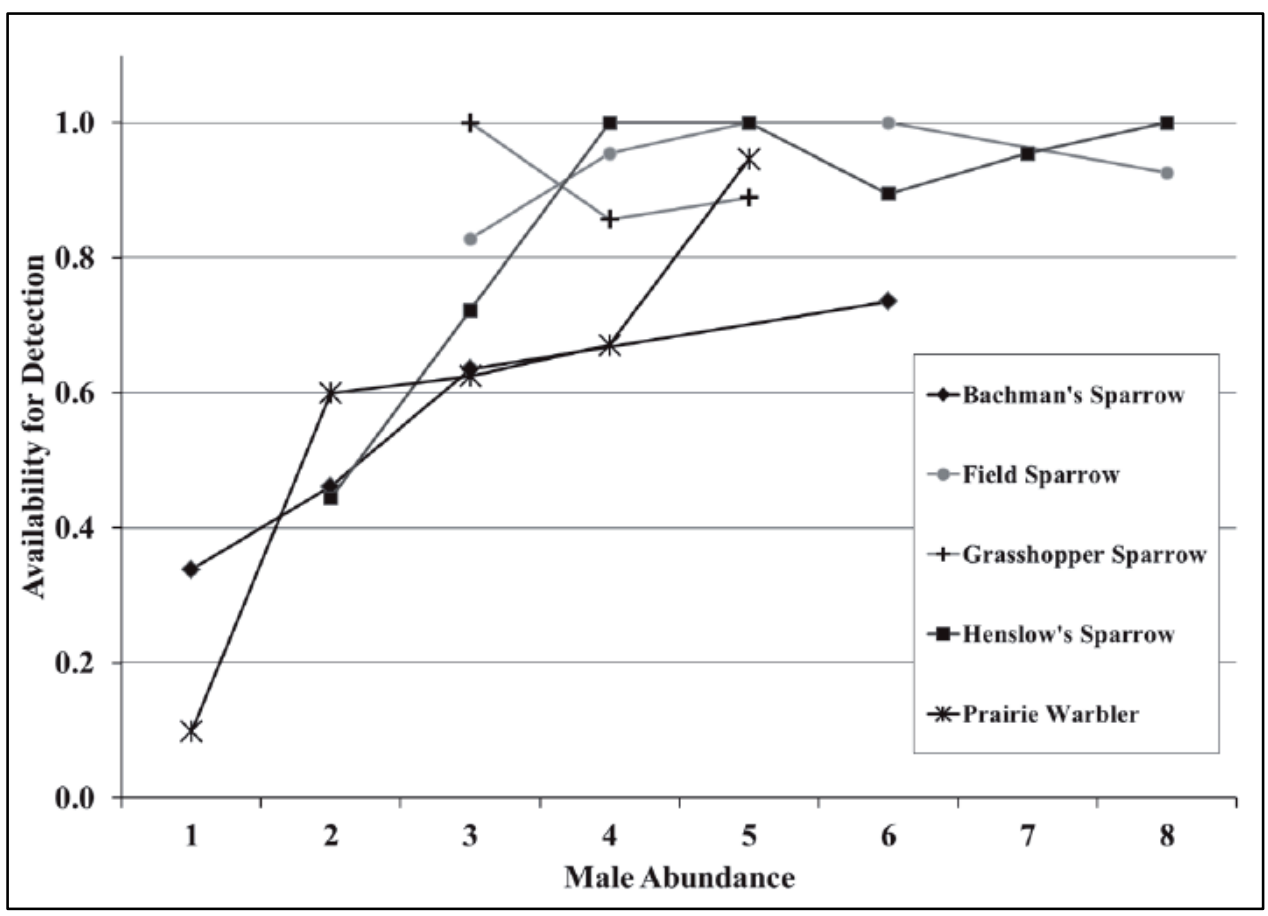

\subsubsection{Cue counts and estimates of male abundance}

Based on ground-based monitoring of focal species on each site during 2012-2013, the relationship between the song rate and relative male abundance for each of the focal songbird species was documented (Figure 5 -12). Four of the five species monitored (except Grasshopper Sparrow) exhibited a positive relationship between male abundance and the total number of songs recorded during a 5 min period. Negative binomial regression models, then, were created of these relationships (Figure 5-13) 
to be used for predicting male abundance from the number of songs detected by the AAARS during a given flight. The lack of a relationship for Grasshopper Sparrow may reflect the fact that the sampling across too limited of a range of Grasshopper Sparrow abundances to document the relationship.

The regression models, then, were used to predict male abundance for AAARS flights for both real birds and for song simulators. The mean abundances for AAARS with the true number of song simulators were compared (Table 5-8). The estimates for AAARS with spot-mapping for real birds and for human-based methods were compared (Table 5-9). Spot-mapping estimates in this case were used as best estimates of what true bird densities were at the time of the surveys.

Table 5-6. Precision (standard errors) of abundance estimates for AAARS vs. humanobserver methods, for real birds and song simulators.

\begin{tabular}{|c|c|c|c|c|}
\hline Real Birds/Species & Method & $\begin{array}{l}\text { Pooled SE } \\
\text { Balloon }\end{array}$ & $\begin{array}{c}\text { Pooled SE } \\
\text { Human }\end{array}$ & $F$ \\
\hline \multirow{3}{*}{ Prairie Warbler } & Point Count & 1.40 & 0.94 & 2.20 \\
\hline & Line Transect & $1.15 *$ & 0.36 & 10.21 \\
\hline & Free Flight & 0.69 & 0.45 & 2.41 \\
\hline Bachman's Sparrow & Free Flight & 0.73 & 0.41 & 3.13 \\
\hline \multirow{3}{*}{ Field Sparrow } & Point Count & 1.96 & 0.75 & 6.88 \\
\hline & Line Transect & 1.12 & 0.32 & 12.15 \\
\hline & Free Flight & 1.32 & 0.20 & 45.54 \\
\hline \multirow{3}{*}{ Henslow's Sparrow } & Point Count & 16.04 & 2.67 & 36.03 \\
\hline & Line Transect & 14.93 & 0.86 & 299.39 \\
\hline & Free Flight & 13.52 & 1.00 & 183.56 \\
\hline \multicolumn{5}{|l|}{ Simulated Birds } \\
\hline \multirow{3}{*}{ Northern Bobwhite } & Point Count & 0.23 & 0.34 & 2.22 \\
\hline & Line Transect & 0.22 & 0.38 & 2.90 \\
\hline & Free Flight & 0.21 & 0.69 & 10.94 \\
\hline \multirow{3}{*}{ Prairie Warbler } & Point Count & 0.48 & 0.54 & 1.27 \\
\hline & Line Transect & 0.17 & 0.30 & 3.16 \\
\hline & Free Flight & 1.88 & 0.74 & 6.48 \\
\hline
\end{tabular}




\begin{tabular}{|l|l|c|c|c|}
\hline Real Birds/Species & Method & $\begin{array}{c}\text { Pooled SE } \\
\text { Balloon }\end{array}$ & $\begin{array}{c}\text { Pooled SE } \\
\text { Human }\end{array}$ & F \\
\hline \multirow{3}{*}{ Bachman's Sparrow } & Point Count & 0.27 & 0.55 & 4.27 \\
\cline { 2 - 5 } & Free Flight & 1.54 & 0.49 & 9.97 \\
\hline \multirow{3}{*}{ Field Sparrow } & Point Count & 0.86 & 0.74 & 1.34 \\
\cline { 2 - 5 } & Line Transect & 0.32 & 0.42 & 1.70 \\
\cline { 2 - 5 } & Free Flight & 0.73 & 0.74 & 1.02 \\
\hline \multirow{3}{*}{ Grasshopper Sparrow } & Point Count & 0.52 & 0.86 & 2.77 \\
\cline { 2 - 5 } & Line Transect & 0.32 & 0.58 & 3.37 \\
\hline \multirow{2}{*}{ Henslow's Sparrow } & Point Count & 2.36 & 1.06 & 4.97 \\
\cline { 2 - 5 } & Line Transect & 0.91 & 0.70 & 1.67 \\
\hline
\end{tabular}

*Standard errors highlighted in red represent significantly poorer precision, $\mathrm{P}<0.05$.

Table 5-7. Correct classification rates based on automated acoustic data analysis methods in program MonitoR for real birds and song simulators.

\begin{tabular}{|l|l|l|c|c|c|}
\hline Species & Location & Trial Type & $\begin{array}{c}\text { \% True } \\
\text { Positive }\end{array}$ & $\begin{array}{c}\text { \% False } \\
(+ \text { and }-)\end{array}$ & $\begin{array}{c}\text { Ratio True }+ \\
\text { /False + }\end{array}$ \\
\hline Bachman's Sparrow & Fort Bragg & Real & $89.99 \pm 7.63$ & $89.61 \pm 4.00$ & $1: 13.65$ \\
\hline Bachman's Sparrow & Fort Bragg & Simulated & $96.10 \pm 4.07$ & $82.72 \pm 4.97$ & $1: 5.79$ \\
\hline Field Sparrow & Big Oaks & Real & $86.09 \pm 2.12$ & $72.21 \pm 3.93$ & $1: 2.84$ \\
\hline Field Sparrow & Big Oaks & Simulated & $92.39 \pm 3.19$ & $58.66 \pm 4.46$ & $1: 1.62$ \\
\hline Field Sparrow & Fort Riley & Real & $88.80 \pm 5.67$ & $73.82 \pm 9.11$ & $1: 2.93$ \\
\hline Field Sparrow & Fort Riley & Simulated & $85.67 \pm 5.01$ & $62.11 \pm 3.82$ & $1: 2.04$ \\
\hline Grasshopper Sparrow & Fort Riley & Real & $97.85 \pm 2.74$ & $68.84 \pm 12.93$ & $1: 2.8$ \\
\hline Grasshopper Sparrow & Fort Riley & Simulated & $94.76 \pm 2.93$ & $89.29 \pm 1.74$ & $1: 10.97$ \\
\hline Henslow's Sparrow & Big Oaks & Real & $97.16 \pm 1.55$ & $87.56 \pm 2.42$ & $1: 11.15$ \\
\hline Henslow's Sparrow & Big Oaks & Simulated & $96.90 \pm 1.48$ & $95.67 \pm 0.87$ & $1: 36.22$ \\
\hline Henslow's Sparrow & Fort Riley & Real & $95.09 \pm 4.72$ & $96.24 \pm 2.23$ & $1: 29.59$ \\
\hline Henslow's Sparrow & Fort Riley & Simulated & $95.53 \pm 3.36$ & $96.23 \pm 1.50$ & $1: 39.62$ \\
\hline Prairie Warbler & Big Oaks & Real & $96.07 \pm 5.66$ & $94.37 \pm 1.58$ & $1: 29.09$ \\
\hline Prairie Warbler & Big Oaks & Simulated & $97.25 \pm 4.19$ & $85.06 \pm 7.96$ & $1: 13.17$ \\
\hline Prairie Warbler & Fort Bragg & Real & $100.0 \pm 0.00$ & $94.97 \pm 1.46$ & $1: 23.87$ \\
\hline Prairie Warbler & Fort Bragg & Simulated & $98.83 \pm 1.58$ & $76.02 \pm 5.52$ & $1: 4.39$ \\
\hline
\end{tabular}


Figure 5-12. Male abundance and songs detected on 5 min point counts for six focal avian species.

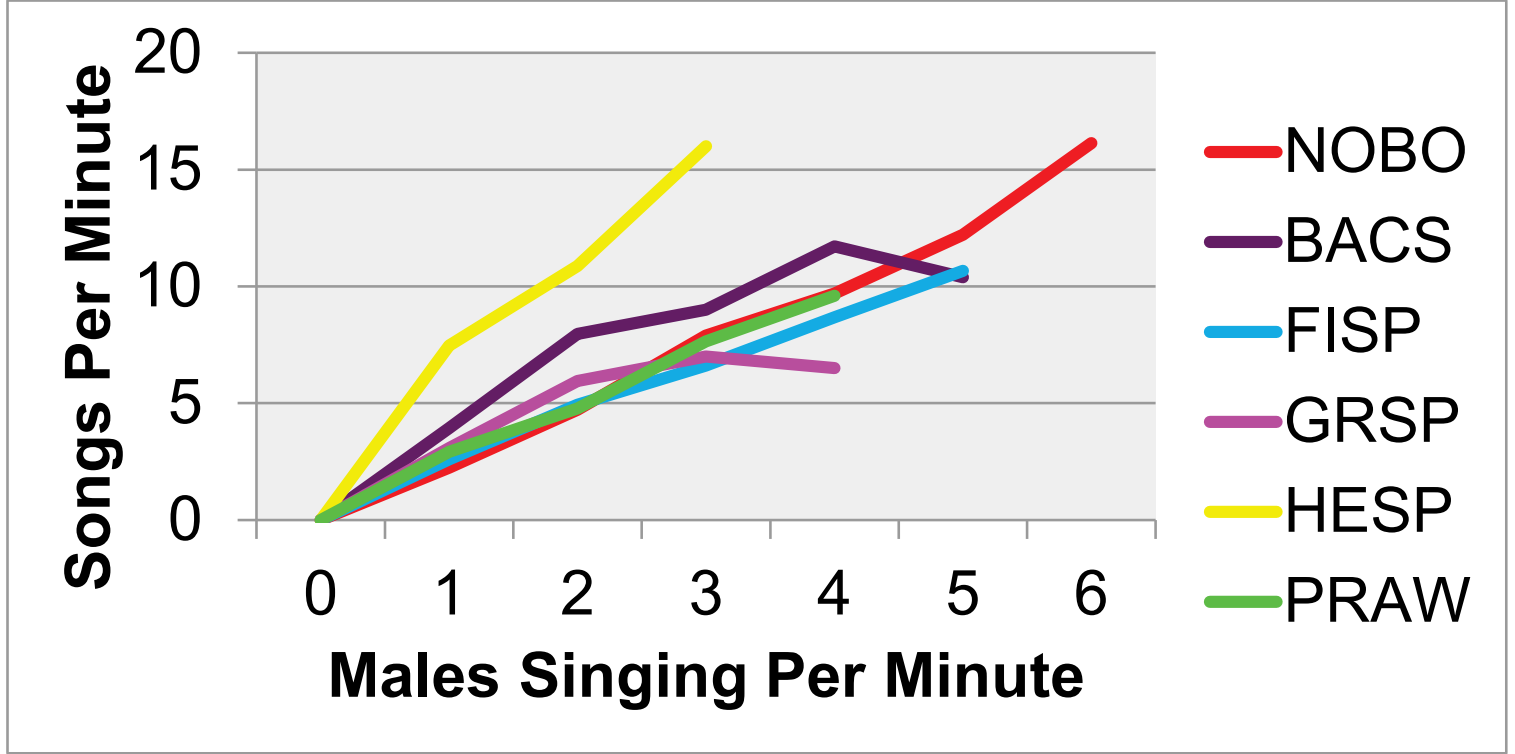

Figure 5-13. Negative binomial regression models predicting average male abundance the total cumulative number of songs detected on 5 min acoustic recordings for five focal songbird species.

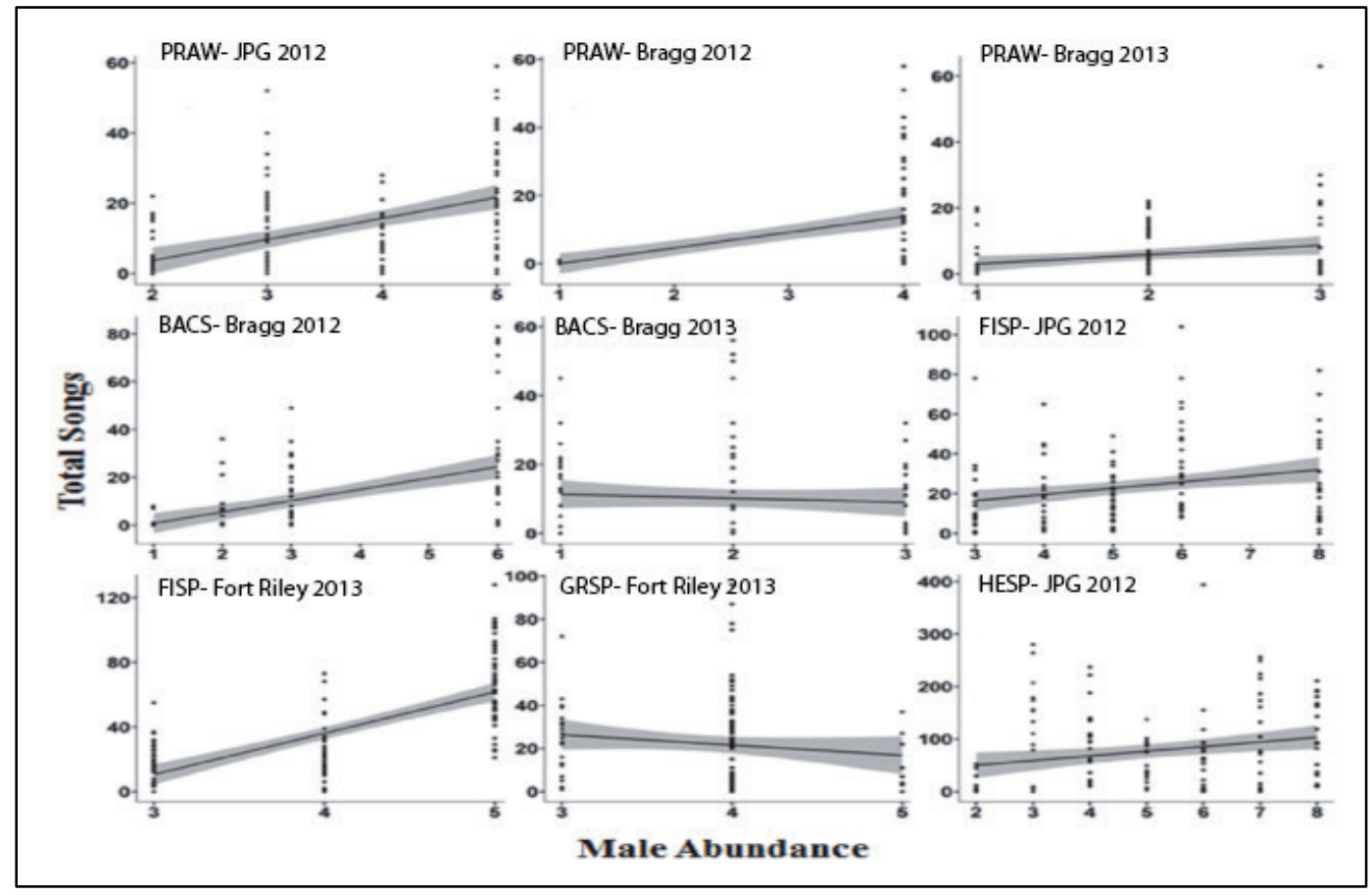


Table 5-8. Comparison of mean abundance estimates for AAARS vs. true values for song simulators among point count (PC), line transect (LT), and free flight (FF).

\begin{tabular}{|c|c|c|c|c|c|c|c|}
\hline Species & $\begin{array}{l}\text { Abundance } \\
\text { Method }\end{array}$ & $\begin{array}{l}\text { Least- } \\
\text { Squares } \\
\text { Means }\end{array}$ & SE & df & $\begin{array}{l}\text { Lower } \\
95 \% \mathrm{Cl}\end{array}$ & $\begin{array}{l}\text { Upper } \\
95 \% \mathrm{Cl}\end{array}$ & $\begin{array}{l}\text { Tukey } \\
\text { group }\end{array}$ \\
\hline Northern Bobwhite & Balloon PC & 3.81 & 0.08 & 501 & 3.66 & 3.97 & A \\
\hline Northern Bobwhite & True PC & 3.85 & 0.08 & 501 & 3.70 & 4.01 & A \\
\hline Northern Bobwhite & Balloon LT & 3.94 & 0.13 & 501 & 3.69 & 4.19 & $A B$ \\
\hline Northern Bobwhite & True FF & 4.44 & 0.17 & 501 & 4.11 & 4.77 & $\mathrm{BC}$ \\
\hline Northern Bobwhite & Balloon FF & 4.66 & 0.17 & 501 & 4.33 & 4.99 & C \\
\hline Northern Bobwhite & True LT & 4.71 & 0.13 & 501 & 4.47 & 4.96 & C \\
\hline Prairie Warbler & True FF & 2.85 & 0.18 & 399 & 2.50 & 3.21 & A \\
\hline Prairie Warbler & True PC & 3.50 & 0.10 & 399 & 3.30 & 3.71 & B \\
\hline Prairie Warbler & Balloon LT & 3.58 & 0.18 & 399 & 3.22 & 3.93 & $A B$ \\
\hline Prairie Warbler & Balloon PC & 3.71 & 0.10 & 399 & 3.50 & 3.92 & B \\
\hline Prairie Warbler & Balloon FF & 3.85 & 0.18 & 399 & 3.50 & 4.21 & $\mathrm{BC}$ \\
\hline Prairie Warbler & True LT & 4.49 & 0.18 & 399 & 4.13 & 4.84 & $C$ \\
\hline Bachman's Sparrow & True FF & 2.79 & 0.25 & 199 & 2.30 & 3.28 & A \\
\hline Bachman's Sparrow & Balloon PC & 2.91 & 0.19 & 199 & 2.54 & 3.29 & A \\
\hline Bachman's Sparrow & True PC & 3.46 & 0.19 & 199 & 3.09 & 3.83 & A \\
\hline Bachman's Sparrow & Balloon FF & 5.55 & 0.25 & 199 & 5.06 & 6.04 & B \\
\hline Field Sparrow & True PC & 3.62 & 0.16 & 580 & 3.30 & 3.95 & A \\
\hline Field Sparrow & True FF & 3.65 & 0.35 & 580 & 2.96 & 4.34 & $A B$ \\
\hline Field Sparrow & Balloon PC & 3.97 & 0.16 & 580 & 3.64 & 4.29 & $A B$ \\
\hline Field Sparrow & Balloon FF & 4.22 & 0.35 & 580 & 3.53 & 4.90 & $A B C$ \\
\hline Field Sparrow & True LT & 4.60 & 0.26 & 580 & 4.09 & 5.11 & $\mathrm{BC}$ \\
\hline Field Sparrow & Balloon LT & 5.39 & 0.26 & 580 & 4.88 & 5.90 & C \\
\hline Grasshopper Sparrow & Balloon LT & 2.26 & 0.20 & 171 & 1.87 & 2.64 & A \\
\hline Grasshopper Sparrow & Balloon PC & 2.43 & 0.14 & 171 & 2.17 & 2.70 & A \\
\hline Grasshopper Sparrow & True PC & 2.45 & 0.14 & 171 & 2.18 & 2.72 & A \\
\hline Grasshopper Sparrow & True LT & 3.30 & 0.20 & 171 & 2.91 & 3.69 & B \\
\hline Henslow's Sparrow & True PC & 2.38 & 0.23 & 368 & 1.93 & 2.82 & A \\
\hline Henslow's Sparrow & Balloon PC & 2.54 & 0.23 & 368 & 2.09 & 2.99 & A \\
\hline Henslow's Sparrow & True LT & 3.25 & 0.30 & 368 & 2.66 & 3.83 & $A B$ \\
\hline Henslow's Sparrow & Balloon LT & 3.87 & 0.30 & 368 & 3.28 & 4.45 & B \\
\hline
\end{tabular}

*Abundance estimates with the same letters did not differ ( $P$ > 0.05), based on Tukey's comparison of means test. 
Table 5-9. Comparison of mean abundance estimates (birds/ha) for AAARS vs. human-observer PC and line-transect (LT) methods for real birds. "Human FF" refers to human observer line-transect surveys conducted along the AAARS free flight (FF) path.

\begin{tabular}{|c|c|c|c|c|c|c|c|}
\hline Species & Method & $\begin{array}{c}\text { Least-squares } \\
\text { means }\end{array}$ & SE & df & $\begin{array}{l}\text { Lower } \\
95 \% \mathrm{Cl}\end{array}$ & $\begin{array}{l}\text { Upper } \\
95 \% \text { Cl }\end{array}$ & $\begin{array}{l}\text { Tukey } \\
\text { Group }\end{array}$ \\
\hline Prairie Warbler & Human FF & 1.12 & 0.52 & 33 & 0.07 & 2.17 & $A$ \\
\hline Prairie Warbler & Balloon FF & 2.46 & 0.52 & 33 & 1.40 & 3.51 & $A B$ \\
\hline Prairie Warbler & Human LT & 2.64 & 0.61 & 41 & 1.40 & 3.88 & $A B$ \\
\hline Prairie Warbler & Balloon LT & 2.91 & 0.61 & 41 & 1.67 & 4.15 & $A B C$ \\
\hline Prairie Warbler & SpotMap & 2.92 & 0.47 & 27 & 1.97 & 3.88 & B \\
\hline Prairie Warbler & Human PC & 3.69 & 0.61 & 41 & 2.45 & 4.93 & $\mathrm{BC}$ \\
\hline Prairie Warbler & Balloon PC & 4.89 & 0.61 & 41 & 3.65 & 6.12 & C \\
\hline Bachman's Sparrow & Human FF & 0.98 & 0.32 & 11 & 0.27 & 1.69 & A \\
\hline Bachman's Sparrow & SpotMap & 2.05 & 0.32 & 11 & 1.33 & 2.76 & $\mathrm{~B}$ \\
\hline Bachman's Sparrow & Balloon FF & 2.62 & 0.32 & 11 & 1.90 & 3.33 & B \\
\hline Field Sparrow & Human FF & 0.86 & 0.83 & 37 & -0.82 & 2.54 & A \\
\hline Field Sparrow & Human LT & 1.19 & 0.77 & 31 & -0.38 & 2.77 & A \\
\hline Field Sparrow & SpotMap & 2.50 & 0.73 & 27 & 1.00 & 4.00 & $\mathrm{AB}$ \\
\hline Field Sparrow & Human PC & 2.55 & 0.75 & 29 & 1.01 & 4.08 & $\mathrm{AB}$ \\
\hline Field Sparrow & Balloon LT & 4.11 & 0.77 & 31 & 2.54 & 5.69 & $\mathrm{BC}$ \\
\hline Field Sparrow & Balloon FF & 5.25 & 0.83 & 37 & 3.57 & 6.93 & C \\
\hline Field Sparrow & Balloon PC & 5.58 & 0.75 & 29 & 4.04 & 7.11 & C \\
\hline Henslow's Sparrow & Human FF & 5.23 & 8.92 & 51 & -12.67 & 23.13 & A \\
\hline Henslow's Sparrow & Human LT & 6.19 & 8.15 & 44 & -10.24 & 22.62 & A \\
\hline Henslow's Sparrow & SpotMap & 7.84 & 7.60 & 39 & -7.54 & 23.22 & A \\
\hline Henslow's Sparrow & Human PC & 14.63 & 7.86 & 41 & -1.23 & 30.49 & A \\
\hline Henslow's Sparrow & Balloon FF & 47.93 & 8.92 & 51 & 30.03 & 65.83 & B \\
\hline Henslow's Sparrow & Balloon LT & 56.56 & 8.15 & 44 & 40.13 & 72.98 & B \\
\hline Henslow's Sparrow & Balloon PC & 85.68 & 7.86 & 41 & 69.82 & 101.54 & C \\
\hline
\end{tabular}

*Abundance estimates with the same letter for a given species did not differ $(P>0.05)$. 


\subsubsection{Ease of use}

The amount of time it took field personnel to conduct pre-flight and postflight operations during every 3 week period of the field season was documented. A simple plot of time versus time-period in the season across the $3 \mathrm{yr}$ of the field demonstration shows how field personnel became more proficient with the technology over time (Figure 5-14). Note that the field personnel being evaluated were novices at the start of each field season.

Figure 5-14. The amount of time it took field personnel to complete pre-flight and post-flight operations from 2011-2013.

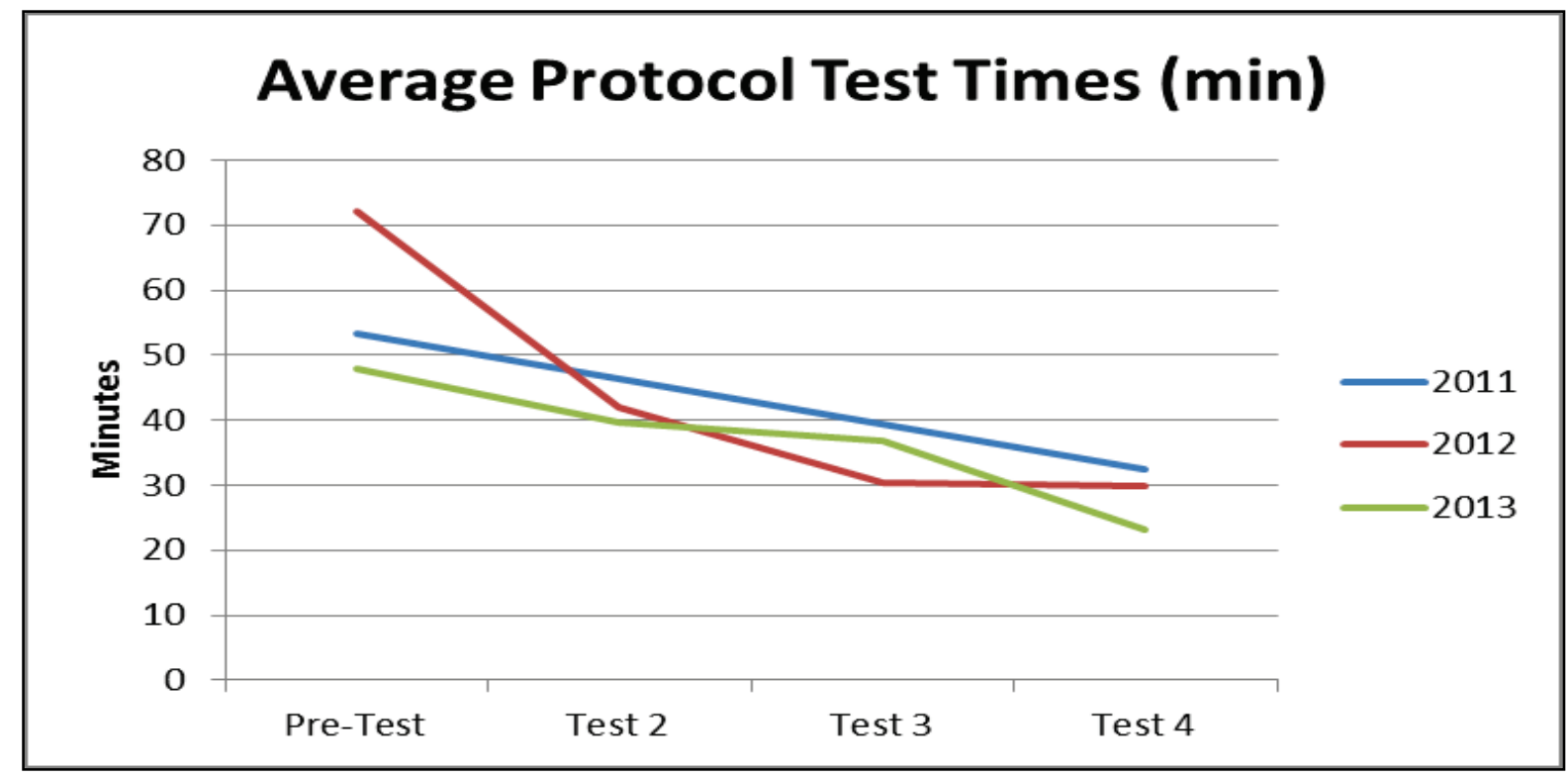

*Note that field personnel were novices at the beginning of each field season. 


\section{Performance Assessment}

The basis for the performance assessment was the evaluation of individual success criteria for each performance objective. For some of the performance objectives, the assessment involved a simple comparison with a performance standard-such as in Objective 1 where the standard was that $90 \%$ of all short distance flights are successful. For other performance objectives, the assessment was based on comparison against truth. For example, for Objective 4 involving detection probabilities, the assessment was comparing the AAARS performance in detection against the known availability of the song simulators. Finally, for some performance objectives, the assessment involved a comparison between the AAARS performance and standard human-observed methods. In this case, statistical tests were used to determine whether a given parameter (e.g., detection rate) was greater for the AAARS than for the humanobserver methods. The analysis and statistics for these assessments are summarized in Table 6-1.

Table 6-1. Analytical approach for evaluation of performance objectives.

\begin{tabular}{|l|l|l|}
\hline $\begin{array}{l}\text { Performance } \\
\text { Objective }\end{array}$ & Metrics & Analytical Approach \\
\hline $\begin{array}{l}\text { 1) Improve AAARS } \\
\text { flight performance } \\
\text { over the course of } \\
\text { the project }\end{array}$ & $\begin{array}{l}\text { Number of pre- } \\
\text { flights, flights, and } \\
\text { recoveries } \\
\text { conducted; } \\
\text { performance of } \\
\text { each flight stage } \\
\text { (mission } \\
\text { accomplished or } \\
\text { not); altitude }\end{array}$ & $\begin{array}{l}\text { The analysis was a simple accounting of how many } \\
\text { flights were conducted and what their level of success } \\
\text { were (did they cover the target area and the target } \\
\text { altitude). The statistics reported involve the percentage } \\
\text { of flights that achieved the target area and altitude } \\
\text { range, and the percentage of flights in which the AAARS } \\
\text { was successfully recovered, compared with the success } \\
\text { criteria. }\end{array}$ \\
\hline $\begin{array}{l}\text { 2) Meet or exceed } \\
\text { good signal } \\
\text { strength at long } \\
\text { range for RF } \\
\text { modem } \\
\text { communications }\end{array}$ & $\begin{array}{l}\text { Maximum distance } \\
\text { (km) at which good } \\
\text { communications } \\
\text { can be maintained }\end{array}$ & $\begin{array}{l}\text { The analysis for this objective involved a simple linear } \\
\text { plot of signal strength by distance of the base station } \\
\text { from the AAARS. The analysis documented the } \\
\text { relationship and quantified the limits of acceptable } \\
\text { signal strength for operation purposes. }\end{array}$ \\
\hline
\end{tabular}




\begin{tabular}{|c|c|c|}
\hline $\begin{array}{l}\text { Performance } \\
\text { Objective }\end{array}$ & Metrics & Analytical Approach \\
\hline $\begin{array}{l}\text { 3) Meet or exceed } \\
\text { an acceptable } \\
\text { standard of } \\
\text { performance for } \\
\text { latitude-longitude } \\
\text { control system }\end{array}$ & $\begin{array}{l}\text { Number of flights; } \\
\text { coverage of target } \\
\text { area; distance } \\
\text { traveled prior to } \\
\text { recovery; success of } \\
\text { recovery after } \\
\text { invoking lat-long } \\
\text { control system }\end{array}$ & $\begin{array}{l}\text { The analysis was a simple accounting of how many } \\
\text { flights were conducted where lat-long control was used } \\
\text { and what the disposition of those flights was in terms of } \\
\text { covering the target area and success of the recovery. } \\
\text { The statistics reported involved the percentage of flights } \\
\text { that achieve the target area and successful recovery. } \\
\text { These percentages were directly compared with the } \\
\text { success criteria. }\end{array}$ \\
\hline $\begin{array}{l}\text { 4) Meet or exceed } \\
\text { an acceptable } \\
\text { standard for } \\
\text { detection of } \\
\text { simulated audio } \\
\text { sources }\end{array}$ & $\begin{array}{l}\text { Detection rate } \\
\text { compared to truth } \\
\text { for individuals and } \\
\text { focal species }\end{array}$ & $\begin{array}{l}\text { Baseline characterization determined that there should } \\
\text { be an ability to detect } 90 \% \text { of the bird song simulators } \\
\text { when they are located within the footprint of the AAARS. } \\
\text { The assessment involved documenting what percentage } \\
\text { of the flights actually achieved that performance } \\
\text { standard. }\end{array}$ \\
\hline $\begin{array}{l}\text { 5) Meet or exceed } \\
\text { an acceptable } \\
\text { standard for } \\
\text { detection of real } \\
\text { birds }\end{array}$ & $\begin{array}{l}\text { Availability for } \\
\text { detection rate for } \\
\text { individuals and focal } \\
\text { species }\end{array}$ & $\begin{array}{l}\text { Baseline characterization determined that we should be } \\
\text { able to detect } 80 \% \text { of the real birds when they are } \\
\text { located within the AAARS footprint. The assessment } \\
\text { documented what percentage of individuals by species } \\
\text { actually sing and thus are available for detection. }\end{array}$ \\
\hline $\begin{array}{l}\text { 6) Improve AAARS } \\
\text { accuracy over } \\
\text { standard human- } \\
\text { observer methods }\end{array}$ & $\begin{array}{l}\text { Detection rates for } \\
\text { individuals and foca } \\
\text { species from AAARS } \\
\text { and human- } \\
\text { observer methods- } \\
\text { simulated audio } \\
\text { sources }\end{array}$ & $\begin{array}{l}\text { Analysis of variance tests were used to compare } \\
\text { detection rates for each species on each flight by each } \\
\text { method and versus truth. }\end{array}$ \\
\hline $\begin{array}{l}\text { 7) Improve AAARS } \\
\text { precision } \\
\text { compared to } \\
\text { standard human- } \\
\text { observer methods- } \\
\text { Simulated audio } \\
\text { sources }\end{array}$ & $\begin{array}{l}\text { Precision (standard } \\
\text { error) of detection } \\
\text { rate estimates for } \\
\text { individuals and focal } \\
\text { species from AAARS } \\
\text { and human- } \\
\text { observer methods- } \\
\text { simulated audio } \\
\text { sources }\end{array}$ & $\begin{array}{l}\text { Calculated standard errors for means calculated above } \\
\text { and used analysis of variances to test for differences in } \\
\text { standard errors by each method. }\end{array}$ \\
\hline $\begin{array}{l}\text { 8) Meet or exceed } \\
\text { an acceptable } \\
\text { standard for } \\
\text { classification rates } \\
\text { for individuals and } \\
\text { focal species- } \\
\text { simulated audio } \\
\text { sources }\end{array}$ & $\begin{array}{l}\text { Classification rates } \\
\text { of individuals and } \\
\text { species from } \\
\text { simulated audio } \\
\text { files compared to } \\
\text { truth }\end{array}$ & $\begin{array}{l}\text { Baseline characterization determined that there should } \\
\text { be an ability to achieve } 90 \% \text { correct classification rates. } \\
\text { The assessment involved documenting what percentage } \\
\text { of the flights actually achieved that performance } \\
\text { standard. }\end{array}$ \\
\hline
\end{tabular}




\begin{tabular}{|l|l|l|}
\hline $\begin{array}{l}\text { Performance } \\
\text { Objective }\end{array}$ & Metrics & Analytical Approach \\
\hline $\begin{array}{l}\text { 9) Improve } \\
\text { classification rates } \\
\text { for individuals and } \\
\text { focal species- } \\
\text { AAARS for real } \\
\text { birds }\end{array}$ & $\begin{array}{l}\text { Classification rates } \\
\text { of individuals and } \\
\text { species from real } \\
\text { birds from AAARS }\end{array}$ & $\begin{array}{l}\text { The assessment involved documenting what percentage } \\
\text { of the flights actually achieved that performance } \\
\text { standard of 80\% correct classification rates. }\end{array}$ \\
\hline $\begin{array}{l}\text { 10) Meet or exceed } \\
\text { an acceptable } \\
\text { accuracy standard } \\
\text { for AAARS density } \\
\text { estimates for focal } \\
\text { species for } \\
\text { simulated audio } \\
\text { sources }\end{array}$ & $\begin{array}{l}\text { Density estimates } \\
\text { simulated audio } \\
\text { sources compared } \\
\text { to truth }\end{array}$ & $\begin{array}{l}\text { Analysis of variances tests were used to compare the } \\
\text { AAARS densities against the known densities of the } \\
\text { song simulators and against estimates from human- } \\
\text { observer methods. }\end{array}$ \\
\hline $\begin{array}{l}\text { 11) Improve AAARS } \\
\text { density estimates } \\
\text { for focal species- } \\
\text { real birds } \\
\text { compared to } \\
\text { human-based } \\
\text { methods }\end{array}$ & $\begin{array}{l}\text { Density estimates } \\
\text { by species from real } \\
\text { birds from AAARS } \\
\text { and human- } \\
\text { observer data } \\
\text { analyses }\end{array}$ & $\begin{array}{l}\text { Analysis of variances tests were used to compare the } \\
\text { AAARS densities against the densities from spot } \\
\text { mapping and from human-observer methods. }\end{array}$ \\
\hline $\begin{array}{l}\text { 12) Increase ease } \\
\text { of use }\end{array}$ & $\begin{array}{l}\text { Experience of field } \\
\text { personnel and time } \\
\text { to complete pre- } \\
\text { flight and post-flight } \\
\text { procedures }\end{array}$ & $\begin{array}{l}\text { Visual inspection of a plot of the amount of time to } \\
\text { complete pre-flight and post-flight procedures against } \\
\text { the week of the field season (a measure of flight } \\
\text { experience) for 2011-2013. }\end{array}$ \\
\hline
\end{tabular}

\subsubsection{Performance Objective 1}

Success rates by stage were calculated based on the number of trials achieving success divided by the total number of trials $\times 100 \%$ (Figure 5 8). Improvement in performance over time was assessed by compared 2011 performance vs. 2013 performance. There was significant improvement from 2011 (66\% success) to 2013 (86\% success) in overall performance.

- $\quad$ Pre-flight goal = 95\%; 2011-13 actual 95\%; standard met.

- $\quad$ Flight goal = 90\% for flights $<5 \mathrm{~km} ; 2013$ actual-90\% hit target, maintained altitude and had good audio; standard met. The quality of the audio data in general was very good in spite of the fact that there are various sources of ambient noise (i.e., cicadas) and anthropogenic noise (military training operations and highway noise). 
- Recovery goal $=95 \% ;$ 2011-2013 recovery $=99 \%$; standard met . AAARS was recovered in 99\% of the trials during the 2011-2013 field seasons, which included recovery in forested settings at Fort Bragg. On two occasions during tethered operation in 2012, payloads were lost when the tether broke because of operator error and communication with the payload was lost prior to recovery. Recovery at Fort Bragg occurred in mature pine forests. In this setting, the balloon usually ruptured as the AAARS passed through the canopy and then fell to the ground. On several occasions ( $<20 \%)$, the AAARS hung up in the canopy and required either climbing the tree in which the payload was lodged and using a $10 \mathrm{~m}$ telescoping pole to free it or shooting a line over the limb in which the payload was lodged and shaking the payload free.

- Overall performance in 2013: total operational success $=85 \%$; standard met.

\subsubsection{Performance Objective 2}

Objective 2 refers to validating the performance of the RF modem.

- Good communications in $95 \%$ of flights up to $10 \mathrm{~km}$; actual $95 \%$ commands received and 49\% complete GPS data at $16 \mathrm{~km}$; standard exceeded.

\subsubsection{Performance Objective 3}

Objective 3 refers to validating the performance of the latitude-longitude control system.

- Goal $=95 \%$ of flights contained within target box; actual = 96\% of 109 flights successful; standard exceeded.

\subsubsection{Performance Objective 4}

Objective 4 involves performance standard in terms of detection of simulated songs by AAARS (Table 5-5).

- Goal $=90 \%$ detection; actual for Henslow's Sparrow at Fort Bragg and $\mathrm{JPG}=94 \% ;$ standard exceeded. 


\subsubsection{Performance Objective 5}

Objective 5 involves documenting availability for detection for real birds present and singing on the site (Figure 5-11).

- $\mathrm{Goal}=80 \%$ detection of real birds; detection rates for real birds, based on a 5 min count period, do not approach this standard unless there are three or more singing males present at a point. This result highlights a challenge in all bird monitoring-for species with relative low populations, the detection probabilities can be low. Conclusion: does not meet standard for low populations.

\subsubsection{Performance Objective 6}

Objective 6 describes the detection rates of the AAARS compared to human-based methods for Henslow's Sparrow (Table 5-5).

- $\mathrm{Goal}=10 \%$ greater detection rates by AAARS over human observers; actual $94 \%$ detection for AAARS vs. $72 \%$ detection for human observers; standard exceeded.

\subsubsection{Performance Objective 7}

Objective 7 compares standard errors of the AAARS compared to humanobserver methods, point counts for point counts, line transects, and free flights (Table 5-6).

- $\mathrm{Goal}=10 \%$ improved precision of estimates by AAARS over human observers; actual-generally no difference between AAARS and human observers standard errors for simulated songs; poor precision for AAARS for Field Sparrow and Henslow's Sparrow for real birds; does not meet standard.

\subsubsection{Performance Objective 8}

Objective 8 compares the classification rate of the audio analysis against a performance standard for song simulators.

- Goal = correctly classify $90 \%$ of simulated songs for various species; actual $>90 \%$ for most species at most locations but with high false positives and negative rates suggest that additional analysis is required 
to perform automated detection; standard met but additional analysis required.

\subsubsection{Performance Objective 9}

Objective 9 relates to classification rates from trials involving real birds, as compared to human-based methods.

- Goal = correctly classify $80 \%$ of simulated songs for various species; actual $>90 \%$ for most species at most locations but with high false positives and negative rates suggest that additional analysis is required to perform automated detection; standard met but additional analysis required.

\subsubsection{Performance Objective 10}

Audio files that were classified to species and individuals were used to generate density estimates and $95 \%$ confidence intervals for each validation trial involving simulated audio sources (Table 5-7). Density estimates were compared to the true mean density of song simulators that were deployed on trials. The spot-map density was used as the standard for comparison of which method was more accurate.

- Goal = AAARS density estimates did not differ $(\mathrm{P}>0.05)$ from true estimates for each focal species. ${ }^{1}$

○ NOBO: standard met for PC and FF but not LT

- PRAW: standard met for PC but not FF and LT

- BACS: standard met for PC but not FF

- FISP: standard met for PC, FF, and LT

○ GRSP: standard met for PC but not LT

○ HESP: standard met for PC and LT

\footnotetext{
1 NOBO: Northern Bobwhite

PRAW: Prairie Warbler

BACS: Bachman's Sparrow

FISP: Field Sparrow

GRSP: Grasshopper Sparrow

HESP: Henslow's Sparrow
} 


\subsubsection{Performance Objective 11}

Audio files from real birds that were classified to species and individuals were used to generate AAARS density estimates and 95\% confidence intervals for each validation trial and were compared against spot mapping and human-observer estimates. Spot-map estimates were considered the standard for comparison of accuracy of methods.

- $\quad$ Goal = AAARS density estimate was 10\% more accurate than humanobserver estimate for each focal species for real birds.

- PRAW: AAARS estimates for point count, free flight, and line transect were each $>10 \%$ closer to the spot-map estimate than human-observer estimates. Met the standard.

○ BACS: AAARS estimates for free flight were $>10 \%$ closer to the spot-map density than human-observer estimates. Met the standard.

- FISP: AAARS estimates point count and free flight differed from spot-map density estimate $(\mathrm{P}<0.05)$, line transect did not differ from spot-map estimate ( $\mathrm{P}>0.05)$; however, human-observer estimates were closer to spot-map estimate. Did not meet the standard.

- HESP: AAARS estimates for point count, free flight, and line transect were greater $(\mathrm{P}<0.05)$ than spot-map estimate and were not closer to the spot-map estimate than human-observer estimates. Did not meet the standard.

\subsubsection{Performance Objective 12}

This performance objective relates to the ease of use of the AAARS based on how long it takes to conduct pre-flight and post-flight procedures (Figure 5-14).

- $\quad$ Goal = Ease of use improves by 10\% each year. Based on examination of Figure 5-14 of time for completion of procedures at the beginning of 2011 vs. beginning of 2013 and the end of 2011 vs. 2013, ease of use has improved by $10 \%$ per year. Met the standard. 


\section{Cost Assessment}

The cost assessment involved tracking costs for development and operation of the AAARS package itself on a per-unit basis, costs associated with equipping and operating the base station tracking systems, and costs associated with analyses of the data after it had been collected.

\subsection{Cost model}

The cost model reflects all cost elements that would be required for implementing the AAARS technology on a DoD site for $3 \mathrm{yr}$ (Tables 7-1 and 7-2). Estimates were developed on the basis that DoD environmental staff would purchase a system that included three payloads and the associated ground-based monitoring equipment. This system would be sufficient to operate the technology on an installation for three field seasons given the expected life of the payloads. The cost model includes the cost to purchase and operate the AAARS, including expenses associated with field personnel and operation of field vehicles and the cost to conduct the acoustic data analysis to produce avian density estimates.

Cost data were collected during the construction of the sensor system and during implementation of the sensor system in the field. Sensor system procurement included the cost of all components and materials necessary to construct the AAARS payloads, launch, fly, track, and recover the system. Sensor system labor costs included the number of hours needed assuming an electronics technician was hired at $\$ 30 / \mathrm{hr}$ and had the skill level required to fabricate each system. The combination of unit cost and the number of units required was used to determine equipment costs for implementing the sensor system. Consumables, primarily in the form of balloons, helium, batteries, and other minor supplies were recorded. These costs were factored into the cost of implementation on a per-flight basis. Audio analysis software costs were associated with a site license required for use of RavenPro computer software. Audio analysis with MonitoR in Program R is open access (free). Other field operational costs, such as the cost of vehicles, were estimated from rental vehicle rates through a University of Tennessee-Enterprise rental contract and hourly labor rates through the University for field personnel. 
Table 7-1. Cost model for monitoring technology.

\begin{tabular}{|c|c|c|}
\hline Cost Element & Data Tracked During the Demonstration & Costs $\$$ \\
\hline Sensor system procurement (3 units) & $\begin{array}{l}\text { Cost data for all components of the AAARS } \\
\text { payload }\end{array}$ & 4,125 \\
\hline Sensor system labor costs & Labor required to construct AAARS payloads & 2625 \\
\hline $\begin{array}{l}\text { Ground-monitoring station } \\
\text { procurement ( } 3 \text { units) }\end{array}$ & $\begin{array}{l}\text { Cost data for all components of the ground- } \\
\text { monitoring stations and support equipment. }\end{array}$ & 2190 \\
\hline Sensor system labor costs & $\begin{array}{l}\text { Labor required to construct ground-monitoring } \\
\text { stations }\end{array}$ & 150 \\
\hline $\begin{array}{l}\text { Ground-monitoring station } \\
\text { procurement ( } 3 \text { laptop computers) }\end{array}$ & Cost data for purchase of 3 laptop computers & 4,500 \\
\hline $\begin{array}{l}\text { Sensor system consumables/4 } \\
\text { flights/day }\end{array}$ & $\begin{array}{l}\text { Cost data with respect to consumable use- } \\
\text { balloons, helium, etc. }\end{array}$ & 160 \\
\hline Field vehicles (2)/day & $\begin{array}{l}\text { Costs to rent and operate (2) four-wheel-drive } \\
\text { trucks/day }\end{array}$ & 200 \\
\hline Audio analysis software & $\begin{array}{l}\text { Costs associated with site license for } \\
\text { RavenPro }\end{array}$ & 400 \\
\hline $\begin{array}{l}\text { Operation costs } / 3 \text { field } \\
\text { technicians/day at } \$ 10 / \mathrm{hr}\end{array}$ & $\begin{array}{l}\text { Labor costs required to deploy, operate, and } \\
\text { recover the AAARS. }\end{array}$ & 240 \\
\hline $\begin{array}{l}\text { Audio file analyses/day; audio } \\
\text { technician at } \$ 10 / \mathrm{hr}\end{array}$ & $\begin{array}{l}\text { Labor costs to analyze audio data files. } \\
\text { Assume } 410 \text { min flights per day; } 30 \text { min } \\
\text { analysis per focal species per } 10 \text { min flight; } \\
\text { assume } 5 \text { focal species }\end{array}$ & 200 \\
\hline Maintenance/day & $\begin{array}{l}\text { AAARS damage/repair rate }=1 \times / 4 \\
\text { flights/day; cost estimate include parts and } \\
\text { labor }\end{array}$ & 35 \\
\hline Sensor system lifetime & $\begin{array}{l}\text { Assume } 1 \text { payload last } 3 \text { field seasons at } 10 \\
\text { flights/season }\end{array}$ & \\
\hline
\end{tabular}

Table 7-2. Cumulative costs to operate the AAARS technology for $3 \mathrm{yr}$.

\begin{tabular}{|l|c|c|c|}
\hline Cost Element & Costs - Year 1 & Costs - Year 2 & Costs - Year 3 \\
\hline $\begin{array}{l}\text { Sensor system procurement (3 } \\
\text { units) }\end{array}$ & 4,125 & -- & -- \\
\hline Sensor system labor costs & 2,625 & -- & -- \\
\hline $\begin{array}{l}\text { Ground-monitoring station } \\
\text { procurement (3 units) }\end{array}$ & 2,190 & -- & -- \\
\hline Sensor system labor costs & 150 & -- & -- \\
\hline
\end{tabular}




\begin{tabular}{|l|c|c|c|}
\hline Cost Element & Costs - Year 1 & Costs - Year 2 & Costs - Year 3 \\
\hline $\begin{array}{l}\text { Ground-monitoring station } \\
\text { procurement (3 laptop } \\
\text { computers) }\end{array}$ & 4,500 & -- & - \\
\hline $\begin{array}{l}\text { Sensor system consumables/4 } \\
\text { flights/day } \times 10 \text { day/field season }\end{array}$ & 1,600 & 1,600 & 1,600 \\
\hline $\begin{array}{l}\text { Field vehicles (2)/day } \times 10 \\
\text { day/field season }\end{array}$ & 2,000 & 2,000 & 2,000 \\
\hline Audio analysis software & 400 & -- & -- \\
\hline $\begin{array}{l}\text { Operation costs/3 field } \\
\text { technicians/day@ } \$ 10 / h r \times 10 \\
\text { day field season }\end{array}$ & 2,400 & 2,400 & 2,400 \\
\hline $\begin{array}{l}\text { Audio file analyses/day; audio } \\
\text { technician at \$10/hr } \times 10 \\
\text { day/field season }\end{array}$ & 2,000 & 2,000 & 350 \\
\hline $\begin{array}{l}\text { Maintenance/day } \times 10 \text { day/field } \\
\text { season }\end{array}$ & 350 & $(350$ & 12,850 \\
\hline Total cost per field season & 21,340 & 12,850 & \\
\hline Average cost/year \$) & 16,013 & & \\
\hline
\end{tabular}

Audio analysis costs are associated with processing audio files to enumerate the number of detections per focal species and generating density estimates. These costs will primarily entail labor. Based on experience, it takes twice as long to transcribe and annotate a file for an audio technician as the duration of the file. Assuming a flight lasts $30 \mathrm{~min}$, it would take a technician $60 \mathrm{~min}$ to transcribe that file for one species. The cost analysis assumes that there would be five focal species per flight for cost-basis purposes; thus four 30 min flights per/day would require $4 \times 30 \times 2 \times 5$ species $=1200 \mathrm{~min}(20 \mathrm{hr})$ of analysis time per day of field monitoring.

Documented maintenance costs averaged $2 \mathrm{hr}$ of maintenance after each day of operation of four flights, including recharging batteries, and downloading and storage of audio files. Estimated costs at \$35/day represent both the cost of field technician labor at $\$ 10 / \mathrm{hr}$ but also for replacement parts. The loss of payloads due to damage or failure to recover was monitored. Two payloads were lost during 176 attempted free flights; thus the loss of payloads generally does not need to be factored into the cost analysis on a per-day or per-field season basis. 
Eight sensors were used to conduct 176 free flights, as well as conducting hundreds of tethered flights. Thus it is assumed that a sensor can be expected to last $>10$ flights/yr for $3 \mathrm{yr}$. The solid-state nature of the system makes obsolescence a more likely reason for the end of a usable life than hardware failures.

\subsection{Cost drivers}

The cost analysis represents the costs associated with purchase of the AAARS and associated ground-monitoring equipment and associated operation of the system for $3 \mathrm{yr}$. For the demonstration, most of the same equipment for $4 \mathrm{yr}$ of operation was used; thus some of the equipment (salvageable payloads, ground-monitoring station equipment, laptop computers, and field supplies) may last beyond the $3 \mathrm{yr}$ period used for the cost basis. In general, after the first year, the cost of operation is reduced by approximately $50 \%$.

\subsection{Cost analysis and comparison}

The ultimate goal of the AAARS technology is to inventory and monitor TER-S birds on impact areas of DoD installations where accessibility by personnel on the ground is limited or non-existent. Alternate methods of determining bird density and population size necessarily involve human access by foot; therefore, there is no comparable method for achieving the goals.

Conversely, the cost estimates of typical bird vocalization monitoring methods that would compare most closely with results of the AAARS would be line transect sampling. Line-transect sampling requires a skilled field technician capable of identifying the acoustic signals of a variety of bird species and estimating distance, accurately placing the birds in space. The average wage of a skilled bird monitoring technician is $\$ 10 / \mathrm{hr}$. On average, an observer can cover $1 \mathrm{~km} / \mathrm{hr}$ line transect or $2 \mathrm{ha} / \mathrm{hr}$ area covered based on $100 \mathrm{~m}$ sampling distance from center line for line transect sampling (Hanowski et al. 1990). Assuming a sampling period of $4 \mathrm{hr} /$ morning, an efficient human observer could complete three 1-hr transects or cover $3 \mathrm{~km}$ of distance and 6 ha of area/observer. Assuming the AAARS is flown four times per sampling morning for $30 \mathrm{~min}$ flights at a speed of $10 \mathrm{~km} / \mathrm{hr}$, the linear distance covered would be $5 \mathrm{~km} /$ flight. Assuming further that the altitude flown was $200 \mathrm{~m}$ with a 1:1 radius to altitude ratio (a good target altitude for detecting species), the area of 
coverage would be $400 \mathrm{~m}$ footprint $\times 5 \mathrm{~km}=200 \mathrm{ha} /$ flight or 800 $\mathrm{ha}$ /sampling morning. It would require 133 human observer days to cover an equivalent area that the AAARS with three personnel could cover in one sampling day. Furthermore, line transect data computer transcription from 133 observer days would require additional time. Assuming a 10 min transcription time/ $\mathrm{km}$ of transect data; 30 min of transcript time/observer day of monitoring $\times 133$ observers $=66.5$ additional hours of labor per sampling day would be needed for line transect data transcription. The cost model comparison below assumes the construction of three AAARS payloads, to allow for rapid deployment of payloads during a given day (i.e., preparation of a payload for the next flight while recovery of the first flight is being accomplished), and to account for potential loss of units.

Although the actual equivalent costs could be calculated for the humanbased line transect method to cover an equivalent area that the AAARS could cover in one sampling morning, the 133:3 ratio in personnel requirements quickly inflates the human-based transect costs to a very unattainable number (i.e., $>\$ 100,000$ per field season). It is sufficient in the cost comparison to note that even in the first year of operation, the AAARS is at least five times more cost efficient, has the additional advantage of creating a permanent acoustic data record of the flight path, and has the ability to monitor inaccessible areas. If the monitoring area includes small, widely dispersed areas where flying AAARS transects are difficult, human-based methods may still be more efficient. 


\section{Implementation Issues}

In spite of the apparent benefits outlined above in implementing an AAARS-based bird monitoring system, there are some issues related to implementation that need to be resolved to take full advantage of the technology. Those issues are outlined by topic below.

\subsection{DoD access restrictions and weather limitations}

Given the ability of the AAARS to cover large areas efficiently, the need for coordination with range control and DoD training schedules is a critical constraint in operation (Table 5-4). On installations that have spatially and temporally extensive training operations during the breeding bird season (May-July), such as Fort Bragg, there may be a very limited number of days (weekends and holidays) in which the AAARS can be fully deployed. This issue is further exacerbated by the weather because poor weather when the access is otherwise good can further compromise the deployment of the technology. A study of weather and access should be conducted for each potential deployment site to better understand these limitations prior to committing to the technology.

\subsection{Acoustic data analysis}

Given the great ability of the AAARS to collect volumes of acoustic monitoring data, there was the presumption that automated acoustic analysis could be used to streamline the data analysis and make it more consistent. Many approaches for automated detection analysis of acoustic data have been undertaken in recent years. The presented approach (Figure 5-7) holds promise for moving the science behind acoustic analysis forward, but this area is still a significant challenge that will require the investment of more time to develop fully automated tools. In the meantime, for AAARS applications that do not generate thousands of hours of acoustic data, it is recommended to continue to use expert human-based transcription as a viable method for data collected via the AAARS. The 4 flights per day for 10 sampling days scenario outlined above (forty 30 min audio files) would be very feasible with human-based transcript of the audio files. 


\subsection{Limitations in communication range of AAARS}

Although the range of communications between the ground-based monitoring stations and the AAARS exceeded the performance standard for communications on the installations in eastern and midwestern United States, the range is still limited for large DoD installations in the western United States and Alaska. To deploy the technology on installations with focal field sites greater than $16 \mathrm{~km}$, monitoring stations need to be established every $30 \mathrm{~km}$ along the expected flight path of the AAARS. Additional engineering development and field testing work may be necessary to determine a means to do this efficiently, such as air drops of monitoring stations from helicopters or unmanned aerial vehicles.

\subsection{Limitations in operation over mountainous terrain}

Although the demonstration documented operation of AAARS across a range of vegetation types from open prairie to closed canopy forest, it was not evaluated how well the system would operate in mountainous terrain found in the western United States. Additionally, testing of flying the AAARS in mountainous terrain would be advisable prior to committing resources for full-scale deployment. 


\section{References}

Buckland, S. R. 2006. "Point-Transect Surveys for Songbirds: Robust Methodologies." Auk 123: 345-357.

Buckland, S. R., D. R. Anderson, K. P. Burnham, J. L. Laake, D. L. Borchers, and L. Thomas. 2001. Introduction to Distance Sampling. Oxford, UK: Oxford University Press.

Burnham, K. P., D. R. Anderson, and J. L. Laake. 1980. "Estimation of Density from Line Transect Sampling of Biological Populations.” Wildlife Monographs 72: 3-202.

Franzreb, K. E. 1976. "Comparison of Variable Strip Transect and Spot-Map Methods for Censusing Avian Populations in a Mixed-Coniferous Forest." Condor 78: 260262.

Fristup, K., and C. Clark. 2009. Acoustic Monitoring of Threatened and Endangered Species in Inaccessible Areas. SERDP SI-1185 Final Report. Cornell Lab of Ornithology. New York: Ithaca.

Hanowski, J. M., G. J. Niemi, and J. G. Blake. 1990. "Statistical Perspectives and Experimental-Design When Counting Birds on Line Transects." Condor 92: 326335 .

Lambert, K. T., and P. G. McDonald. 2014. "A Low-Cost, Yet Simple and Highly Repeatable System for Acoustically Surveying Cryptic Species.” Austral Ecology 39 .

Prevost, S. A. 2016. Estimating Avian Populations Using Passive Acoustic Technology and Song Behavior. Masters thesis. University of Tennessee, Knoxville.

R. 2015. R: A Language and Environment for Statistical Computing. R Foundation for Statistical Computing. Vienna, Austria.

Ralph, C. J., J. R. Sauer, and S. Droege. 1995. Monitoring Bird Populations by Point Counts. General Technical Report PSW-GTR-149. Albany, CA: USDA, Forest Service, Pacific Southwest Research Station.

Reynolds, R. T., J. M. Scott, and R. A. Nussbaum. 1980. "A Variable Circular-Plot Method for Estimating Bird Numbers.” Condor 82: 309-313.

Simons, T. R., M. W. Alldredge, K. H. Pollock, and J. M. Wettroth. 2007. "Experimental Analysis of the Auditory Detection Process on Avian Point Counts." Auk 124: 986-999.

Stein, B. A., C. Scott, and N. Benton. 2008. "Federal Lands and Endangered Species: The Role of Military and other Federal Lands in Sustaining Biodiversity." BioScience 58: 339-347. 
Thomas, L., S. T. Buckland, E. A. Rexstad, J. L. Laake, S. Strindberg, S. L. Hedley, J. R. B. Bishop, T. A. Marques, and K. P. Burnham. 2010. "Distance Software: Design and Analysis of Distance Sampling Surveys for Estimating Population Size." Journal of Applied Ecology 47: 5-14. 


\title{
Appendix A: Example Letter of Agreement
}

\author{
Eagle Airspace Information Center \\ and \\ University of Tennessee Institute of Agricuiture
}

LETTER OF AGREEMENT

EFFECTIVE: 1 Jul-31 Dec 2010

SUBJECT: Release of Heiium Balloons in Restricted Area 3702A (R3702A)

1. Purpose: This letter establishes procedures for the release of helium balloons by University of Tennessee Institute of Agricultural personnel in R3702A.

2. Scope: University of Tennessee personnel will provide Eagle Airspace Information Center (Eagle Radio) with information concerning helium balloon releases including location and time at least 5 minutes prior to release. Fagle Radio will provide this information to other air traffic control agencies and aviators as necessary.

3. Procedures:

a. R3702A balloon releases:

(1) University of Tennessee personnel will notify Eagle Radio by telephone 270798-2967 at least 5 minutes prior to balloon release.

(2) Eagle Radio will provide University of Tennessee personnel with the wind speed and direction as reported at Campbell Army Airfield. Fagle Radio will broadcast the balloon release information to affected air traffic. Eagle Radio will notify other air traffic facilities as necessary.

(3) University of Tennessee personnel will notify Eagle Radio by telephone 270$798-2967$ when the balloon flight terminates.

b. The altitude of the balloon will be at or below 500 feet above ground level unless otherwise coordinated.

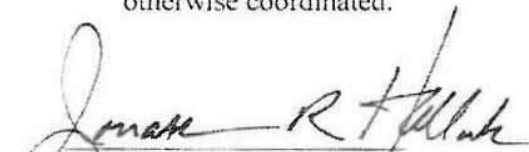

JONATIIAN R. HALLOCK

ATC Chief

Airfield Division

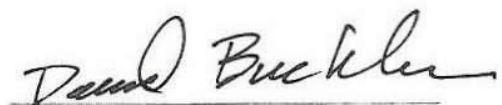

IAVID BUEHLFR

Graduate Program Coordinator

UT Wildlife Science 


\section{Appendix B: Health and Safety Plan}

\section{Introduction}

These guidelines have been prepared to assist in evaluating and controlling risks of fieldwork associated with the AAARS demonstration plan. These guidelines are intended to help prepare for health and safety problems encountered when conducting fieldwork. All technicians should be properly trained, equipped, and prepared to assess and minimize risk and provide aid to themselves and their colleagues in case of an emergency.

\section{Definitions}

-Fieldwork includes any work, or research described in the ESTCP demonstration plan for AAARS conducted by faculty, staff or technicians at a site other than the University of Tennessee (UT) campus. The majority of the fieldwork is considered remote.

-Field leader is the person who has the authority to influence or direct the actions of technicians involved in the activity. There will be one fieldwork leader (Emily Hockman or Stephanie Prevost) assigned to each demonstration location (Jefferson Proving Ground, Fort Bragg, or Fort Riley) for each year of field work.

-Field assistants assist the field leader or may occasionally act as the fieldwork leader in their absence.

\section{Fieldwork approval}

The Health and Safety Plan will be completed by the field leader prior to any fieldwork. Investigators should review and approve the fieldwork safety plan. A copy of the plan should be signed by all fieldworkers (Table B-1) and filed with the investigators.

\section{Written plan}

Planning and preparation are the most important parts of fieldwork. A written plan will assist both the fieldwork group and the investigators for the demonstration plan. A written plan should include the following. 
Table B-1. Health and Safety Plan approval form.

Approval of Health and Safety Plan

Acknowledgement of Fieldwork Members: I acknowledge that I have reviewed the Health and Safety Plan and:

- I have been fully informed of the risks of the fieldwork and I accept them

- I have reviewed and will comply with the established emergency procedures

- I am in a satisfactory health to participate in the fieldwork

\begin{tabular}{|l|l|l|}
\hline Name & Signature & Date \\
\hline & & \\
\hline & & \\
\hline & & \\
\hline & & \\
\hline & & \\
\hline & & \\
\hline & & \\
\hline & & \\
\hline
\end{tabular}

Signature of Lead Investigators

\begin{tabular}{|l|l|l|}
\hline & & \\
\hline & & \\
\hline & & \\
\hline
\end{tabular}

\section{Emergency contacts (Table B-2)}

These contacts are people at or familiar with the installations who can be reached if necessary and who are familiar with the demonstration plan. They should include investigators, site-specific environmental division personnel, and UT safety personnel. Contacts should also be informed of any medical conditions or allergies of the fieldworkers. The contacts should be provided with contact information of whom to contact if the fieldworkers do not return or report in within a predetermined length of time.

A home contact should be provided for each fieldworker to include the name and phone number of a family or friend in case the fieldworker is 
injured or becomes ill. Fieldworkers should check in regularly and should advise any changes in schedules or contact information.

Table B-2. Example of emergency contact list to be filled out before each field season.

\begin{tabular}{|l|l|l|l|}
\hline $\begin{array}{l}\text { Emergency Contacts } \\
\text { Fort Riley } 2011\end{array}$ & Phone Number & $\begin{array}{l}\text { Emergency Phone } \\
\text { Number and Relation }\end{array}$ \\
\hline Position/Relation & Name & & \\
\hline Investigator (UT) & & & \\
\hline Investigator (UT) & & & \\
\hline Field Leader & & & \\
\hline Field Assistant & & & \\
\hline Field Assistant & & & \\
\hline Field Assistant & & & \\
\hline Demonstration Site \\
Contact
\end{tabular}

\section{Emergency procedures (Table B-3)}

Plans should be written in advance with reference to emergency and evacuation information for the fieldwork location. The field leader is responsible for organizing emergency procedures specific to each field site/installation and ensuring all members of the group are aware of the arrangements. The location, phone numbers, and directions to a nearby hospital must be included (Figures B-1 through B-3).

Fieldwork will often take place in remote areas where contacting emergency personnel and evacuation in case of an emergency may be difficult. The most important part of an emergency plan is to have well-defined communication links. Lines of communication must be established prior to fieldwork to ensure that communication within the group, to the installations, to the University, and to local emergency 
services is maintained at all times (See section 4.2). Good communication allows fieldworkers to be forewarned of dangers as well as calling for help in an emergency. Communication arrangements include the following:

- Verifing that communication devices (cell phones, radios, etc.) function at worksites

- Maintaining at least two working communication devices per vehicle to ensure coverage (for example, if cell phones are used, they should each use a different carrier)

- Complying with all military communication requirements regarding contractors, including informing range control of all movements in and out of ranges, training areas, and DZs

- Always carrying photo identification in case of accident or injury.

The field leader or someone within the fieldwork group is encouraged to have up-to-date training in First Aid and Cardiopulmonary Resuscitation (CPR). A list of all trained individuals is included in the emergency procedure table to be filled out as applicable. 
Table B-3. Basic emergency procedures, to be expanded for use at specific demonstration sites.

\section{EMERGENCY PROCEDURES}

In Case of Medical Emergency

- Inform Fieldwork Leader and return to vehicle

- $\quad$ Consult Health and Safety Plan in case of heatstroke, snake bite, or tick bite

- Follow directions to hospital if emergency care is needed

Unexploded Ordinances

- Use GPS to identify approximate location of UXO

- Mark area around UXO with flagging tape

- Inform Range Control of location and type of UXO

- DO NOT APPROACH

Evacuation

- Leave base immediately

- Contact Range Control

- $\quad$ Rendezvous at field housing

First Aid/CPR training: list all individuals who are trained in first Aid and CPR including the type of training and expiration of training.

\begin{tabular}{|l|}
\hline Name $\quad$ Expiration \\
\hline \\
\hline \\
\hline \\
\hline \\
\hline \\
\hline \\
\hline
\end{tabular}


Figure B-1. Directions to hospital with emergency services near Jefferson Proving Grounds, IN.

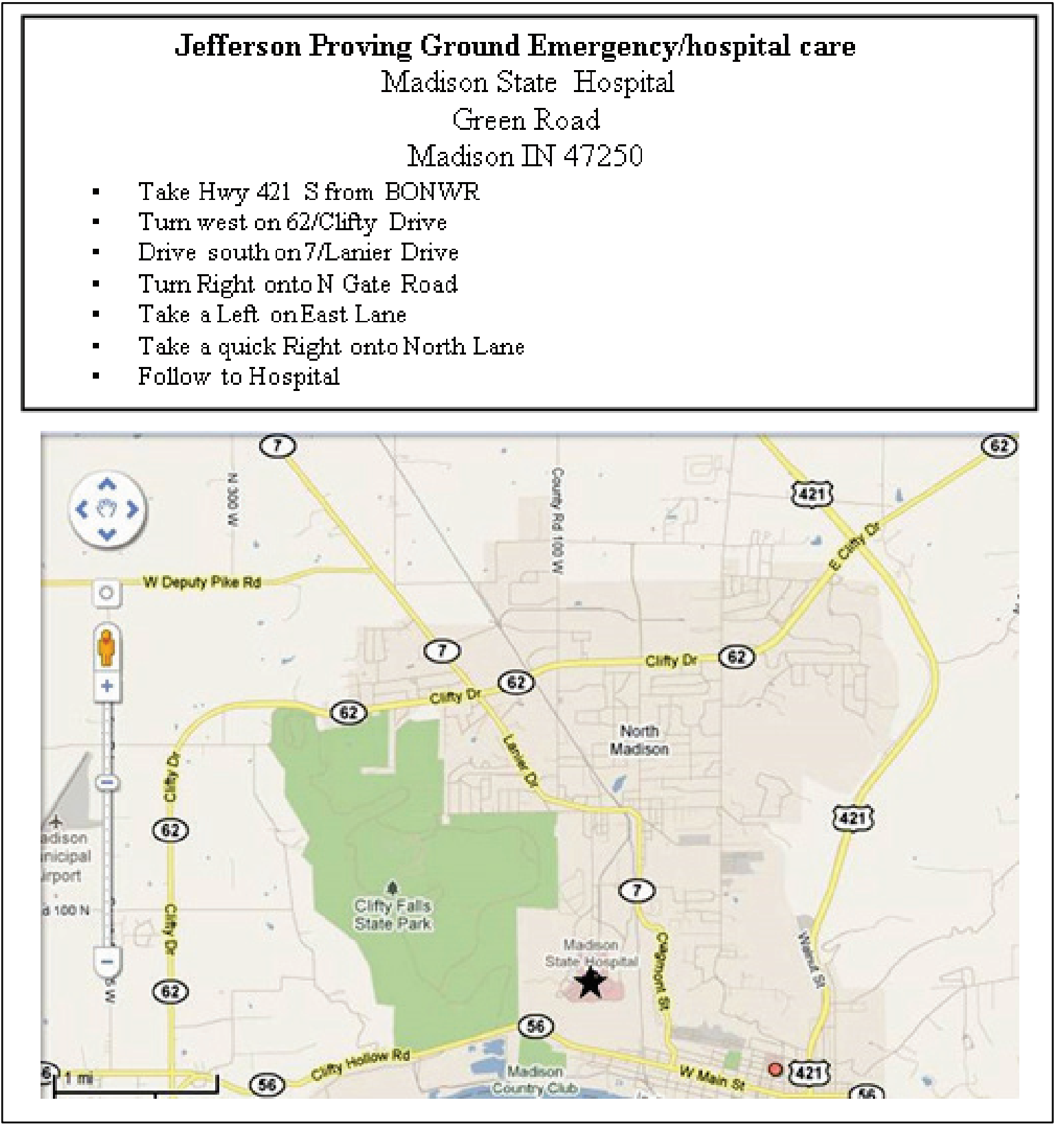


Figure B-2. Directions to hospital with emergency services near Fort Bragg, NC.

\section{Hospitals near Fort Bragg, NC}

Cape Fear Valley Medical Center

1638 Owen Drive

Fayetteville, NC 28304

(910) 615-4000

Directions from Fort Bragg

- Head east to Longstreet Road to the nearest gate off post

- Turn right onto All American Expressway

- Continue of All American Expressway approximately 9 miles

- Continue straight onto Owen Drive for 0.5 miles

- Arrive at Cape Fear Valley Medical Center

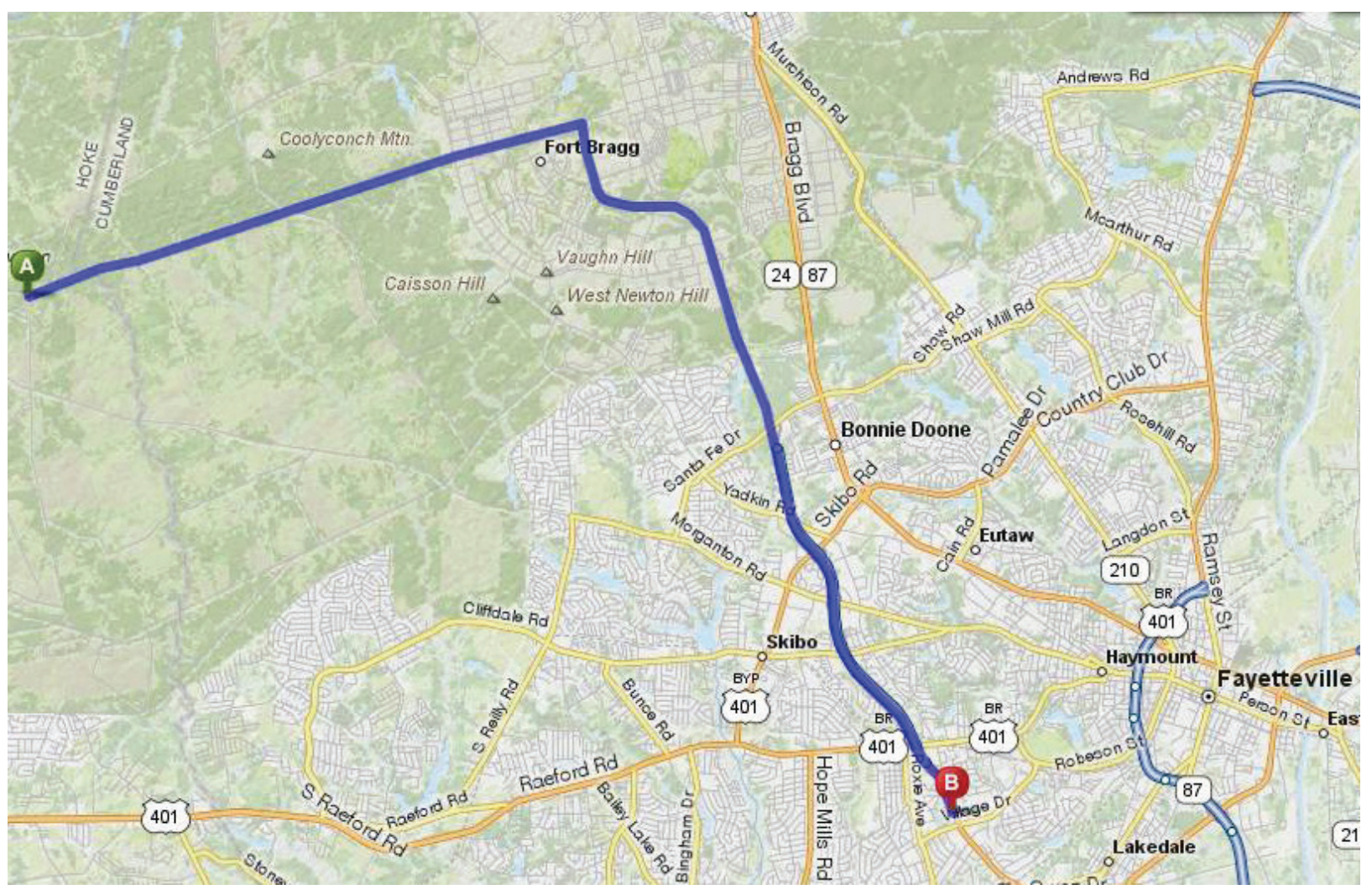


Figure B-3. Directions to hospital with emergency care near Fort Riley, KS.

- From the North

\section{Hospitals near Fort Riley, KS \\ Mercy Regional Health Center \\ 315 South Seth Child Road \\ Manhattan Kansas}

- Drive East on Co Hwy 412/Anderson Avenue

- Turn Right on Seth Child Road, follow signs to hospital

- From the South

- Drive East on 18/Fort Riley Blvd

- Turn Left on Seth Child Road, follow signs to hospital

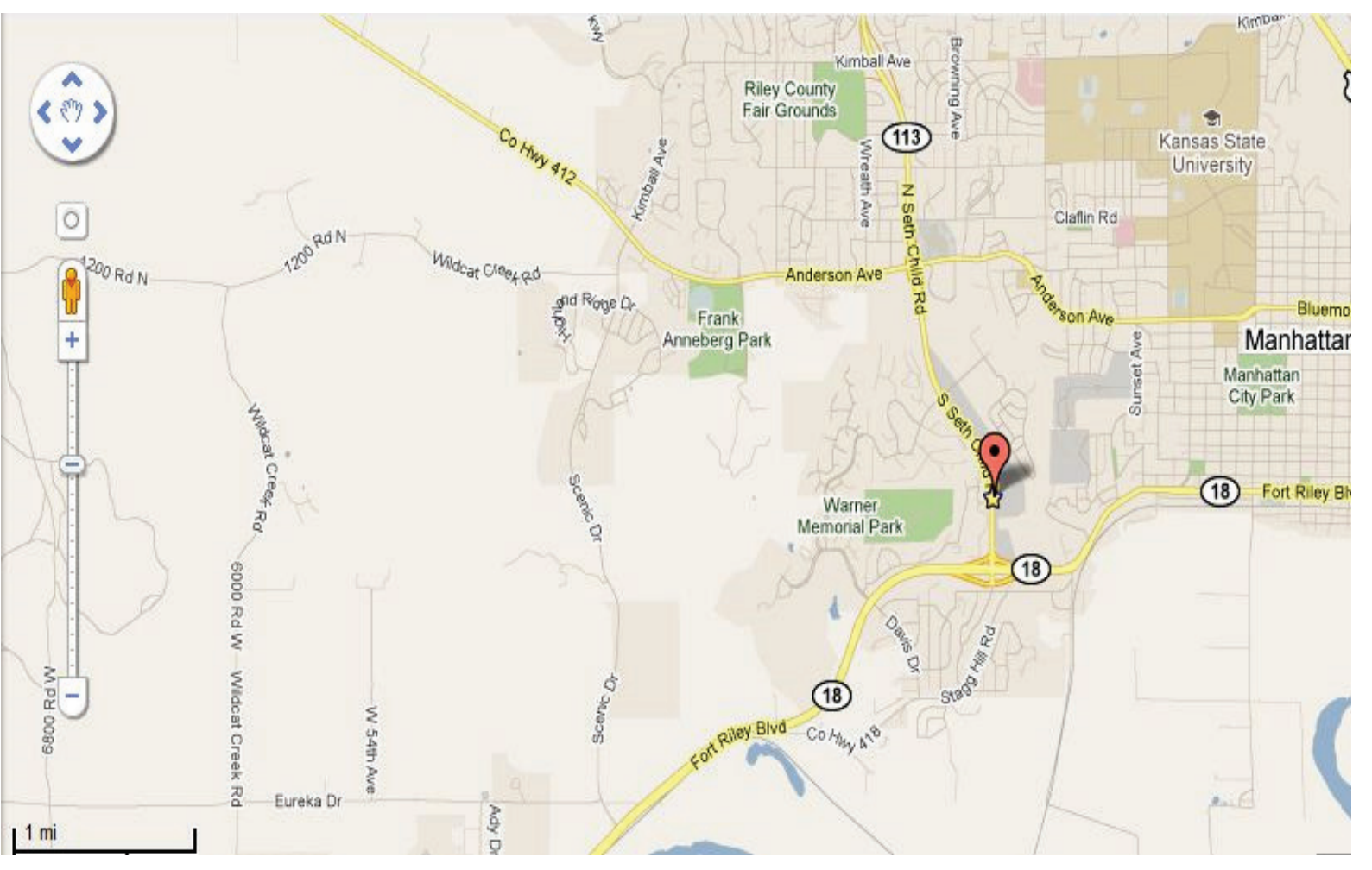




\section{Risk assessment (Table B-4)}

Risk assessment should be performed to identify risks associated with fieldwork activities and the environment surrounding the fieldwork activities. It is important to be familiar with the surroundings such as potentially hazardous plants, animals, terrain, and weather conditions.

Table B-4. Example of the risk assessment table to be included in the health and safety plan.

\begin{tabular}{|l|l|}
\hline \multicolumn{2}{|l|}{ RISK ASSESSMENT } \\
\hline $\begin{array}{l}\text { Identify risks associated with fieldwork activities or the environment surrounding fieldwork } \\
\text { activities (e.g., violence, water, extreme heat or cold, wild animals, endemic disease, firearms, } \\
\text { explosives, high altitudes, climbing, etc.). Also, list appropriate measures to be taken to reduce } \\
\text { the risks. }\end{array}$ & \begin{tabular}{l} 
Preventative Measure \\
\hline Risk
\end{tabular} \\
\hline $\begin{array}{l}\text { Military } \\
\text { exercise/training } \\
\text { location. If training begins in TA, immediately leave. }\end{array}$ \\
\hline UXOs & $\begin{array}{l}\text { Follow emergency procedures, do not approach object, and identify proper } \\
\text { personnel. }\end{array}$ \\
\hline $\begin{array}{l}\text { Environmental } \\
\text { conditions }\end{array}$ & $\begin{array}{l}\text { Wear appropriate clothing for activities/weather. Wear appropriate } \\
\text { footwear. }\end{array}$ \\
\hline Snakes & $\begin{array}{l}\text { Wear snake guards to protect against snake bites. Read attached } \\
\text { information. }\end{array}$ \\
\hline Car Accident & $\begin{array}{l}\text { Only fieldworkers with valid driver's licenses shall be able to drive. Obey all } \\
\text { traffic laws. Do not drive if over tired. Be aware of risks on unpaved roads. }\end{array}$ \\
\hline Heat Stroke & $\begin{array}{l}\text { Carry plenty of water at all times. Inform other fieldworkers if you are } \\
\text { feeling ill and be aware of the warning signs listed in attachment. }\end{array}$ \\
\hline
\end{tabular}

\section{Training}

It is important that each fieldwork member is briefed about safety and that training has been provided where necessary prior to any fieldwork activity. Any trainings and the acknowledgement by the fieldwork member should be documented. This includes training on unexploded ordinances (UXO), which will be set up at the beginning of each field season and is mandatory for all fieldworkers. 


\section{Availability of information}

To ensure that safety procedures and information are available at all times and that fieldworkers have easy access to additional safety information, each vehicle used for the demonstration is required to contain a binder/folder with the following information:

- A copy of the completed written plan, including emergency contacts for each fieldworker

- A complete phone contact list including all fieldworkers, investigators, range control, and air control for each installation

- Directions and addresses to the nearest hospitals

- Documentation of UXO and any other applicable training for all fieldworkers

- Useful information on tick bites, snake bites, heatstroke.

\section{Snake bite information}

Source: Center for Disease Control and Prevention (http://www.bt.cdc.gov)

\section{Signs of snake bites}

Depending on the type of snake, the signs and symptoms may include the following:

- A pair of puncture marks at the wound

- Redness and swelling around the bite

- Severe pain at the site of the bite

- Nausea and vomiting

- Labored breathing (in extreme cases, breathing may stop altogether)

- Disturbed vision

- Increased salivation and sweating

- Numbness or tingling around your face and/or limbs.

\section{What to do if you or someone else is bitten by a snake}

If you or someone you know are bitten, try to see and remember the color and shape of the snake, which can help with treatment of the snake bite.

Keep the bitten person still and calm. This can slow down the spread of venom if the snake is venomous. 
- Seek medical attention as soon as possible.

- Dial 911 or call local Emergency Medical Services.

- Apply first aid if you cannot get the person to the hospital right away. - Lay or sit the person down with the bite below the level of the heart.

- Tell him/her to stay calm and still.

○ Cover the bite with a clean, dry dressing.

\section{What NOT to do if you or someone else is bitten by a snake}

Do not pick up the snake or try to trap it (this may put you or someone else at risk for a bite).

Do not apply a tourniquet.

Do not slash the wound with a knife.

Do not suck out the venom.

Do not apply ice or immerse the wound in water.

\section{Heat stress information}

Source: Mayo Clinic (http://www.mayoclinic.com/health/first-aid-heatstroke/FA00019)

Heatstroke is the most severe of the heat-related problems, often resulting from exercise or heavy work in hot environments combined with inadequate fluid intake.

Young children, older adults, people who are obese and people born with an impaired ability to sweat are at high risk of heatstroke. Other risk factors include dehydration, alcohol use, cardiovascular disease, and certain medications.

What makes heatstroke severe and potentially life threatening is that the body's normal mechanisms for dealing with heat stress, such as sweating and temperature control, are inadequate. The main sign of heatstroke is a markedly elevated body temperature - generally greater than $104^{\circ} \mathrm{F}$ $\left(40^{\circ} \mathrm{C}\right)$ - with changes in mental status ranging from personality changes to confusion and coma. Skin may be hot and dry - although if heatstroke is caused by exertion, the skin may be moist. 
Other signs and symptoms may include the following:

- Rapid heartbeat

- Rapid and shallow breathing

- Elevated or lowered blood pressure

- Cessation of sweating

- Irritability, confusion or unconsciousness

- Feeling dizzy or lightheaded

- Headache

- Nausea

- Fainting, which may be the first sign in older adults.

If you suspect heatstroke, perform the following:

- Move the person out of the sun and into a shady or air-conditioned space.

- Call 911 or emergency medical help.

- Cool the person by covering him or her with damp sheets or by spraying with cool water. Direct air onto the person with a fan or newspaper.

- Have the person drink cool water or other nonalcoholic beverage without caffeine, if he or she is able.

\section{Information on ticks, tick bite prevention, and common tick-borne disease}

Source: Center for Disease Control and Prevention

(http://www.cdc.gov/ticks/index.html)

\section{Repel ticks with DEET or Permethrin}

- Products containing permethrin can be used to treat clothing and gear, such as boots, pants, socks and tents. It remains protective through several washings.

- Repellents containing 20\% or more DEET (N, N-diethyl-m-toluamide) can be applied to the skin, and they can protect up to several hours. Always follow product instructions! Parents should apply this product to their children, avoiding hands, eyes, and mouth.

- Other repellents registered by the Environmental Protection Agency may be found at http://cfpub.epa.gov/oppref/insect/ .

- Find and remove ticks from your body. 
- Wear light-colored clothing to more easily find ticks that are crawling on you.

- Conduct a full-body tick check using a hand-held or full-length mirror to view all parts of your body upon return from tick-infested areas. Parents should check their children for ticks under the arms, in and around the ears, inside the belly button, behind the knees, between the legs, around the waist, and especially in their hair.

- Examine gear and pets. Ticks can ride into the home on clothing and pets, then attach to a person later, so carefully examine pets, coats, and day packs. Tumbling clothes in a dryer on the highest heat for at least 1 hr may help kill remaining ticks.

- Shower soon after being outdoors. Showering within $2 \mathrm{hr}$ of coming indoors has been shown to reduce your risk of being bitten by a tick.

\section{Common tick-borne diseases}

Lyme disease is caused by the bacterium Borrelia burgdorferi and is transmitted to humans by the bite of an infected blacklegged tick. Typical symptoms include fever, headache, fatigue, and a characteristic bullseye skin rash called erythema migrans. If left untreated, infection can spread to joints, the heart, and the nervous system. Lyme disease is diagnosed based on symptoms, physical findings (e.g., rash), and the possibility of exposure to infected ticks; laboratory testing is helpful when used appropriately. Most cases of Lyme disease can be treated successfully with a few weeks of antibiotics. Steps to prevent Lyme disease include using insect repellent, removing ticks promptly, landscaping, and integrated pest management. The ticks that transmit Lyme disease can occasionally transmit other tick-borne diseases as well.

Rocky Mountain spotted fever (RMSF) is a tickborne disease caused by the bacterium Rickettsia rickettsii. This organism is a cause of potentially fatal human illness in North and South America and is transmitted to humans by the bite of infected tick species. In the United States, these include the American dog tick (Dermacentor variabilis), Rocky Mountain wood tick (Dermacentor andersoni), and brown dog tick (Rhipicephalus sanguineus). Typical symptoms include fever, headache, abdominal pain, vomiting, and muscle pain. A rash may also develop but is often absent in the first few days, and in some patients, never develops. Rocky Mountain spotted fever can be a severe or even fatal illness if not treated in the first few days of symptoms. Doxycycline is the first line treatment for adults and children of all ages and is most effective if started before the fifth day of symptoms. The 
initial diagnosis is made based on clinical signs and symptoms, and medical history and can later be confirmed by using specialized laboratory tests. RMSF and other tick-borne diseases can be prevented. 


\section{Appendix C: Points of Contact}

\begin{tabular}{|c|c|c|c|}
\hline $\begin{array}{l}\text { POINT OF CONTACT } \\
\text { Name }\end{array}$ & $\begin{array}{l}\text { ORGANIZATION } \\
\text { Name } \\
\text { Address }\end{array}$ & $\begin{array}{l}\text { Phone } \\
\text { Fax } \\
\text { E-mail }\end{array}$ & Role in Project \\
\hline Dr. Richard Fischer & $\begin{array}{l}\text { US Army Engineer } \\
\text { Research and } \\
\text { Development Center, } \\
\text { Environmental } \\
\text { Laboratory, } 3909 \text { Halls } \\
\text { Ferry Road Vicksburg, MS } \\
39180\end{array}$ & $\begin{array}{l}\text { Office: (502) 454-4658 Email: } \\
\text { Richard.A.Fischer@usace.army.mil }\end{array}$ & $\begin{array}{l}\text { Principal } \\
\text { Investigator }\end{array}$ \\
\hline Dr. David Buehler & $\begin{array}{l}\text { University of Tennessee, } \\
\text { Department of Forestry, } \\
\text { Wildlife and Fisheries, } \\
274 \text { Ellington Plant } \\
\text { Sciences, } \\
\text { University of Tennessee } \\
\text { Knoxville, TN 37996- } \\
4563\end{array}$ & $\begin{array}{l}\text { Office: (865) 974-8845 } \\
\text { Fax: (865) 974-4714 } \\
\text { Email: dbuehler@utk.edu }\end{array}$ & Co-Investigator \\
\hline Dr. Stacy Worley & $\begin{array}{l}\text { The University of } \\
\text { Tennessee } \\
\text { Department of } \\
\text { Biosystems Engineering } \\
\text { and Soil Science, } \\
101 \text { Biosystems } \\
\text { Engineering and Soil } \\
\text { Sciences Office Building, } \\
2506 \text { E J Chapman Drive, } \\
\text { Knoxville, TN 37996- } \\
4531\end{array}$ & $\begin{array}{l}\text { Office Phone: (865) 974-7266 } \\
\text { Fax: (865) 974-4514 } \\
\text { Email: sworley2@utk.edu }\end{array}$ & Co-Investigator \\
\hline Dr. John Wilkerson & $\begin{array}{l}\text { The University of } \\
\text { Tennessee } \\
\text { Department of } \\
\text { Biosystems Engineering } \\
\text { and Soil Science, } \\
309 \text { Biosystems } \\
\text { Engineering and Soil } \\
\text { Sciences Office Building, } \\
2506 \text { E J Chapman Drive, } \\
\text { Knoxville, TN 37996- } \\
4531\end{array}$ & $\begin{array}{l}\text { Office: (865) 974-7266 } \\
\text { Fax: (865) 974-4514 } \\
\text { Email: wilkerj@utk.edu }\end{array}$ & Co-Investigator \\
\hline
\end{tabular}




\section{Appendix D: Avian Survey Protocols and Datasheets}

\section{Variable distance point count (PC) protocol}

(Derived from Ralph et al. [1995] and Reynolds et al. [1980])

PC surveys were conducted at point center of the static simulation grid and at point center of the static real bird grid. Surveys were conducted by three observers sequentially, with the order of observers randomized daily. Surveys were conducted between the dates of 15 May and 15 July and between sunrise and $4 \mathrm{hr}$ after sunrise. The observer quietly approached the point count center and began counting any bird seen or heard in all directions for the duration of $10 \mathrm{~min}$. Birds that were flushed upon approach to the point and birds flying over during the survey should be noted separately. Data recorded were species, distance from center, manner of detection (aural or visual), and (if appropriate) flock size. Count results were tallied in $1 \mathrm{~min}$ intervals. Distances were estimated with a laser range finder and with visual estimation to reference stakes every $10 \mathrm{~m}$. Surveys were not performed under rainy or windy conditions.

\section{Variable distance line transect (LT) protocol}

(Derived from Burnham et al. [1980] and Buckland et al. [2001])

LT surveys were conducted on the dynamic simulation grid and the dynamic simulation grid with real birds. Surveys were conducted by three observers sequentially, with the order of observers randomized daily. Surveys were conducted between the dates of 15 May and 15 July and from sunrise and $4 \mathrm{hr}$ after sunrise. The LTs were established across the simulation grid prior to conducting the survey. The LT was walked at a speed of $1 \mathrm{~km} / \mathrm{hr}$ ((Hanowski et al. 1990)). The $500 \mathrm{~m}$ transect took $\sim 30$ min to traverse while recording the perpendicular distance of each bird observed to the line. Data recorded were species, distance from line, manner of detection, and flock size. Distances were estimated with a laser range finder and visual estimation with reference stakes every $50 \mathrm{~m}$. Observers spent a majority of their time scanning forward and near the center of the line because it was assumed all birds on the line were detected. 


\section{Spot mapping protocol}

(Derived from Franzreb [1976])

Spot mapping was conducted on the sites in which static and dynamic validations tests were being conducted on mornings in which no other testing is occurring. The $200 \times 500 \mathrm{~m}$ grid with $50 \times 50 \mathrm{~m}$ grid cells for the dynamic tests served as the reference grid for the spot mapping.

Reference stakes were placed at grid intersections, labeled with its grid position to aid in mapping. Surveys were conducted between the dates of 15 May and 15 July, between sunrise and $4 \mathrm{hr}$ after sunrise. Each line of the grid was walked slowly and a map filled in with the location of each individual bird observed. Each sighting noted species, sex, age, and behavior. The grids were visited eight times during the breeding season with a new map created for each visit. During analysis, all maps were overlaid and territories were delineated for each species so that density could be estimated. 
Variable Point Count Datasheet

Fort (circle): Ft Riley Big Oaks Ft Bragg

Field

Circle one: Real birds/Simulated birds (track \# Location on Field

Temp $\left({ }^{\circ} \mathrm{F}\right)$

Sky code

Ave. Wind Speed (mph)

Barometric pressure

\begin{tabular}{|l|l|}
\hline $\begin{array}{l}0 \text { Clear or a few } \\
\text { clouds }\end{array}$ & $\begin{array}{l}\text { 4 Fog or } \\
\text { smoke }\end{array}$ \\
\hline 1 Partly cloudy & 5 Drizzle \\
\hline 2 Cloudy & 8 Showers \\
\hline
\end{tabular}

\begin{tabular}{|c|c|c|c|c|c|c|c|c|c|c|c|c|c|c|}
\hline \multirow[b]{2}{*}{ Species } & \multirow{2}{*}{$\begin{array}{l}\text { Distance } \\
\text { from } \\
\text { center }(\mathrm{m})\end{array}$} & \multirow{2}{*}{$\begin{array}{l}\text { Transect } \\
\text { N E S W }\end{array}$} & \multicolumn{10}{|c|}{ Time period first detected (min) } & \multirow{2}{*}{$\begin{array}{l}\text { Observation } \\
\text { type } \\
\mathrm{A} \text { (ural) } \\
\mathrm{V} \text { (isual) }\end{array}$} & \multirow[b]{2}{*}{ Notes } \\
\hline & & & $0-1$ & $1-2$ & $2-3$ & $3-4$ & $4-5$ & $5-6$ & $6-7$ & $7-8$ & $8-9$ & $9-10$ & & \\
\hline & & & & & & & & & & & & & & \\
\hline & & & & & & & & & & & & & & \\
\hline & & & & & & & & & & & & & & \\
\hline & & & & & & & & & & & & & & \\
\hline & & & & & & & & & & & & & & \\
\hline & & & & & & & & & & & & & & \\
\hline & & & & & & & & & & & & & & \\
\hline & & & & & & & & & & & & & & \\
\hline & & & & & & & & & & & & & & \\
\hline & & & & & & & & & & & & & & \\
\hline & & & & & & & & & & & & & & \\
\hline & & & & & & & & & & & & & & \\
\hline
\end{tabular}




\section{Variable Line Transect Datasheet}

Date (mm-dd-yy)

Fort (circle): Fort Riley Big Oaks Fort Bragg

Field Transect walked

Sky code
Start Time (hh:mm)

Grid Start location
End time (hh:mm)

Grid End location Real birds or Simulated Birds Track \#
Barometric pressure

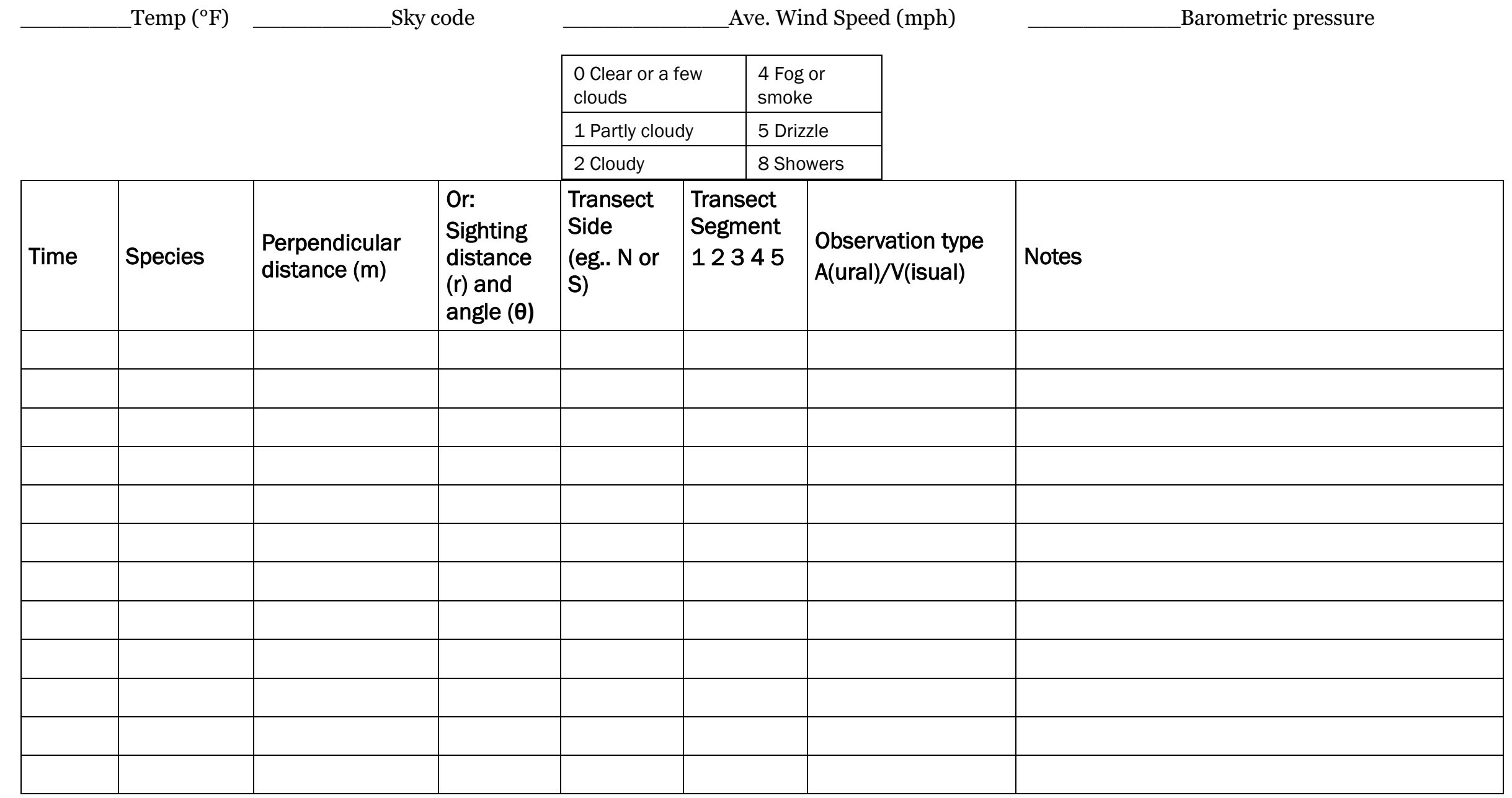




\section{Simulation Grid Program Datasheet}

(Written automatically to a text file in Lab view each time a simulation is run)

Date Location

Repetition number

Temp

Test type (static, dynamic or free flight)

Pressure

Humidity

Wind speed

Cloud cover Start Time End Time

\begin{tabular}{|c|c|c|c|}
\hline MP3\# & $\begin{array}{l}\text { Location } \\
\text { X UTM }\end{array}$ & $\begin{array}{l}\text { Location } \\
\text { Y UTM }\end{array}$ & Simulation Program \\
\hline \multicolumn{4}{|l|}{1} \\
\hline \multicolumn{4}{|l|}{2} \\
\hline \multicolumn{4}{|l|}{3} \\
\hline \multicolumn{4}{|l|}{4} \\
\hline \multicolumn{4}{|l|}{5} \\
\hline \multicolumn{4}{|l|}{6} \\
\hline \multicolumn{4}{|l|}{7} \\
\hline \multicolumn{4}{|l|}{8} \\
\hline \multicolumn{4}{|l|}{9} \\
\hline \multicolumn{4}{|l|}{10} \\
\hline \multicolumn{4}{|l|}{11} \\
\hline \multicolumn{4}{|l|}{12} \\
\hline \multicolumn{4}{|l|}{13} \\
\hline \multicolumn{4}{|l|}{14} \\
\hline \multicolumn{4}{|l|}{15} \\
\hline \multicolumn{4}{|l|}{16} \\
\hline \multicolumn{4}{|l|}{17} \\
\hline \multicolumn{4}{|l|}{18} \\
\hline \multicolumn{4}{|l|}{19} \\
\hline \multicolumn{4}{|l|}{20} \\
\hline \multicolumn{4}{|l|}{21} \\
\hline \multicolumn{4}{|l|}{22} \\
\hline \multicolumn{4}{|l|}{23} \\
\hline \multicolumn{4}{|l|}{24} \\
\hline 25 & & & \\
\hline
\end{tabular}




\section{Acronyms and Abbreviations}

$\begin{array}{ll}\text { AAARS } & \text { Autonomous Aerial Acoustic Recording System } \\ \text { ARU } & \text { Autonomous Recording Unit } \\ \text { BONWR } & \text { Big Oaks National Wildlife Refuge } \\ \text { DLO } & \text { Cornell Lab of Ornithology } \\ \text { DZ } & \text { Department of Defense } \\ \text { ESTCP } & \text { Erop zone } \\ \text { FAA } & \text { Federal Aviation Administration } \\ \text { GPCH } & \text { Greater Prairie-Chicken } \\ \text { GPS } & \text { Global Position System } \\ \text { INRMP } & \text { Integrated Natural Resources Management Plan } \\ \text { I/O } & \text { input/output } \\ \text { JPG } & \text { Jefferson Proving Grounds } \\ \text { LI } & \text { lithium ion } \\ \text { LZ } & \text { landing zone } \\ \text { MBTA } & \text { Migratory Bird Treaty Act } \\ \text { MOU } & \text { Memorandum of Understanding } \\ \text { Mitary readiness activities }\end{array}$




$\begin{array}{ll}\text { NDAA } & \text { National Defense Authorization Act } \\ \text { NEPA } & \text { National Environmental Policy Act } \\ \text { PC } & \text { original equipment manufacturer } \\ \text { PCB } & \text { point count } \\ \text { RAM } & \text { random access memory } \\ \text { RCWO } & \text { Red-cockaded Woodpecker } \\ \text { ROM } & \text { read only memory } \\ \text { RF } & \text { radio frequency } \\ \text { SD } & \text { secure digital } \\ \text { TER-S } & \text { threatened, endangered, and at-risk Species } \\ \text { USFWS } & \text { US Fish and Wildlife Service } \\ \text { UXO } & \text { Unexploded ordnance }\end{array}$




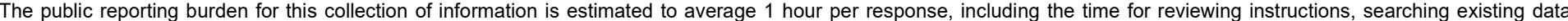

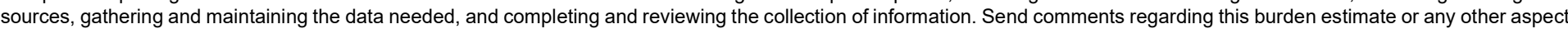

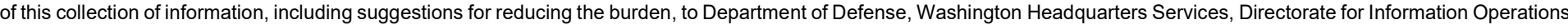

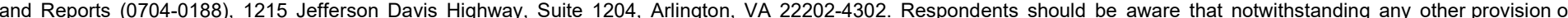
law, no person shall be subject to any penalty for failing to comply with a collection of information if it does not display a currently valid OMB control number. PLEASE DO NOT RETURN YOUR FORM TO THE ABOVE ADDRESS.

\begin{tabular}{l|l|l}
$\begin{array}{l}\text { 1. REPORT DATE } \\
\text { March } 2021\end{array}$ & $\begin{array}{l}\text { 2. REPORT TYPE } \\
\text { Final Report }\end{array}$ & 3. DATES COVERED (FrOm - To)
\end{tabular}

\section{TITLE AND SUBTITLE}

Demonstration of Autonomous Aerial Acoustic Recording Systems to Inventory Department of Defense Bird Populations

5a. CONTRACT NUMBER

W912HZ-11-2-0024

5b. GRANT NUMBER

5c. PROGRAM ELEMENT NUMBER

5d. PROJECT NUMBER

RC-201112

David A. Buehler, Richard A. Fischer, John B. Wilkerson, Stacy Worley, David R. Smith, Emily Hockman, and Stephanie Prevost 5e. TASK NUMBER

5f. WORK UNIT NUMBER

8. PERFORMING ORGANIZATION REPORT NUMBER Department of Forestry, Wildlife, and Fisheries 246 Ellington Plant Sciences Building Knoxville, TN 37996
ERDC/EL TR-21-1

7. PERFORMING ORGANIZATION NAME(S) AND
ADDRESS(ES)
Environmental Laboratory
US Army Engineer Research and
Development Center
3909 Halls Ferry Road
Vicksburg, MS 39180-6199

9. SPONSORING/MONITORING AGENCY NAME(S) AND ADDRESS(ES)

Strategic Environmental Research and Development Program/

Environmental Security Technology Certification Program 4800 Mark Center Drive, Suite 17D03

Alexandria, VA 22350-3605
10. SPONSOR/MONITOR'S ACRONYM(S) SERDP/ESTCP

11. SPONSOR/MONITOR'S REPORT NUMBER(S)

\section{DISTRIBUTION/AVAILABILITY STATEMENT}

Approved for public release; distribution is unlimited.

\section{SUPPLEMENTARY NOTES}

\section{ABSTRACT}

This demonstration project addressed the Department of Defense need for innovative technology for monitoring avian populations in inaccessible areas. This report presents results from field validation tests for an autonomous aerial acoustic recording system, a heliumfilled weather balloon that transported an instrument payload over inaccessible areas (e.g., ordnance impact areas) to record avian vocalizations.

\section{SUBJECT TERMS}

Bird populations, Birds_-Acoustics, Environmental management, Military bases, Remote sensing, Wildlife monitoring

\section{SECURITY CLASSIFICATION OF:}

a. REPORT

b. ABSTRACT

Unclassified
Unclassified
17. LIMITATION OF ABSTRACT

SAR
18. NUMBER

OF PAGES

115 19a. NAME OF RESPONSIBLE PERSON Richard A. Fischer

19b. TELEPHONE NUMBER (Include area code) $502-454-4658$ 